\title{
Obstructive micturition problems in elderly male : prevalence and diagnosis in general practice
}

Citation for published version (APA):

Wolfs, G. G. M. C. (1997). Obstructive micturition problems in elderly male : prevalence and diagnosis in general practice. [Doctoral Thesis, Maastricht University]. Universiteit Maastricht. https://doi.org/10.26481/dis.19971205gw

Document status and date:

Published: 01/01/1997

DOI:

10.26481/dis.19971205gw

Document Version:

Publisher's PDF, also known as Version of record

\section{Please check the document version of this publication:}

- A submitted manuscript is the version of the article upon submission and before peer-review. There can be important differences between the submitted version and the official published version of record.

People interested in the research are advised to contact the author for the final version of the publication, or visit the DOI to the publisher's website.

- The final author version and the galley proof are versions of the publication after peer review.

- The final published version features the final layout of the paper including the volume, issue and page numbers.

Link to publication

\footnotetext{
General rights rights.

- You may freely distribute the URL identifying the publication in the public portal. please follow below link for the End User Agreement:

www.umlib.nl/taverne-license

Take down policy

If you believe that this document breaches copyright please contact us at:

repository@maastrichtuniversity.nl

providing details and we will investigate your claim.
}

Copyright and moral rights for the publications made accessible in the public portal are retained by the authors and/or other copyright owners and it is a condition of accessing publications that users recognise and abide by the legal requirements associated with these

- Users may download and print one copy of any publication from the public portal for the purpose of private study or research.

- You may not further distribute the material or use it for any profit-making activity or commercial gain

If the publication is distributed under the terms of Article $25 \mathrm{fa}$ of the Dutch Copyright Act, indicated by the "Taverne" license above, 
Obstructive micturition problems in elderly male 
ISBN $905278230 \mathrm{X}$

G.G.M.C. Wolfs, 1997

cover design: Chris Voskamp

cover photo: Sjef Frijns

cover editing: Roland Tonnard

distribution and printing: Datawyse / Universitaire Pers Maastricht

The study presented in this thesis was conducted at the Research Institute for Extramural and Transmural Health Care (ExTra), which participates in the Netherlands School of Primary Care Research (CaRe), acknowledged in 1995 by the Royal Dutch Academy of Science (KNAW). 


\section{Obstructive micturition problems in elderly male}

prevalence and diagnosis in general practice

Proefschrift

ter verkrijging van de graad van doctor aan

de Universiteit Maastricht, op gezag van de Rector Magnificus, Prof. mr. M. J. Cohen, volgens het besluit van het College van Decanen in het openbaar te verdedigen op vrijdag 5 december 1997 om 14.00 uur door

George G.M.C. Wolfs 


\section{Promotores:}

Prof.dr. J A. Knottnerus

Prof.dr. R.A. Janknegt.

\section{Beoordelingscommissie:}

Prof dr. F. Sturmans (voorzitter)

Prof.dr. W.M. Garraway (University of Edínburgh, United Kingdom)

Prof.dr. Ph.E.V.A. van Kerrebroeck

Prof.dr. P. Pop

Prof.dr. C. van Weel (Katholieke Universiteit Nijmegen)

Financial support for this study was obtained from the Netherlands Organization for Scientific Research as part of the Incentive Fund Programme for General Practice Research (NWO-Grant 900-715-156) and Merck, Sharp \& Dohme BV, Europe. 


\section{Contents}

CHAPTER 1

Introduction

CHAPTER 2

Benign Prostatic Hyperplasia: a problem for the patient and the general practitioner

\section{CHAPTER 3}

Prevalence and detection of micturition problems among elderly males:

a population study in $2734 \mathrm{men}$

CHAPTER 4

Determinants of doctor consultation for micturition problems in an elderly male population

\section{CHAPTER 5}

Occurrence and determinants of urinary flow abnormalities of elderly men in an open population

\section{CHAPTER 6}

Detection of bladder outflow obstruction among elderly men in the community with symptomatology and flowmetry

CHAPTER 7

General Discussion

CHAPTER 8

General Summary

ALGEMENE SAMENVATTING

II Questionnaire used to measure possible factors with influence on doctor consultation 
Introduction 
Benign prostatic hyperplasia (BPH) is present in most of the men above 60 years. Prevalence rates from $60-90 \%$ have been reponted. ${ }^{\prime}$ Micturition problems are also often: present, and BPH-surgery was the most frequent operative procedure among elderly men at the time this study was formulated. ${ }^{2,3}$ The efficacy of prostate operation is an issue of debate in terms of indication, risk, benefit and costs $4,5,6$ also because it is difficult to undertake walid randomized controlled trials with operative intervention. Whth the introduction of medication and alternative treatments, management options are increasing. Facing these options, research on occurrence, diagnosis and natural history in unselected older male populations is of basic importance. Such research could give information on detection and progress of various clinical entities and the risk for possible BPH-related complications like bladder decompensation, renal failure, urinary tract infection, hematuria, disabling symptoms and acute painful urinary retention.

Studies in urological clinic can evaluate only onethird of the number of the patients found in general practice. 7.8 And in population based studies even larger numbers of patients could be found. Based on the patient lists of 10 general practices in Maastricht we could create a setting in which nearly the whole popullation was covered. Therefore, the "iceberg phenomena" of problems not presented to a doctor could be part of our studies.

As yet, diagnostic research on BPH and related problems was nearly always carried out in clinical settings with a poorly defined epidemiological denominator. ${ }^{9-16}$ Also, conclusions from these studies were conflicting. Selection bias may have caused distortion in potentially relevant associations. ${ }^{17}$ Therefore, the evidence base of clinical decision making might be limited to only a small part of the spectrum of obstructive micturition problems found in outpatient clinics.

Therefore our research formulated three questions:

1. What is the prevalence of micturition symptoms among older men registered in the basic (general) population of general practices? In what respect do symptoms, complaints or cognitive information bring a man to see a doctor for micturition symptoms?

2. What is the value of diangnostic information indicating possible BPH, like patient descriptives, symptoms, physical examination, uroflowmetry, medical history and laboratory information.

3. What is the predictive value of diagnostic information which can be collected by a general practitioner, for diagnosing clinically relevant fower urinary tract obstruction?

A literature study on $\mathrm{BPH}$ is presented in chapter 2, where also the general practitioner can find relevant information on the subject.

The first two questions have been investigated by performing a cross-sectional study among all elderly men, registered in 10 general practices located in Maastricht (chapters 3,4 and 5). A questionnaire inquiring about symptoms and doctor's visits. was followed by mone ellaborate sludies at their general practice. As an indicator of 
bladder outflow obstruction, urinary flow results and clinical determinants of low flow were studied.

The third question was studied by referring a subgroup of the men to undergo a standardised urological examination aimed at measuring bladder function and prostate qualities (chapter 6).

In a prospective cohort study my colleague Thea van der Waart will investigate the determinants of incidence and clinical course history of BPH and related entities, using the cross-sectional study described in this thesis as the baseline.

\section{References}

1. Randall A. Hinman F. Surgical anatomy of the prostatic lobes. In Hinman F. (ed). Benign prostatic hypertrophy. New York: Springer 1983.

2. Yearbooks Dutch Medical Registration, SIG Utrecht 1988.

3. Morrison AS. Prostatic hypertrophy in Greater Boston. J Chron Dis 1978; 31 : 357-362.

4. Wemberg JE, Roos N, Sola L, Schori A, Jaffe R. Use of claims data systems to evahuate health care outcomes. JAMA 1987; 257:933-936.

5. Barry MJ, Mulley AG, Fowler FJ, Wennberg JW. Watchfull waiting vs. immediate transurethral resection for symptomatic prostatism: the importance of patients" preferences. JAMA $1988 ; 259: 3010-3017$.

6. Wennberg JE, Mulley AG Jr, Hanley D, Timothy RP, Fowler FJ, Roos NP, Barry MJ, McPherson K, Greenberg ER. An assessment of prostatectomy for benign urinary tract obstruction. JAMA 1988; 259: 3027-3030.

7. Lamberts H. Morbidity in General Practice. Huisartsenpers, Utrecht 1984.

8. Morbidity figures from General Practice. Department of General Practice, Nijmegen 1986.

9. Frimodt-Müller PC, Jensen ME, Iversen P, Madsen PO, Bruskewitz RC. Analysis of presenting symptoms in prostatism. J Urol 1984; 132: 272-276.

10. Andersen JT, Nordling J, Walter S. Prostatism. 1. The correlation between symptoms. cystometric and urodynamic findings. Scand J Urol Nephrol 1979; 13:229.236.

11. Anikwe RM. Correlations between clinical finding and urinary flowlate in bengen prostatic hypertrophia. Int Surg 1976:61: 392-394.

12. Jensen ME, Bruskewitz RC, Iversen P, Madsen PO. Significance of prostatic weight in prostatism. Urol Int 1983;38:173-178.

13. Meyhof HU, Hald T. Are doctors able to assess prostatic size? Scan J Uroll Nephrol 1978; 12: 219-221.

14. Abrams PH. Prostatism and prostatectomy: the value of urine flowrate measurement in the preoperative assesment for operation. J Urol 1977; 117: 70-71.

15. Chisholm GD. Significance of symptoms and urodynamics in outflow tract obstruction. Turk J Ped 1984:26:81-87.

16. Ball All, Fenely $\mathbb{R C}$, Abrams PH. The natural history of untreated "prostaltism". Brit J Urol 1981: 53:613-616.

17. Knotmerus JA. The influence of disease verification and referral on the retationship between symptoms and discases. Med Decis Making 1987; 7: 139-148. 


\section{Benign prostatic hyperplasia: a problem for the patient and the general practitioner}

G.G.M.C. Wolfs J.A. Knottnerus 


\section{Summary}

In elderly men, Benign Prostatic Hyperplasia (BPH) is the rule rather than the exception. The disease involves quite a number of health problems and constitutes the most frequent indication for surgery in elderly men. Yet, there remains much to be elucidated about diagnostics, course and complications, and on the effects and side-effects of surgical and pharmacological treatment. Selection processes from primary to secondary care limit the generalisability of medical knowledge from the hospital to general practice. Due to the lack of sound efficacy studies, no unequivocal management advice can be given for the large group of patients in primary care for whom there is no absolute surgery indication and in whom the clinical picture is largely determined by complaints. In these cases, watchful waiting seems an appropriate option. In most cases one may monitor the natural course, while in diagnostic uncertainty or with motivated patients for invasive therapy referrall to the urologist should be considered. The question to what extent uroflowmetry in general practice may be a helpful deserves further study.

\section{Introduction}

Although the youth has the future, this future will include an increasing number of elderly persons. While the population ages only moderately up to the year 2000 , the process will then start to accelerate: around the year 2030 , one quarter of the Dutch population will consist of people older than 65 (now around $12.5 \%$ ). 'As a consequence, geriatric urologic disorders, such as prostatic carcinoma and benign prostatic hyperplasia (BPH) will almost double with respect to their incidence in the coming 50 years. Recent treatment advances promise to enlarge the possibilities of men to cope with the problem. In addition, taboos to bring the subject of micturition and its related problems to the attention of the doctor are dissolving. Knowledge and insight in this area will therefore become even more important to the general practitioner (GP) than before. In this paper we will discuss a number of aspects of so-called "BPH". We will start with a general outline of the scope and nature of BPH as a health care problem. Then we will discuss: frequency and manner of presentation of BPH in general practice, and the questions around diagnostics, therapy and the medical decision process. There is a special focus on the question which diagnostic data and additional examinations in general practice may be useful in selecting referrals for the secondary health care setting. 


\section{Scope and nature of the problem}

In elderly men, the "condition" BPH is the rule rather than the exception: three quarters of the men aged 50 years and older would have BPH to a higher or lesser degree. ${ }^{2}$ BPH not only occurs frequently, it is also a major health cate problem. An American study showed that $30 \%$ of the men are operated for $\mathrm{BPH}$ before age 80 ; in some regions this percentage was even $60,3,4$ The National Medical Registration of the Netherlands shows that prostatectomy for $\mathrm{BPH}$ is the most frequent surgical indication in men over 65 in the Netherlands: in $1986,16.728$ men were hospitalized $(2-3$ per GP on average), $90 \%$ of whom were operated. The fact that 1972 onlly an estimated 9200 prostatic operations were performed in the Netherlands, including operations for carcinoma, demonstrates that this indication area was growing. ${ }^{5}$ Before alternative treatments becoming available, a decrease in prostatectomy became however visible (1992: 15.632), which was more pronounced in 1994: only 11.769 men then were operated. This $30 \%$ decrease in operation rate was accompanied with an increase in doctor consultation. ${ }^{6}$

The less burdensome transurethral resection is now clearly considered the therapy of choice. In 1972 the ratio between transurethral and other resections was $0.8 / 1$, while in 1986 this ratio was - and since then stayed - the reverse: $9 / 1.7,89$

In the absolute sense, BPH is not frequently mentioned as cause of death: 3 in 100.000 men annually. ${ }^{5}$ Yet, this equals the mortality rate for peptic ulcer; in men over 75, the mortality rate associated with BPH equals the mortality rate for diabetes mellitus. ${ }^{10}$ In most centres, the reported peri-operative mortality is around $0.2 \%-2 \%{ }^{11}$ 16 , but reports of peri-operative complications amount to $15-25 \%$. ${ }^{17-27}$ Here we should also take into account that the percentages published in the literature might make reallity look better than it is, since one would prefer to publish results one is proud of (publication bias): for example a publication using unselected American insurance claims reported mortality percentages following prostatic operations of 2.8 to $4.1 \%$. 28 With respect to long-term complications of surgery, one must take into account sexual dysfunction (impaired fertility, retrograde ejaculation), incontinence and recurrent symptoms. Fowler et al. found that $4 \%$ of the patients who had no incontinence complaints before the operation, had developed permanent complaints one year after the operation, and that $5 \%$ had not had an erection anymore. ${ }^{17}$ On the other hand, however, complications possibly related to the spontaneous course of BPH also deserve attention. Complications may include: bladder muscle decompensation, hydronephrosis and renal insufficiency, recurrent urinary tract infections, bladder stones and acute retention. There are however insufficient data known on the frequency and severity of these complications in a non-selected population. There is some information from clinical series, but the results reported show great variation and discrepancies between the various patient groups. ${ }^{29}$ Ball et al. found in a selected series of 107 referred but not operated patients, that three quarters were the same or better after 5 years. ${ }^{30}$ As yet it is reasonable to assume that clinically relevant obstructive signs dewelop in no more 
than $10 \%$ of the men ${ }^{31}$ Recent followup studies report that symptom progression is variable. ${ }^{32-35}$ Also improvement of flow performance without treatment is noted 35 Wicly accepted indications for surgery include "obstruction-induced" recurrent acute retention, hydronephrosis, renal insufficiency, recurent urinary tract infections and recunent macroscopic hematuria. But the majority of the surgery patients is within a "grey" area of indications in which subjective complaints and considerations determine the decision process. ${ }^{36}$ Often the interaction between lower urinary tract obstruction and bladder function is more complicated than it seemed. It is difficult to predict the benefit of surgery, as randomized efficacy studies have not yet been published. The relation between subjective and objective improvement of urinary flow by surgery on the one hand and the short and long-term complications on the other, requires further evaluation.

In recent years studies are published showing efficacy of drugs with respect to symptom improvement and flow ${ }^{37}$ These involve, among others, LHRH agonists ${ }^{38}$, plant extracts ${ }^{30}, \alpha$-adrenergic-receptor blocking agents ${ }^{40}$ (perhaps improving the prognosis regarding occurrence of acute painful retention) and $5 \alpha$-reductase-inhibitors. ${ }^{4}$ Questions remain as to whether the relatively modest effect of drugs is permanent and acceptable in relation to side-effects and disease progression. In studies where the patient himself can decide, drugs were by far the most popular choice.42 Costs of medication are substantial, also compared with operation. It has been suggested that cost of medication for the nation can even outweight the hospital costs for operative treatment. ${ }^{43444}$ In the meantime, the availability of medication and "allernative" (= other than operatwon) treatments will attract many new patients and medisa.

\section{Presentation in general practice}

It is remarkable that so little is known about a clinical condition which is so widespread, particulatly with respect to the course in a population not selected by referm. The fact that such a selection takes place, is apparent from a comparison of statistics of the national medical registration and the results of general practice registrations: each year GPS make 2-3 times as many new BPH diagnoses as the number of patients hospitalized with BPH as the main diagnosis. 4548 There is even a higher degree of selection with respect to GP visits. For a "standard practice" of 2500 subjects, one may expect to tind on average 150 men with BPH among the age group over 60: from the Nijmegen Continuous Morbidity Registration it appears that in such a practice in any given year no more than 11 cases are known, while only 5 new cases are added. ${ }^{45}$ Therefore some $80 \%$ of the BPH cases are not known to the GP. $49-50$ Also the results of the Transition Project suggest that some 6 new cases occur in a standard practice each year 4 (iceberg phenomenon). 
It is not only the severity of complants that plays a role in this selection. Other factors may include: the degree to which men accept micturition symptoms as wherent to old age, fear for the consequences of treatment, education level, opinions, worksetting and diagnostic attitude of the doctor. ${ }^{51}$

The Transition Project shows the following picture of the situation in general practice ${ }^{47-48}$ Urinary complaints constitute a relatively frequent first presentation of a new episode of BPH (52\% of the cases). Then there is a range of other reasons for first contact, in which complaints directly suggestive of a prostatic disorder are a clear minority (9\%). It even happens somewhat more often that the GP takes the initiative for the consultation in question ( $10 \%$ ). During an episode, the GP usually limits himself to diagnostics (especially physical examination) and advice. In less than $1 / 5$ of the cases medication is given. During the course of the episode, especially during follow-up contacts, catheterisation is sometimes done, about once a year in each standard practice. Referral to a specialist finally occurs in $30 \%$ of the episodes, which is in line with what has been stated previously about selection from the primary to the secondary health care setting.

\section{Diagnostic aspects}

As not all men with BPH are eliguble for urologic treatment, and in view of its possible invasiveness and complications, the GP does well to make a first selection. But what instruments does he have to do this as accurately as possible? On the basis of which diagnostics may the GP make a statement on the existence of a clinically relevant, prostate-induced urinary outflow obstruction?

\section{A number of data-sources qualify}

First, of course, the medical history. The following symptoms are generally aken as being caused by lower urinary tract obstruction: hesitancy in starting urinary flow or prolonged flow, weak or interrupted urinary flow, sensation of incomplete emptying, dribbling, and increased frequency of urination. 52 The history taking may be supported by asking the patient to keep a micturition diary for a few days in which he writes down the micturition time, drinking habit, quality of micturition and eventually voided quantity. The physician will get an even better picture of the pattern of complaints by observing micturition. Remarkably, in many research reports symptoms were not related to abnormality found with urological diagnostic examinations which are believed to reflect true "bladder outflow obstruction". 53-55 Also no symptom score (ats many other diagnostic aids) is clearly reported to have predictive value. The AUA-symptom index show acceptable construct validity $4.56-57$ and helps to diagnose "BPH" with age-matched controls but seems to have little extra to offer in companison to the ICS symptom score of the modified Boyarski-score. 
Making a clear diagnosis with a symptomscore is not feasible, and "prostatism symptoms" also can be seen among women. Also specific symtoms or urological diagnostic information do not predict pathologically anatomically defined BPH.

Based on older literature, however, it is good to keep an open eye on incidental calses of hydronephrosis: malaise, hypertension, abdominal tumor, noctural incontinence in the fifties were clinical hallmarks, 58.62

Unfortunately, research in general practice on the value of history taking has been sparse and reported on fragments ${ }^{63-67}$ However, we should not rule out that history data are more important to the GP than to the urologist. In almost all cases, the latter will see men with prostatism complaints (which are usually the reason for referral) among those being referred for BPH. On the basis of these complaints (present in almost all referred men), it is no longer possible to distinguish between people with and without severe outflow obstruction. ${ }^{68}$ (table I illustrates this selection mechanism).

Therefore complaints might guide a GP to make a good first "separation" "and it is important to study this matter further. The pattern of complaints is and will remain a first reason for any clinical suspicion and further diagnostics or therapy, and in practice turns out to be the decisive factor in deciding on referral and intervention. In addition. a diagnosis of a micturition problem may trigger the doctor to recognize the patient being afraild for prostate cancer, being worried about his sexual life or about old age., or having fear for acute painful retention.

A somewhat ambivallent situation also exists with respect to digital rectall examina. tion. Each GP or specialist wishes to perform a digital rectal examination (DRE) where prostatism complaints are involved (although practice registration indicates a low percentage of actually undertaken $\mathrm{DRE}^{48}$ ) However, prostatic size is considered of little value, even when disregarding the anticipated variation between observers ${ }^{69-71}$ The site of primary importance is the part immediately adjacent to the urethra, where only a slight enlargement may constrict the urinary tract. No relevant correlation has been found in research between prostatic size, symptoms and the degree of obstruction. ${ }^{7(0-7)}$ However, here it should be taken into account again that the studies mentioned took place in secondary health care setting, where the prior probability of prostatic enlargement after selection is already considerable. Like subjective complaints, this finding will then hardly differentiate between relevant and less relevant obstuctions. To evaluate a possible referral effect this topic should be studied in general practice. ${ }^{68}$ Of primary interest with digital rectal examination is the presence of a nodule or induration on the prostate. In case a GP detects a hard nodule, then in $26-34 \% 44,69,72-78$ he would correctly malke the diagnosis of biologically important prostate cancer. This percentage is equal to the diagnostic yield found for urologists. ${ }^{79}$ In case he (1) judges the DRE of the prostate as normal, (2) there is no clinical indication for metastasis of prostate cancer, and (3) hematuria is not present, then an older man can be reassured. as having no relevant prostate cancer. Serum PSA-dletection can be undertaken with younger patients or when more certainty is needed. With values above 10 and below 2.5 one can be reasonably sure about presence or absence of prostate cancer. But the 
Table 1. The loss of diagnostic power of clinical data when used as strong selection criteria tor referal (hypothetical example) Diagnostic power of the clinical picture (history and physical diagnostic) with respect to the existence of a clinically relevant infravestcal obstuction, in generil practice.

\section{Obstruction}

$+\quad-\quad$ Total

\begin{tabular}{lrrrr}
\hline Clinical picture & $*$ & 90 & 180 & 270 \\
suspicious & & & & \\
Not Suspicious & - & 10 & 720 & 730 \\
Total & & 100 & 900 & 1000
\end{tabular}

Sensitivity of clinical picture $=90 \%(=90 / 100)$ : Speciticity of clinical picture $=80 \%(=720 / 900)$; Likelihood ratio of a positive clinical picture $=$ sensitivity $/(1-$ specificity $)=4.5$

The GP refers no one without a positive (suspicious) clinical picture, and $1 / 3$ of those with a positive picture. The latter can no longer differentiate between obstruction and non-obstruction.

\section{Obstruction}

$+\quad$ Total

\begin{tabular}{llrrr}
\hline Clinical picture & + & 30 & 60 & 90 \\
Not suspicious & - & 0 & 0 & 0 \\
Total & & 30 & 60 & 90 \\
\hline
\end{tabular}

Sensitivity of clinical picture $=100 \%(=30 / 30)$, Specificity of clinical picture $=0 \%(=0 / 60 \%$; Likelihood ratio of an positive clinical picture $=1.0$

grey area between certainty about presence or absence of cancer is large. ${ }^{80-81}$ Repeat examination after some months or referral are options. The question "Is it cancer on not" can be difficult to answer. Also to predict prognosis of a small tumor is quite a challenge to the doctor and his patient.

With respect to additional diagnostics for $\mathrm{BPH}$, microscopic analysis of the urinary sediment may give clues as to the presence of infection or hematuria. However, the analysis is not very sensitive nor specific for BPH or urinary outflow obstruction, and says more about potential complications, such as recurrent infections or urinary calculi. than about the BPH itself. ${ }^{82}$ Serum creatinin determination gives information on possible azotemia in hydronephrosis secondary to outflow obstruction. This is a rare complication $^{58}$ and it takes some time for creatinin to react to it. ${ }^{59-61}$ Nephrologic co-morbidity in elderly men should also be taken into account as explanation of 
abnormal findings. Creatinin elevation in itself is an independent predictor of BPH related mortality and $\mathrm{BPH}$ treatment complication rate. ${ }^{36.61}$

The examinations described above may be done by the GP in his own practice. The same applies to the simplest form of flow measurement with the aid of a measuring can and a stopwatch - which could also be done by the patient himself-: the time required for urination is measured and related to the urinated volume. ${ }^{83-84} \mathrm{~A}$ rule of thumb is that in the absence of pathology, an average of $10-20 \mathrm{ml} / \mathrm{sec}$ is urinated. An average flow rate of less than $10 \mathrm{ml} / \mathrm{sec}$ with an urinary volume $>150 \mathrm{ml}$ would suggest outflow obstruction. ${ }^{85}$ Also the more objective form of flow measurement can be done by the GP. Here the urinary flowrate is directly measured in $\mathrm{ml} / \mathrm{sec}$ and also other more subtle flow parameters can be evaluated, while the patient urinates in a special funnel. Graphic patterns of patients with and without obstructions may be compared with each other, if needed by the computer.

In a simple form and performed only once, the (interpretation of the) flow measurement may be hindered by quite a bit of interference, among others due to intercurrent increase of intra-abdominal pressure; ${ }^{86-89}$ there is also a poor correlation with clinical signs. ${ }^{90}$ However, modern equipment, home flowmetry, ${ }^{91}$ ambulatory urodynamic monitoring 92 and computer software ${ }^{93-94}$ have been developed, and the results are promising. The question whether this will yield a practical method for clinical practice and whether computerisation can be seen as a clinical improvement, ${ }^{95}$ deserves further study. In addition to validity, feasibility should also be addressed: the patient must have a full bladder, and in many cases the procedure must be repeated. Another question is whether the GP will perform this examination often enough to become sufficiently familliar with it and to achieve an acceptable cost-effectiveness ratio.

Flowmetry only gives information on the flow, not on the bladderpressure. Combined pressure and flow measurements are possible, and allow a differentiation between outflow obstruction and bladder dysfunction. ${ }^{94,95}$ This examination is more burdensome because the intravesical pressure is also registered -through a catheter or suprapubic bladder puncture- and poses some risk. ${ }^{96.97}$ It is appealing to see this examination as giving the most important information to the responsiveness to therapy. but numerous reports (usually retrospective, no comparison between therapy and no therapy) give conflicting advice as to its use. ${ }^{98-106}$

Uttrasonography, particularly transrectal, can in principle give a more objective impression of prostatic size than digital rectal examination. However, variation between observers cannot yet be accounted for, ${ }^{107}$ and more importantlly: this examination has similar limitations as digital rectal examination when it comes to evaluating the degree of outflow obstruction (which does not show a strong correlation with prostatic volume). Some recent reports show that ultrasonography can detail the prostate zone around the urethra, ${ }^{108}$ but still this will only give more insight in the anatomic part of bladder outflow obstruction, and not in functional problems. 
Transabdominal ultrasonography is useful in the exclusion of hydroureter and hydronephrosis (which are indications for surgery), and may also provide insight into the urinary residual after micturition. This examination replaced intravenous urograpby (TVU), which in case of a suspicious (but sometimes false-positive) ultrasonogram can be made when there is a clinical indication (recurrent or severe infection, hematuria). Its clinical use lays in detecting dilatation among patients in the watchful waiting strategy, where detecting the four clinical signs of hydronephrosis is blurred. 61.110

There are various opinions on the diagnostic value of the postvoid residual (PVR). Some patients with severe obstruction symptoms have little residu, others with slight obstruction symptoms have much residu. An impaired bladder contractility should be taken into account, which often does not correlate with the degree of obstruction. PVR in itself seems -contrary to common belief-no independent risk factor for complications. $99.110-113$

Cystoscopy is another option available to the urologist. It will suffice here to say that this examination is more and more reserved for preoperative evaluation, and that in many clinics it no longer plays a role of importance in deciding whether or not to operate. $114-116$

\section{The question of the "gold standard"}

In determining the value of a diagnostic examination, the same urgent question always arises: with which "gold standard" is this examination being compared? 17 In other words: what clinical phenomenon is it that we are looking for? This is not only a technical, but primarily a conceptual problem.

The starting point is a morphologically (pathologically/anatomically) defined problem: BPH. However, it then becomes apparent that the issue is not prostatic volume, but the degree of infravesical obstruction of the urinary outflow. This is not only a local and site-specific problem, but also at functional problem in which the interaction between bladder function and infravesical anatomic dimensions is essential. One and the same infravesical lumen may present problems in one case and be problemfree in another. This interaction is best measured by urodynamic examination. Where the problem was at first pathologic-anatomic, we now reach a non-anatomic standard. However, there is still room for discussion on the question of the best reference criterion, and for the risk of circular reasoning: The symptoms - which represent the main clinical problem for the patient-are often dismissed as diagnostics because they hardly correlate with urodynamic data or prostatic volume. At the other hand, the importance of prostatic volume or urodynamic results is frequently measured by the degree to which they correlate with the clinical picture: sometimes disappointedly little. So in dealing with "BPH" it is good to keep in mind that this term is often used to cover three vaguely interrelated conditions: (1) anatomic prostatic hyperplasia, 
(2) the presence of symptoms commonly referred to as prostatism, and (3) the urodymamic presence of obstuction. "It Moreover, the final standard is not to be found within diagnostics itself, but in the degree to which it contributes to a better prognosis.

\section{Diagnostics and therapy}

Diagnostics should differentiate between persons in whom it is to be expected that (a certain) therapy will favorably affect the signs and symptoms and the risk of complications, and persons for whom this is not the case. The trouble is that little can be definitively said about this yet, due to the lack to good efficacy studies, particularly on the large grey area of not directly clear surgery indications. The same applies to drug treatment, which now does attract much attention. Almost all efficacy studies on operative therapy for $\mathrm{BPH}$ consist of before/after comparisons without a suitable concurrent control group. The objective is to find out what percentage of surgery patients has improved in comparison with the situation before surgery. The sometimes impressive high percentages $(80.90 \%)$ are not conclusive though, because improvement may also frequently occur without an operation. ${ }^{12}$ Furthermore it is unclear whether the surgery patients constitute an unfavorable or a favorable selection of all referred patients. In order to establish a better surgery indication within the "grey" area, several diagnostic parameters (such as complaints, flow and urodynamics) have been studied for the degree to which they predict a favorable surgery outcome. The major limitation of such research is that the effect of surgery as compared with no surgery, including possible complications, is not examined, for example at different baseline flow levels. Therefore the interpretation with respect to timing and definition of operation indication remains very indirect.

A mainstream in literature decribes the impossibility to predict therapeutic effect on the basis of symptoms, symptomscore, uroflowmetry, pressureflow, residuall urine, age and prostate size. ${ }^{44}$ The results of Wennberg et al. studying postoperative findings ane quite interesting. ${ }^{28}$ Accurate analysis of their follow-up data suggests that the open prostatic resection -a more burdensome intervention (but giving equal short term improvement in quality of life ${ }^{1}$ ) than the transurethral resection-gives a much smaller long-term risk of a re-operation (figure 1). This brings up the question to what extent the strong preference which transurethral resection has enjoyed in recent years is justified. Although the transurethral resection patient group may have different chanacteristics from the open resection group, it would be difficult to explain a discrepancy as in figure I otherwise than by a (technically plausible) higher recurrence risk following transurethral resection. 


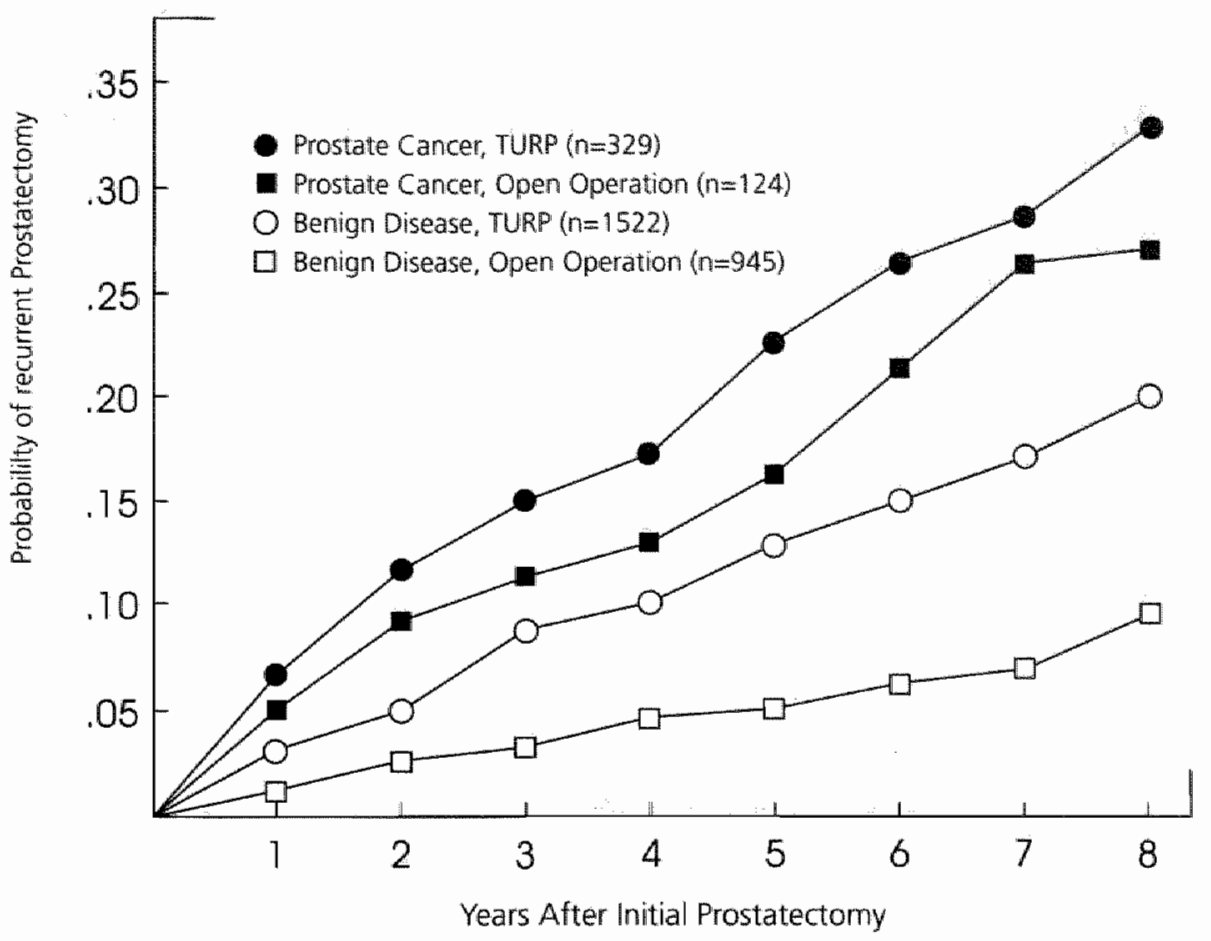

figure 1. Chance of re-operation following tansurethral resection and following open prostatectomy for prostatic carcinoma and following BPH. ${ }^{120}$

\section{Decision process and clinical decision analysis}

All in all, the diagnostic and therapeutic decision process with respect to BPH, or better infravesical outflow obstruction, is quite complex and allows, especially with the current state of knowledge, different interpretations in several respects. The decision whether or not to refer to the urologist takes a central place in this for the GP.

Decision process elements include: paltern of complants, discriminative power and the degree of burden associated with the available diagnostics, and last but not leasl, the efficacy, adverse effects and complications of treatment and its uncertanties in comparison with spontaneous course. The decision problems with respect to treatment of BPH patients has inspired a number of investigators to perform clinical decision analysis. $119-121$

Essential elements of such an analysis are:

- the structuring of the medical problem in a decision tree in which the compared strategies are presented with their possible outcomes; adding probabilities to the 
decision tree based on sound clinical research, including the probability of spontaneous improvement, the effects of therapy and the rates of peri-operative mortallity and morbidity; allocating values (utilities or weights) to each clinical endpoint.

An example of the latter element could be: a complaint-free situation receives the maximum value of 1.0 , immediate surgery with death the value 0.0 ; other outcomes fall within this range. Also the duration of follow-up may be involved: multiplying the life expectancy with the utilities mentioned leads to an estimation of the "Quality Adjusted Life Expectancy" (QUALE).

By using clinical decision analysis calculations, the strategy with the highest QUALE score needs to be identified. Usually this also depends on the baseline situation such as patient age, severity of clinical picture and comorbidity.

Figure 2 shows the decision tree formulated by Krumins et al. for the decision to perform versus not perform a transurethral resection, based on certain assumptions. ${ }^{120}$

Krumins et al. conclude that the degree to which complaints are subjectively experienced as severe, is very important to the decision to be taken.

Barry's analysis points in this same direction. 119 As symptoms are experienced as less bothersome, an operation becomes less of an alternative. The same is true as age and the risk of surgery complications increase, or the degree to which these complications are considered severe. The analyses by Krumins et al. and by Barry provoke some criticism. The decision tree by Krumins et al. is not complete (surgical montality and recurrence have not been included) and there is no clear time axis for which the analysis applies. Furthermore the origin of many quantifications is unclear in both cases, if only because there are many gaps in the research performed so far (such as the lack of sound efficacy studies). Finally it is inevitable that, in order to allow a comparison between the several strategies, "utilities" are allocated to each outcome, although their exact values for each individual case remain debatable and may vary among and within patients.

Research allowing the fully informed patient to choose between risks in treatment modalities shows that in most cases operative therapy plays a minor role. The room for operative therapy seems much smaller if the patient can decide than in daily urological routine. Patients treatment choices seem to be stable in a two year period. ${ }^{42}$ Among patients on a waiting list for operation relatively favourable clinical courses occur which lead to substantial witdrawal rates $(48 \%)$ from the list. ${ }^{122-123}$ 


\begin{tabular}{|c|c|c|c|c|c|}
\hline & P(robability) & \multicolumn{2}{|c|}{ P(robatibility) } & \multicolumn{2}{|c|}{ 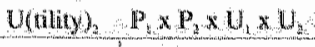 } \\
\hline & \multicolumn{3}{|l|}{ U(nility), } & $\mathrm{TLO}$ & Expoced Qualiy \\
\hline & & $(988)$ & No complications & 1.0 & 89 \\
\hline & & $(010)$ & Impotence & 0.9 & .0081 \\
\hline & 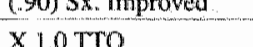 & $(0011)$ & Incontinence & 0.8 & .00072 \\
\hline & & $(001)$ & Impotence \& Incontinence & 0.6 & .00054 \\
\hline \multicolumn{6}{|l|}{ turp } \\
\hline & \multirow{2}{*}{$\begin{array}{l}\text { (.10) Sx. Unimproved } \\
\text { or worse }\end{array}$} & $(.010)$ & Impotence & 0.9 & .00054 \\
\hline & & $(0001)$ & Incontinence & 0.8 & .000048 \\
\hline & X $0.6 \mathrm{TTO}$ & $(001)$ & Impotence \& Incontinence & 0.6 & .000036 \\
\hline & \multicolumn{3}{|l|}{ (.25) Sx lmproved } & 1.0 & 25 \\
\hline No turp & \multicolumn{3}{|c|}{ (.75) Sx. Unimproved or worse } & 0.6 & 45 \\
\hline
\end{tabular}

EQ turp minus EQ no urp = Expected Gain in Quality (EGQ)

figure 2. Example of an (overly) simplified decision tree for the consideration of surgical versus non-surgical treatment in BPH ITTOJchance $x$

Decision tree for TURP vs. no TURP with probability and time trade-off values from a sample patient.

\section{Explanation of decision tree}

The decision tree should be interpreted as follow, using the upper branch (TUR) as illustration.

If a TUR is performed, improvement is anticipated in $90 \%$ of the cases $(0.90)$, and not in the remaining $10 \%$. Both situations then have a certain risk of the development of complications: $1 \%(0.01)$ risk of impotence, $0.1 \%$ of incontinence and $0.1 \%$ risk of both complications. Then a value (utility) has been allocated for each outcome: e.g. a value of 0.6 if following surgery complaints have decreased, while impotence and incontinence have occurred. The value of the TUR strategy is now found by first multiplying each possible utility with its risk. For "symptoms improved" followed by "no complications" this is $0.9 \times 0.988 \times 1.0$. Finally all products of the TUR branch have been added, leading to a value of 0.959 . This value is higher than the "no "UR" branch. On the basis of these values, an operation would be preferred in this specific case.

Source: Krumins et al. ${ }^{120}$ 


\section{Absolute indications for referral, and usually surgery}

If one of the signs below occurs in a patient, there is no longer a "grey" indication for surgical intervention. However, this situation occurs in only a minority of currently operated patients.

- Repeated complete urinary retention (incidence) in symptomatic cases varies from $0.2 \%$ annually ${ }^{31.122}$ to $1.3 \% .^{125}$ In $30 \%$ of the cases, retention may be a one-time event. ${ }^{126}$ The recurrence risk of retention, and thus the chance of an operation, is highest in the first days following retention. A frequent urination schedule and lifestyle rules will probably reduce the risk of a recurrence. As far as we know, the risk of development of a painfull retention does not correlate with severity and duration of urinary complaints.

- Demonstrated signs of renal congestion (hydronephrosis, azotemia) secondary to obstruction.

- Recurrent (chronic) infection due to the increased risk of severe infections, such as pyelitis or urosepsis.

- Prostate-induced recurrent macroscopic hematuria.

Severe hinder in day to day living, particularly due to frequency of urination. This could disrupt the night rest considerably and limit the radius of action of an otherwise healthy man to a world that is not much bigger than a few yards around the toilet.

\section{Discussion}

When looking back at the questions put up in the first part of this paragraph: which diagnostic instruments he Jp making the diagnosis BPH, it can be concluded that age is perhaps the most powerful instrument. The older the patient gets, the more likely the diagnosis is. Prevalence can reach almost $100 \%$ among the men 80 years and older.

In elderly men, BPH as a "pathologic-anatomic condition" is the rule rather than the exception. In view of the aging population, the incidence of BPH will increase in the next 50 years. BPH involves many health problems. It is likely that a clinically relevant imphravesical obstruction will develop in no more than $20 \%$ of the men. $30-31$ There are still many gaps in our knowledge with respect to this disease. The implications of the clinical picture in relation to objective disorders, the value of diagnostic tests, and the efficacy of therapeutic modalities are being debated. There is still astonishing little relevant diagnostic information available predicting the clinical course of chronic micturition problems in unselected populations or differentiating BPH from other relevant diseases. In daily practice many urollogists seem to use too many diagnostic aids, ${ }^{\text {st }}$ often underestimating the importance of an open dialogue to 
inform the patient on relevant aspects and to help him to decide about treatment or to choose a "wait-and-see" policy. The AHCPR publication" 48 BPH prowides much support to this latter approach.

One might wonder whether the term "BPH" -as a pathologic-anatomic conceptshould be replaced with a more functional term such as bladden outflow obstruction (whether or not as part of a greater complex of urodynamic problems).

There is a reasonable degree of consensus on the following surgical indications: recurrent acute retention, recurrent urinary tract infections, hydronephrosis and (threathening) renal insufficiency, recurrent macroscopic hematuria and severe social obstruction (box). In these cases, a referral to the urologist is desirable. However, the majority of indications are formed by a "grey" area of subjective complaints. It is as yet not possible to formulate sufficiently substantiated general guidelines for this area. Taking the patient's particular situation and wishes into consideration, the GP will have to decide upon his own strategy for each case, in consultation with the patient, on the possible benefits and disadvantages of treatment. With respect to treatment indications not (yet) sufficiently substantiated, an attitude of restraint c.q. watchful waiting while observing the spontaneous course, seems justified. In case of diagnostic doubt, urodynamic evaluation by an urologist may be useful. Thene is a great need for well designed efficacy studies which will have to clarify effects, side-effects and the range of indications for prostatic surgery aimed at infravesical obstruction. Also the results of ungoing drug trials and their consequences for a possible reduction of the range of indications for surgery, are eagerly awaited.

More research is desired on the predictive value of the diagnostics that the GP in principal has available (from history to uroflowmetry) with respect to the rationale of deciding on further examinations and/or treatment or referral. Results of such studies will have to be linked to those of the efficacy studies mentioned.

\section{References}

1. Anonymous. Nota 2000. Leidschendam: Ministerie van WVC, 1986.

2. Randall A, Hinman F. Surgical Anatomy of the prostatic lobes. In: Hinman F, ed. Benign prostatic hypertrophy. New York: Springer 1983: 672-7.

3. Glunn RJ, Campion EW, Bouchard GR, Sillbert JE. The development of benign prostatic hyperplasia among volunteers in the nomative aging study. Am J Epidem 1985:121:78-90.

4. Wennberg J, Gittelsohn A. Variation in medical care among small areas. Sci Am 1982:246:120134.

5. Anonymous. Jaarboeken Landelijke Medische Registratie. Utrecht: Stichting Informatie Gezondheidszorg. $1972-1994$.

6. Newling DWW. Diagnostiek wan benigne prostaathyperplasie. In DIMS, MP Springer, (ed); Den Haag, juli 1993. 
7. Karlsborg $M$, Seyr T, Bilde T. Trends in a Danish urologic department during the years 1979 and 1984. Scand J Urol Nephrol 1993;27(2):231-4.

8. Breslin DS, Muecke EC, Recker JM, Fracchia IA. Changing trends in the management of prostatic disease in a sinle private practice: a 5-year followup. J Urol 1993 Aug; 150 (2 pt 1) $347-50$.

9. Mozes B, Cohen YC, Olmer $L$, Shabtai $E$. Factors affecting change in quality of life after prostatectony for BPH: the impact of surgical techniques. J Urol 1996; 155:191-196.

10. Compendium Gezondheidsstatistiek. 's-Gravenhage: Statsuitgeverij, 1980.

11. Roos NP, Wemberg JE, Malenka Dע, Fisher ES, McPherson K, Andersen TF, Cohen MM, Ramsey E. Mortality and reoperation after open and transurethral resection of the prostate for benign prostatic hyperplasia. N Engl J Med 1989;320:1120-4.

12. Kuo HC, Chang SC, Hsu T. Predictive factors for succesful surgical outcome of benign prostatic hypertroplny. Eur Urol 1993;24(1):12-9.

13. Concato J, Horwitz RI, Feinstein AR, Elmore JG, Schiff F. Problems of comorbidity in mortality after prostatectomy. JAMA 1992;267:1077-82.

14. Teboul F, Ecochard $F$, Colin $C$, Matillon $Y$, Berger $N$. Descriptive analysis of a series of operations for prostatic adenomas in inhabitants of Lyon. France in 1988. Urological college of Lyon. Eur Urol 1991;20(Suppl 1):18-21.

15. Pientka L, Loghem J van Hahn E, Guess H, Keil U. Comorbidities and perioperative complications among patients with surgically treated benign prostatic hyperplasia. Suppl Urol, $1991 ; 38: 43-49$.

16. Boyle P, Maisonneuve P, Steg A. Decrease in montality from BPH: a major unheralded health triumpl. J Urol 1995; 155:176-80.

17. Fowler FJ, Wennberg JE, Timothy RP, Barry MJ, Mulley, A, Hanley D. Symptom status and quality of life following prostatectiomy. JAMA 1988;259:3018-22.

18. Stephenson WP, Chute CG, Guess HA, Schwartz S, Lieber M. Incidence and outcome of surgery for benign prostatic hyperplasia among residents of Rochester, Minnesota: 1980-87. Urology (Suppl 1) 1991:38:32-42.

19. Folmer Andersen T, Bronnum-Hansen H, Sejr T, Roepstorff C. Elevated mortality following transurethral resection of the prostate for benign hypertrophy! But why? Med Care 1990;28:870-9.

20. Doll HA, Black NA, MoPherson K, Flood AB, Williams GB, Smith JC. Mortality, Morbidity and complications following transurthral resection of the prostate for benign prostatic hypertrophy. J Urol 147;1566-1573:1992,

21. Epstein RS, Lydick E, deLabry L, Vokonas PS. Age-related differences in risk factors for prostatecony for benign prostatic hyperplasia: the VA normative aging study. Urol 1991: (Suppl)38:9-12.

22. Weis KA, Epstein RS, Huse D, Deverka P, Oster G. The costs of prostatectomy for benign prostatic hyperplasia. Prostate $1993 ; 22(4): 325-34$.

23. Coppinger SWV, Hudd C. Risk factor for myocardial infarction in transurethrall resection of the prostate. Lancet, $1989,2: 859$. 
24. Napalkov P, Maisonneuve P. Boyle P. Worldwhde patterns of prevalence and mortality from benign prostatic hyperplasia. Urology 1995;46(supp 3A):41-46.

25. Kliewer $\mathbb{E}$. Benign prostatic hyperplasia morbidity and mortality among immigrants in Australia and Canada. Prostate 1996;28(4):211-8.

26. Black $\mathrm{N}$ et al. Do doctors and patients agree? Views of the outcome of tatusurethral resection of the prostate. Int J Techn Ass Health Care, 1991;7:4:533-544.

27. Davidov MI, Goriunov VG. [The indications and contraindications for emergency adenomectomy in patients with severe concominant diseases] Pokazamiia il proticopokazaniaia $k$ neotlozhnoi adenomektomii u bol'nykh s tiażheylymi soputstvuiushchimi zabolewaniami. Urol Nephrol Mosk 1994 Now-Dec (6); 30-4.

28. Wennberg JE, Roos N, Sola L, Schori A, Jaffe R. Use of claims data systems to evaluate health care outcomes. Mortality and reoperation following prostatectomy. JAMA 1987;257:933-6.

29. Barry MJ. Determining the utility of surgery for benign prostatic hypertrophy. Boston (Mass.): Massachussets General Hospital, 1986.

30. Ball AJ, Fenely RC, Abrams PH. The natural history of untreated 'prostatism', Br J Urol 1981: 53: 613-6.

31. Brosman SA. Benign prostatic hypertrophy. When should you consider prostatectomy for youn patient. Geriatrics 1979 (april); 25-34.

32. Jorgensen JB, Jensen KM, Mogensen $\mathbb{P}$. Long-term probability of prostatism vs general morbidity and mortality. Prospectively obtained data in a randomly selected cohort aged $>50$ years. Scan I Urol Nephrol 1994; Jun; 28(2):163-9.

33. Jensen KM, Jorgensen JB, Mogensen P. Urodynamics in prostatism: I. Prognostic value in urofllowmetry. Scan J Urol Nephrol 1988;22(2):109-17.

34. Garraway WM, Armstrong C, Auld S, King D, Simpson RJ. Follow-Up of a Cohort of Men with Untreated BPH. Eur Urol 1993; 24:313-318.

35. Prescott RJ, Garraway WM. Regression to the mean occurs in measuring peak urinary flow. Brit J Urol 1995;76:611-613.

36. Mebust WK, Holtgrewe HL, Cockett ATK, Peters PC and Writing Committee.Transurethral prostatectomy: immediate and postoperative complications. A cooperative study of 13 participating institutions evaluating 3,885 patients. IUrol 1989;14:243-7.

37. Anonymous. Medical treatment of benign prosiatic hyperplasia. [Editoriall. Lancet 1988; i: 1083-4.

38. Peters CA, Walsh PC. The effect of nafarelin acetate, LHRH-agonist, on benign prostatic hyperplasia. N Engl J Med 1987;317:599-604.

39. Berges RR. Windeler J, Trampisch HJ, Senge Th et al. Randomised, placebo-controlled, double-blind trial of beta-sitosterol in patients with benign prostatic hyperplasia. Lanced $1995 ; 345: 1529-1532$.

40. Jardin A, Bensadoun H. Delauche-Cavallier MC. Attali P, and the BPH-ALEF Group. Alfuzosin for treatment of benign prostatic hypertrophy. The Lancet, 1991; june 15:1457-1461.

41. Gormley GJ, Stonen E, Bruskewitz RC, Imperato-McGinley I ea. The effects of finasteride in men with benign prostatic hyperplasia. N Engl J Med, 1992;327:1185-1191. 
42. Kaplan SA, Golubotf ET, Olsson CA, Dewerka PA, Chmiel JJ. Effect of demografic factors, urinary peak flow ratas, and Boyarski symptom scores on patient treatment choice in benign prostatic hyperplasia. Urology $1995,45: 398-405$.

43. Lange PH. Is the prostate pill finally here? N Engl J Med 1992;327:1234-6.

44. MoConnell JD, Barry MJ, Brusikewitz RC, Bueschen AJ, Denton SE, Holtgrewe HL, Lange JL, McClennan BL, Mebust WK. Reilly NJ, Roberts RG, Sacks SA, Wasson JH. "Benign Prostatic Hyperplasial: Diagnosis and Treament, Clinical Practice Guideline," Number 8. AHCPR Publication No 94-0582. Rockwille, MD: Agency for Health Care Policy and Research, Public Health Service, U.S. Department of Health and Human Services. February 1994.

45. varn den Hoogen HJM, Huygen FJA, Schellekens JWG, Straat JM, wan der Velden HGM, eds. Morbidity figures from general practice. Nijmegen: Nijmegen University Department of General Practice, 1985 .

46. van de Lisdonk EH, van den Bosch WJHM, Huygen FJA, Lagro-Janssen ALM. Ziekten in de huisartspraktijk. Utrecht: Bunge, 1990:239-41.

47. Lamberts $H$. Morbidity in general practice. Utrecht: Huisartsenpers, 1984.

48. Lamberts $\mathrm{H}$, Brouwer H, Groen ASM,Huisman H. Het transitiemodel in de huisartspraktijk. Huisarts Wet 1987; 30: 105-13, supplement March 1989 on ICPC rubrics Y85.

49. Wolfs GGMC, Knotmens JA, Jankinegt RA. Prevalence and detection of micturition problems among 2,734 elderl men. J Urol 1994;152: \$467-70.

50. Wille-Gussenhoven MJE, de Bock $\mathrm{G}$, de Beer-Büjs MJM, Burgers SMTh, Butrman CMM, Evenar M, Springer MP. Prostate symptoms in general practice: seriousness and inconvience. Scan I Prim Health Care 1997:15:39-42.

51. Stoevelaar, HJ. Management of Benign Prostatic Hyperplasia: practice variation and appropriateness of care. Thesis, Erasmus University Rotterdam, 1996.

52. Abrams P. Managing lower urinary tract symptoms in older men. BMJ 1995 April 29; 310(6987):1113-7.

53. Frimodr-Möller PC, Jensen ME, Iversen P, Madsen PO, Bruskewitz RC. Analysis of presenting symptoms in prostatism. J Urol 1984;132:272-6.

54. Anderssen JT, Nordling J, Watter S. Prostatism 1. The correlation between symptoms, cystometric and urodynamic findings. Scand J Urol Nephrol 1979;13:229-36.

55. Abrams P. Hofner K. Editorial. World J Urol 1995;13:1-2.

56. Barry MJ, Fowler FJ Jr, O'Leary MP. Bruskewitz RC, Holtgrewe HL, Mebust WK. Cockett ATK. AUA Measurement Committee. The American Urological Association symptom index for benign prostatic hyperplasia. J Urol 1992, Nov:148:1549-57.

57. Barry MJ, Fowler FJ Jr, O'Leary MP, Bruskewitz RC. Holtgrewe HL, Mebust WK, AUA Measurement Committec. Correlation of the American Urological Association Symptom Index with self-administered versions of the Madsen-Iverson, Boyarsky and Maine Medical Assessment Program Symptom Indexes. J Uroll 1992 Nov; 148:1558-63.

58. Ewert EE, Summons HJ. "Silent" Prostatism. Surg Clin N Am 1951,31:659. Mukamel E, Nissenkorn 1. Boner $\mathrm{G}$, Sevadio C. Occult progressive renal damage in the elderly male due to benign prostutic hyperplasia. J Am Geriatr Soc 1979;27:403-6.

59. Dick VS. Unrecognized Prostatism. JAMA 1952:148:925-928. 
60. Dowd JB, Ewent EE. Silent Prostatism. Unrecognized bladder heok obstruction. JAMA 1961:178:296-300.

61. Melchior J, Valk WL, Foret JD. Mebust WK. Transurethal prostatectomy in the arotenic patient. J Urol $1974 ; 112: 643-6$.

62. George NJR. Chapter 10, Basic considerations, chapter /1 and 12: Obstrtetive and functional abnormalities part I and 11. pp.198-289. In O'Reilly: Obstructive uropathy. Berlin: Springer Verlag, 1985.

63. McLoughlin J, Gill KP, Abel PD, Williams G. Sympioms wersus flow rules versus urodynamics in the selection of patients for prostatectomy. Br J Urol 1990:66:303-5.

64. Bosch JL, Hop WC, Kirkels WJ, Schroder FH. Natural history of bening prostatic hyperplasia: appropriate case definition and estimation of its prevalence in the comnunity. Urology 1995 Sep: 46(3 Suppl A): 34-40.

65. Garraway WM, Collins GN, Lee RJ. High prevalence of benign prostatic hypertrophy in the community. Lancet, 199 | ; 338:469-7I.

66. Roberts RO, Rhodes T, Panser LA, Girman CJ, Chute CG, Guess HA, Oesterling JE, Lieber MM, Jacobsen SJ. Association between family history of benign prostatic hyperplasia and urimary symptoms: results of a population-based study. Am J Epid. 1995 Now 1; 142(9): 965-73.

67. Girman CJ, Panser LA, Chute CG, Oesterling JE, Barett DM, Chen CC, Arrighi HM, Guess HA, Lieber MM. Natural history of prostatism: urinary flow rates in a community based study. J Urol 1993 Sept; $150(3): 887-92$

68. Knotmerus JA. The influence of disease-verification and referral on the relationship between symptoms and diseases. Med Decis Making 1987;7:139-48.

69. Muris JWM, Starmans R, Wolfs GGMC, Pop P. Knottnerus JA. The diagnostic value of rectal examination. Family Practice, 1993; /: : 1-4.

70. Meyhof $\mathrm{HH}_{4}$ Hald T. Are doctors able to asses prostatic size? Scan J Urol Nephrol 1978; 12 : 219-21.

71. Jensen ME,Bruskewitz RC, Iversen P, Madsen PO. Significance of prostatic weight in prostatism. Urol In 1983:38:173-8.

72. Lee F, Litrup PJ Torp-Pedersen ST, Mettlin C. McHugh TA, Gray IM, Kumatsaba GH McLeary RD. Prostate cancer: comparison of transiectal US and digital rectal examination for screening. Radiology 1988: 168:389-94

73. Andersen JT, Nordling J, Walter S. Prostatism. Scand J Urol Nephrol,1979:13:229-236.

74. Pedersen V, Carlsson P, Varenhorst $\mathrm{E}$, Lofman O, Berglund $\mathrm{K}$ Screening for carcinoma of the prostate by digital rectal examination in a randomly selected population. Br Med J.1990;300:1041-1044,

75. Chadwick DJ, Kemple T, Astley JP. Maciver AG, Gillat DA, Abrams P. Gingell JC, Pilot study of screening for prostate cancer in general practice. Lancet, 1991;338: 613-16.

76. Kil PJM. Hendrikx AJM, Debruyne EJM. Transrectale echografie van de prostata en de watude ervan bij opsporen van prostatatcarcinoom. Ned Tijdschr Geneeskd 1990;134:385-390.

77. Cooner WH, Mosley BR. Rutherford CL.Jr. Beard IH. Pond HS, Terry WI, Igel "TC. Kidd DD Prostate cancer detection in a clinical urological practice by ultrasonography, digital rectal examination and prostate specific antigen. J Urol 1990;143:1146-54. 
78. Johansson JE, Adam HO, Andersson SO, Bergstrom R, Krusemo UB, Kraaz W. Natural history of localised prostatic cancer. Lancet, 1989;april, 799-803.

79. Smith DS, Catalona WJ. Interexaminer wariability of digital rectall examination in detecting prostate cancer. Urology $1995 ; 45(1): 70-4$.

80. Anonymous. The prostate question, tunanswered still. [Editorial] Lancet 1997;349:443.

81. McNaughton Collins M. Bany MJ. Controversies in prostate cancer screening: analogies to the early lung cancer screening debate. JAMA 1996;276:1976 1979.

82. Ezz-EL-Din K, Koch WF, de Wildt MJ, Debnyne FM, de la Rosette JJ. The predictive value of microscopic haematuria in patients with lower urinary tract symptoms and benign prostatic hyperplasia. Eur Urol 1996;30:409-413

83. Drach $G W$, Binard W. Disposable peak urinary flowmeter estimates lower urinary tract obstruction. J Urol 1976;115:175.

84. Bloom DA Foster WD, McLeod DG, Mittemeyer DG, Stutzman RE. Cost-effective uroflometry in men. J Urol $1985 \mathrm{Mar}$ 133(3): 421-4.

85. Cockett ATK, Khoury S, Aso Y, Chatelain C, Denis L, Griffiths K, Murphy G (ed): "Proceedings of the 2 nd International Consultation on Benign Prostatic Hyperplasia (BPH),", 1993 June 27-30; Paris, France. Jersey, Channel Islands: Scientific Comunications Int. Lid. 1993.

86. Jensen KM, Jorgensen JB, Mogensen P. Reproducibility of uroflowmetry variables in elderly males. Urol Res 1985:13(5):237-9),

87. Siroky MB. Interpretation of urinaty flow rates. Urol Clin North Am 1990 Aug; 17(3): 537-42.

88. Grino PB, Bruskewitz. R, Blaivas JG, Siroky MB, Andersen JT, Cook T, Stoner E. Maximum urinary flow rate by uroflowmetry: automatic or visual interpretation. J Unol 1993 Febr; $149(2)$ : 339-41.

89. Jensen KME, Jorgensen JB, Mogensen P. Reproducibility of uroflowmetry variables in elderly males. Urol Res, 1985; 13:237-239.

90. Matzkin K. Greenstein A, Prager-Geller T, Sofer M, Braf Z. Do reported micturition symptoms on the AUA questionnaire correlate with 24-hour home uroflowmetry recordings? J Urol 1996; 155: $197 \% 199$.

91. Colstrup H, Andersen JT. Waller S, Ryt S. A disposable uroflowmeter for recording of maximum flow rate. Accuracy and clinical acceptability. Scand J Urol Nephrol 1983; 17(3): $303-6$.

92. van Walalwijk van Doorn $\mathbb{E S}$, Rkemmers A, Janknegt R. Extramural ambulatory urodynamic monitoning during nantal filling and normal daily activities: evaluation of 100 patients. IUrol 199 ! Jul; $\| 46(11): 124-31$.

93. Rollema HJ, Uroflowmetry. In Krane RJ, Siroky MB (ed). "Clinical Neuro-urology," Boston: Little. Brown and Company, 1991, pp $201-244$.

94. Rollema $\mathrm{HJ}$, van Mastrigt R: lmproved indication and followup in transurethrol resection of the prostate using the computer program CLIM: a prospective study. J Urol 1992;148:111-116.

95. Schafer $W$. Analysis of bladder outlet function with the linearized passive urethral resistance relation. LinPURR. and a diseasse-specific approach for grading obstruction: from complex to simple. World J Unol 1995:13(1):47-58 
96. Harari D, Malone-Lee J, Ridgway JL. An age-related investigation of urimary tract symptoms and infection following urodynamic studies. Age Ageing 1994 Jan; $23(1): 624$.

97. Berge V. Eri LM, Tveter KJ. Complications of inwakive urodynamic examination and prostate biopsies in patients with benign prostatic hyperplasia. Scand $f$ Urol Nephrol Suppl $1995 ; 172: 95-8$.

98. Bruskewitz RC. Jensen KM-E, Iversen P, Madsen PO. The relevance of minimum urethal resistance in prostatism. J Urol 1983;129:769-71.

99. Abrams $\mathrm{PH}$, Grifliths $\mathrm{DJ}$. The assessment of prostatic obstruction from urodynanaic measurements and from residual urine. Br J Urol 1.979;51:129-34.

100. Djurhuus JC, Sorensen SS, Jorgensen TM, Taagehoj-Jensen F. Predictive value of pressure flow studies for the functional outcome of reconstructive surgery for hydronephrosis. Brit I Urol 1985 Feb;57(1):6-9.

101. Jensen KM-E, Andersen JT. Urodynamic implications of benign prostatic hyperplasia Urologe [A] 1990;29:1-4.

102. Poulsen AL, Schou J, Puggaard L, Totp-Pedersen S, Nordling J. Prostatic enlargement, symptomatology and pressure/flow evaluation: interelation in patients with symptomatic BPH. Scand J Urol Nephrol Suppl 1994;157:67-73.

103. Abrams P. In support of pressure-flow studies for evaluating men with lower urinary tract symptoms. [editorial] Urology 1994 Aug;44(2):153-5.

104. McConnell JD. Why pressure-flow studies should be optional and not mandatory studies for evaluating men with benign prostatic hyperplasia. leditoriall Urology 1994 Aug,44(2):156-8.

105. Yalla SV, Sullivan MP, Lecamwasam HS, DuBeau CE, Vickers MA, Cravalho GE Correlation of Americal Urological Association symptom index with obstructive and nonobstructive prostatism. J Urol 1995 Mar: $153(3 \mathrm{pt} 1)$ : 674-9; discussion 679.80.

106. Robertson AS, Griffiths $C$, Neal DE. Conventional urodynamics and ambulatory monitoring in the definition and management of bladder outflow obstruction. J Urol 1996 Feb; 155(2):50611.

107. Styles RA. Neal DE. Powell PH. Reproducibility of measurement of prostatic volume by ultrasound. Comparison of transrectal and transabdominat methods. Jur Urol 1988.14:266269.

108. Kaplan SA, Te AE. Pressler LB, OIsson CA. Transition zone index as a method of assessing benign prostatic hyperplasia: correlation with symptoms, urine low and detrusor pressure. J Urol 1995 Nov: 154(5):1764-9.

109. George NJR, O'Reilly PH, Barnard RJ, Blacklock NJ. High pressure chronic retention. Br Med $J .1983 ; 286: 1780-1783$.

110. Lacey De G, Johnson S, Mee D. Prostatism: how useful is routine imaging of the urinary ract? Br Med I.1988; 296:965-967.

111. Shoukry I. Susset JG, Elhilali MM. Dutarte D. Role of uroflowmetry in the assessment of lower urinary tract obstruction in adult males. Br J Urol 1975;47 (Pt 2): 559-66.

112. Neal DE, Styles RA, Powell PH, Ramsden PD. Relationship between detrusor function and residual urine in men undergoing prostatectomy. Br J Urol 1987:60:560-6. 
113. Courthey $S \mathrm{P}$, Wightman IAK. The value of ultrasound scaning of the upper unimary tract in patients wh bladder outlet obstruction. Br J Urol, $1991 ; 68: 169-171$.

114. Simonsen 0 , Moller-Madsen $B$, Dorflinger $T$. Norgard JP, Jorgensen HS, Lundhus $E$. The significance of age on symptoms and urodynamic and cystoscopic findings in benign prostatic hypertrophy. Urol Res 1987;15:355-8.

115. Andersen IT, Nordling J. Prostatism II. The correlation between cystomurethroscopic, cystometric and urodynamic findings. Scand i Urol Nephrol 1980;14:23-7.

116. Madsen FA, Rhodes PR, Bruskewitz RC. Reproducibility of pressure-flow wariables in patients with symptomatic BPH. Urology 46(6): 816-820; 1995 .

1 17. Knotherus JA, Volovics A. Her onderscheidend vermogen van diagnostisehe tests. Huisarts Wet 1989;32:338-46.

118. Hald $\mathrm{T}$. Urodynamics in benign prostatic hyperplasia: a survey. Prostate Suppl 1989:2:69-77.

119. Barry MJ, Mulley AG, Fowlel FJ, Wennberg JW: Watchful waiting versus immediate transurethral resection for symptomatic prostatism. The importance of patients" preferences. JAMA 1988;259:3010-7.

120. Krumins PE, Filhn SD, Kent DL. Symptom severity and patients* values in the decision to perform a transurethral resection of the prostate. Med Decis Making 1988;8:1-8.

121. Llewellyn-Thomas HA, Williams JI, Levy L, Naylor CD. Using a tracle-off technique to assess patients' treatment preferences for benign prostatic hyperplasia. Med Decis Making $1996: 16: 262-272$.

122. Schou J, Poulsen AL, Nordling J. The anatomy of a prostate waiting list: a prospective study of 132 consecutive patients. Brit J Uroll 1994: 74:57-60.

123. Barham CP. Pocock RD, James ED. Who Needs a Prostatectomy? Review of a Waiting List. Brit J Urol ע993;72,314-317.

124. Elzinga GJW, Gorgels WJMJ, Wolfs GGMC, Janknegt RA, Knotnerus JA. Acute retentie bij mannen > 55 jaar: ook voor de huisarts een dringend probleem? [English abstract] Huisarts Wer 1997; 40: 102-104.

125. Craigen AA, Hickling JB, Saunders CR, Carpenter RG. Natural history of prostatic obstruction. I Roy Coll Gen Pract 1969:226-32.

126. Breum L, Klarskov P. Munck LK, Nielsen TH. Significance of acute urinary retention due to intravesical obstruction. Scan J Urol Nephrol 1982;16:21-4. 


\section{Prevalence and detection of micturition problems among elderly males: a population study in 2734 men}

G.G.M.C. Wolfs'

J.A. Knottnerus ${ }^{1}$

R.A. Janknegt ${ }^{2}$

From the Department of General Practice, "Department of Urology, ${ }^{2}$

University of Limburg, Maastricht, the Netherlands

Published in: J. Urol. 1994;152:1467-70 


\section{Abstract}

In previous studies, symptom prevalence of micturition problems in the population appeared to be high. Our study supports these data and adds retrospective data on doctor's visits. $25 \%$ reported a doctor"s visit over the last 5 years for a micturition problem. However, all symptoms (hematuria, dysuria, incontinence and symptoms possibly related to $\mathrm{BPH}$ ) showed substantial numbers of patients who were not sufficiently motivated -or not had the opportunity- to visit a doctor for diagnosis and advice. Multiple logistic regression analysis showed a number of symptoms that independently predict doctor's visit for BPH and related diseases (frequent urination at night, frequent urination during the day, incomplete emptying, dysuria and incontinence).

We conclude that the iceberg phenomenon applies to both the number of patient visits and the predictive value of symptoms for prognosis of several prostate cliseases.

Key Words: prostatic hypertrophy, symptoms, prostate, epidemiology, cross-sectional studies

\section{Introduction}

Public awareness of benign prostatic hyperplasia (BPH) seems to increase. To patient and doctor the introduction of effective medication for BPH and the growing number of relatively noninvasive treatments may suggest that BPH can be cured more easily than before. These developments may have substantial effects on the number of patients presenting with symptoms possibly related to BPH. Therefore, it is important to gain insight in the 'iceberg phenomenon' of BPH and possibly related symptoms; that is, the occurrence of such symptoms in the general population and the proportion of patients that visit a doctor.

Clinically relevant BPH will manifest itself in (presumably) obstructive micturition symptoms, varying from 'mild" and 'moderate" to "severe'. In particular, moderate symptoms represent a grey area where the patient's decision to consult a doctor can be very much influenced by external factors. This may also affect the probability of a patient undergoing surgery: Fowler ${ }^{1}$, Krumins $^{2}$ and Mebust ${ }^{3}$ demonstrated that the patient"s evaluation of symptoms plays a key role in at least $70 \%$ of operations.

In the community the prevalence of BPH has been reported to be $25 \%{ }^{4}$ From epidemiological data it can be deduced that a large number of symptomatic men are not known to a doctor. ${ }^{5}$ This, together with the referral pattern of general practitioners may substantially influence disease verification. ${ }^{6}$ An additional consequence is that there is no clear and explicit clinical epidemiologic picture of the prognosis of BPH and its determinants in an unselected population. A better understanding of the 
relationship between symptoms in the community and the visit to a doctor helps to assess the influence of these selection phenomena.

In this paper we present results of a survey in an open elderly mate population that measures urinary symptom prevalence and report micturition problems. In addition, the extent to which men with different manifestations of micturition problems (symptoms, patient's complaints, operations) are known to health care providers was determined.

\section{Material and methods}

All men aged 55 years or older who were registered at 10 general practices (14 general practitioners) in Maastricht, a city of 115000 persons in the south of the Netherlands, were considered for inclusion in the study $(\mathrm{n}=2734) .99$ (3.6\%) persons were excluded because they were bedridden, had a terminal illness, were chronically institutionalized persons or had severe memory problems.

In this context, it is important to note that all Dutch inhabitants are registered in a local general practice. As a consequence, the patient list represents a general population denominator. In addition, Dutch patients need to consult their general practitioner before consulting other doctors. Therefore, the medical record at the general practice integrates all information of all specialties and other health care workers.

A questionnaire modified from Boyarsky et $\mathrm{al}^{7}$ was used to rate micturition symptoms (See appendix I). The questionnaires were sent out between may 1990 and may 1992. Each symptom was scored according to a 5 -point scale for frequency, with a score of 1 indicating the absence of a symptom and a score of 5 the presence of the symptom with each voiding ("never", "less than half the time', "half the time", "more than half the time", "always'). For 3 questions different scoring categories were defined: frequency during daytime (1-2 times, 3-4, 5-7, 8-1 1,12 and up), nocturia $(<1$. $1,2,3-4,5$ and up) and impairment of the size and force of the urinary stream ("normal', "normall-weak', "weak", "weak-dribbling", "dribbling"). After symptom inventory the men were asked to indicate the duration of micturition complaints -if any. Dysuria and hematuria were inventoried for the previous 3 months.

The total symptom score was calculated from the response to 7 questions about urinary hesitancy, terminal dribbling, impaiment of the size and force of the urinary stream, incomplete emptying, straining or pushing to start urinary flow, frequency during daytime, and nocturia. The score ranged from 7 to 35 .

The second part of the questionnaire dealt with doctor's visits. The patient was asked to list every operation on the kidney and the urogenital tract, including the doctor"s name and the year the operation(s) took place. Finally the patient was asked to report every visit to a doctor for micturition problems and/or urogenital problems and/or kidney problems which had occurred in the past 5 years. When a doctor had been visited, the year of the visit(s), the name and discipline of the doctor and a short 
explanation was written down. In case of any unclarity the patient was phoned or the questionnaire was sent back in order to complete the information. If this did not resolve the unclarity, direct information was obtained from the medical record. When 1 or 2 questions were missing, the missing questions received a score of 1 and the total score was calculated. When more than 2 questions were missing, the total score was not calculated but was considered as missing. In this study, obstructive micturition problems were defined as being present if the symptom score was among the highest $14 \%$ (score 16 and up) of the responders or if the responder reported chronic micturition problems without other explanatory diagnosis.

In the statistical analysis the chi-square test for independent proportions was used and, for the 2 by $k$-tables, the Mantel-Haenszel test for linear trend. ${ }^{8}$ Multiple logistic regression analysis ${ }^{9}$ was used to calculate odds ratios (and their $95 \%$ confidence interval) for the relation between consultation for BPH (dependent variable) and the studied symptoms and signs (independent variables), taking the included variables into consideration simultaneously (full model).

\section{Results}

An overall response rate of $64.3 \%$ was obtained after two written reminders ( $\mathrm{n}=$ 1692). With increasing age the non-response rate doubled from $27 \%$ for the 55-60 age group to $54 \%$ for ages 80 and up. For $3.0 \%$ of the men answers to one or two of the 7 symptom sumscore questions were missing. No score could be calculated for $1.6 \%$. Missing scores were related to age: $2.5 \%$ in the age group below 65 and $20 \%$ above 80 years.

The mean age of the responders was 66.0 (SD 7.0, median 65.0, max 92 years) and of the non-responders 68.3 (SD 7.3, median 67.1, $\max 92$ years).

Dribbling was a highly prevalent symptom, appearing in $48.8 \%$ of the study population during the past week (table 1). Hesitancy, intermittency and incomplete emptying were also prevalent, especially as moderate symptoms. Incontinence was reported in at least $10.5 \%$ of the cases. This was the question most often not answered $(7.2 \%)$. If going to the toilet for micturition at least once a night is regarded as a symptom, then $58.9 \%$ was symptomatic. Also, voiding twice or more at night was very frequent: $25.6 \%$ (table 2). $54 \%$ noted a decrease in size and force of their urinary stream. During the previous 3 months, $11.3 \%$ noted painful urination and $1.8 \%$ hematuria. Overall, $21.9 \%$ felt they had micturition complaints. Age dependency of symptoms could be shown for hesitancy, straining. dribbling and incomplete emptying, but only for the more severe answering categories.

A substantial proportion (19.4\%) of the population had undergone surgery for kidney or micturition problems. In half of the cases $(9.2 \%)$ prostate surgery had been undertaken (table 3 ). The age-specific prevalence of surgery increased from $3 \%$ for age group $55-59$ to $32 \%$ for 80 years and older. 
table 1. Prevalence of urinary symptoms in men aged 55 years and older reported for the past week

$$
\text { prevalence (percentage) }
$$

mone than half the time /always

age groups

\begin{tabular}{lccccc}
\cline { 3 - 5 } symptom & total & $55-64$ & $65 \times 75$ & 75 and up & total \\
\hline No.pts. & 1692 & 774 & 698 & 220 & \\
dribbling & 48.8 & 15.7 & 16.1 & 19.6 & 16.3 \\
incontinence & 10.5 & 1.8 & 1.9 & 1.9 & 1.7 \\
urge incontinence & 14.6 & 0.9 & 1.9 & 1.0 & 1.3 \\
incomplete emptying & 22.8 & 3.9 & 5.3 & 7.7 & 5.0 \\
hesitancy & 27.3 & 2.4 & 4.9 & 6.9 & 4.0 \\
straining & 6.2 & 0.5 & 0.8 & 2.3 & 0.9 \\
intermittency & 32.6 & 4.7 & 3.5 & 5.0 & 4.3 \\
\hline
\end{tabular}

1. left column is total symptom prevalence for positive categories ("less than hat the time", "half the time', 'more than half the time", "always'); the right column represents the total of "more than half the time' and 'always"; the three middle columns specify the result from the right column lor age groups.

The second largest operation group was stone surgery which in most cases was performed before the introduction of modern urinary tract stone-removing therapies. Urinary stones proved to be a problem mainly of the younger age group.

The rate of doctor's visits for irritative symptoms (percentage of responders with at least one visit to a doctor for a micturition problem during the past 5 years) was independent of age. For obstructive symptoms, the visit rate at $55-59$ years is $2.4 \%$, increasing to $9.6 \%$ at $70-74$ years and decreasing again to $4.9 \%$ above 80 years.

Lower urinary tract infections as well as tumors appear to occur most often in the older age groups.

Only $7 \%$ reported no symptoms (table 4 ). Starting with a score of 9 each point higher on the scale was less prevalent with 31 as highest score reported by one respondent. The rate of visits for any micturition or genital or kidney problem during the last tive years for the total group is $25.2 \%$, ranging from $11 \%(8 \% \mathrm{BPH}$ and related problems) for symptom score $7-8$ to $60 \%(38 \% \mathrm{BPH}$ and related problems) for symptom score 19 or more.

With the cutoff point set at the highest $14 \%$ of symptom scores, it can be seen that almost $70 \%$ of the symptomatic men with complaints were not seen by a doctor during the last 5 years. Among the men who presented with BPH and possibly related 
table 2. Distribution of micturition frequencies (daytime and night) reported for the past week $(n=1692)$, stratified for age

\begin{tabular}{lcrrr}
\hline & \multicolumn{2}{l}{ age groups } & & \\
\cline { 2 - 4 } frequency & $55-64$ & $65-74$ & 75 and up & total \\
daytime & 1.0 & 2.4 & 2.3 & 1.8 \\
\hline $1-2$ times & 29.0 & 27.9 & 25.5 & 28.0 \\
3-4 times & 55.0 & 54.7 & 59.5 & 55.6 \\
$5-7$ limes & 12.5 & 11.7 & 10.0 & 11.8 \\
8-11 times & 2.0 & 2.4 & 2.7 & 2.2 \\
12 or more & & & & \\
\hline
\end{tabular}

\begin{tabular}{lcccc} 
& \multicolumn{2}{l}{ age groups } & & \\
\cline { 2 - 4 } frequency & $55-64$ & $65-74$ & 75 and up & total \\
\hline never/sometimes & 40.6 & 4.1 .0 & 42.7 & 41.1 \\
I time & 33.9 & 32.1 & 31.4 & 32.8 \\
2 times & 18.0 & 18.2 & 17.3 & 18.0 \\
$3-4$ times & 6.5 & 7.0 & 7.7 & 6.9 \\
5 or more & 0.3 & 1.1 & 0.9 & 0.7 \\
\hline
\end{tabular}

column percentages

diagnoses, the symptom score was positive in more than $50 \%$. A large group of presently nonsymptomatic persons with doctor's visits in the past $(8.4 \%)$ had undergone prostate operation.

When different cutoff points for the symptom score were used, or if we only looked at the patient complaining of his micturition, table 5 did not clange much as for the proportion of symptomatic patients not presenting to a doctor (between 64-72\%).

Bivariate analysis of the relation between more severe symptoms and visit rate showed high positive correlations for 6 out of 11 symptoms (table 6). Hematuria represented the highest percentage of cases presenting to a doctor. For dysuria, incontinence, straining and incomplete emptying more than half of the symptomatic men had presented. However, substantial numbers of symptomatic men did not visit their doctor.

Using multiple logistic regression analysis of the correlation between visiting related to BPH (dependent variable) and all dichotomized symptoms simultaneously entered as independent variables, we found positive odds ratios (significantly greater than 1.00) for frequent urination at night, frequent urination during the day, dysuria, 
table 3. Percentage of patients with a history of symptoms or diseases presented to a doctor and operations of the urinary tract $(n=1692)$

\begin{tabular}{lll}
\hline & within last five years & total \\
\hline prostate operation & 3.2 & $9.2^{*}$ \\
BPH/obstructive sympioms & 2.0 & 5.6 \\
imitative symptoms & 0.8 & 2.0 \\
lower urinary tract infection & 2.1 & 3.7 \\
urinary tract stones & 1.5 & 6.0 \\
urinary tract /genital tumors & 0.6 & 1.2 \\
other urinary/genital & & \\
/kidney diseases & 1.6 & 8.2 \\
\hline
\end{tabular}

$* 0.4 \%$ with prostate cancer

table 4. Symptom score and total doctor ${ }^{2} s$ visit rate

\begin{tabular}{|c|c|c|}
\hline symptom score & $\begin{array}{l}\text { prevalance } \\
(\mathrm{n}=\llbracket 692) \\
\text { percentages }\end{array}$ & $\begin{array}{l}\text { doctor"s visit rate } \\
\text { per symptom score } \\
\text { pencentage (number of patients) }\end{array}$ \\
\hline $7-8$ & 7.0 & $\llbracket 1(17)$ \\
\hline $9-10$ & 29.8 & $\| 4(73)$ \\
\hline $11-12$ & 24.0 & $25(1100)$ \\
\hline $13-14$ & 15.5 & $29(77)$ \\
\hline $15-16$ & 8.5 & $36(52)$ \\
\hline $17-18$ & 5.2 & $41(36)$ \\
\hline $19 \cdot 20$ & 2.6 & $59(26)$ \\
\hline $2 \|-22$ & 1.6 & $56(16)$ \\
\hline 23 and more & 1.0 & $60(10)$ \\
\hline
\end{tabular}

1. at least one doctor's visit during the last 5 years for any urological/genital problem.

2. Mantel-Haenszel test for linear trend: $96, \mathrm{df}=1$, significance $<0.00000$ 
table 5. Symptom status (accoridng to symptom score and/or complant) versus doctor"s visit for $\mathrm{BPH}$ and possibly retated diaginoses, stratified by age

\begin{tabular}{lrrrrrrr}
\hline age & $N$ & $S+V+$ & $S+V_{-}$ & $S-V_{+}$ & $S-V_{-}$ & odds ratio & $95 \%$ CI \\
\hline $55-64$ & 774 & $63(8.1)$ & $131(16.9)$ & $66(8.5)$ & $514(66.4)$ & 3.79 & $2.55-5.61$ \\
$65-74$ & 698 & $61(8.7)$ & $128(18.3)$ & $51(7.3)$ & $458(65.6)$ & 4.28 & $2.81-6.53$ \\
$\geq 75$ & 220 & $16(7.3)$ & $44(20.0)$ & $15(6.8)$ & $145(65.9)$ & 3.51 & $1.60-7.68$ \\
lotal & 1692 & $140(8.3)$ & $304(18.0)$ & $132(7.8)$ & $1116(66.0)$ & 3.89 & $2.97-5.10$ \\
\hline
\end{tabular}

between brackets: percentage of age group; doctor's wisit were counted in case of any note on

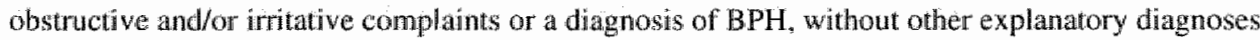
which explain the presence of complaints in the previous 5 years. * $S$ - is symptom score $\leq 15$ nor complaint; $\$+$ is symptom score $>15$ and/or complaint $*+$ is doctor visited, $V$ - no doctor's visit $* 95 \% \mathrm{CI}=95 \%$ confidence intervals.

table 6. Relation between symptoms and doctor's wisit rate

\begin{tabular}{lcll}
\hline & number & doctor"s visit rate $(\%)$ & $\begin{array}{l}\text { odds ratio }(95 \% \\
\text { confidence interval })^{\text {*** }}\end{array}$ \\
\hline dribbling & 377 & $37^{*}$ & $1.16(0.78-1.72)$ \\
incontinence & 50 & $60^{*}$ & $2.13(1.18-3.85)$ \\
urge incontinence & 47 & 57 & $0.75(0.42-1.33)$ \\
size and force decreased & 914 & $30^{*}$ & $1.06(0.62-1.80)$ \\
nocturia (mote than $\mathrm{Ix})$ & 432 & 37 & $1.74(1.18-2.55)$ \\
hesitancy & 136 & 40 & $1.10(0.71-1.72)$ \\
straining & 33 & 52 & $1.29(0.70-2.37)$ \\
intermiltency & 150 & 40 & $0.61(0.39-0.96)$ \\
frequency day (more than $7 \mathrm{x})$ & 238 & 38 & $1.60(1.03-2.49)$ \\
dysuria & 190 & $56^{*}$ & $2.22(1.37-3.58)$ \\
hematuria & 30 & $80^{*}$ & $0.43(0.12-1.58)$ \\
incomplete emptying & 124 & $51 *$ & $2.19(1.41-3.41)$ \\
\hline
\end{tabular}

Pearsons test for $2 \times 2$ table with $p<0.001$; significant increase of visit rate. *w full model for the relationship between visiting related to BPH (yes, no) and all symptoms (at least as 'hall the time') simultaneously as independent variables. 
sensation of incomplete emptying and incontinence (table 6 ). The odds ratio for hernaturia was most substantial $(0.43)$ but did not reach significance $(p=0.14)$. The negative value of this ratio can be understood in relation to visiting related to $\mathrm{BPH}$, while hematuria had a positive effect on doctor"s visit in general. A negative odds ratio also was found for intermittency. The other symptoms and the total symptom score did not show a significant correlation with health care consumption for BPH. Also, age did not modify the relation between symptoms and visits related to $\mathrm{BPH}$.

\section{Discussion}

In an open population of elderly males a high symptom prevalence was found with substantial visit rates for urological problems in the previous five years. For individual symptoms, the highest prevalence was found for decrease in stream $(54 \%)$. Age dependency of symptoms could be shown for hesitancy, straining, dribbling and incomplete emptying, but only for the more severe categories. Absence of any symptom could be found for maximal $7 \%$ of the population. The urinary symptom score shows a strong positive correlation with health care consumption for BPH and other urological entities with a fivefold increase in visit rate, comparing the lowest and highest symptom score categories.

However, in most cases clearly symptomatic men did not consult their doctor in a substantial number in the previous 5 years $(68 \%)$ for a potentially treatable condition.

Even for symptoms where medical attention urgently can be adviced: hematuria and dysuria, $20 \%$ and $44 \%$ of the men respectively, did not present themselves to their doctor.

Six symptoms were found to contribute to health care consumption for BPH (frequent urination at night, frequent urination during the day, intermittency, incomplete emptying, dysuria and incontinence).

With our reminder protocol the nonresponders appeared to be somewhat older than the responders. At a more advanced age, men may find it more difficult to find the interest, capacity or intellectual skill to reply. The healthy elderly male above 75 years may tend to respond more often to our questionnaire than symptomatic elderly so that an even higher symptom prevalence might perhaps be found when interviewing men at their homes. The symptomatic male above 75 years showed lower consumption for $\mathrm{BPH}$ than the younger age groups. Age by itself was not a explanatory factor, but the symptoms.

A Scottish study ${ }^{4.10}$ also showed a high prevalence of BPH measured by symptoms, peak urinary flow and prostatic size. This study reported on men between the age of 40 to 80 years, representing a younger age group, excluding men operated on their prostate. While our study confirms the reported high prevalence of symptoms, we find a lower prevalence for straining (Garraway: 11, Wolfs: 5) and a higher prevalence for hesitancy (Garraway: 13, Wolfs 24). American datall on prevalence of symptoms 
suggest even higher numbers. For age related prevalence of symptoms we found similar results for 7 out of 8 comparable symptoms. Nocturia did not show any age trend in our study. We focused on age related prevalence for the more severe answering categories (table 1). Age trends were not present when looking at less severe answering categories. An important difference with the American data is the fact that we included in the study also the persons with for example a history of prostate operation. However, analysis without these subjects does not influence our results on age dependency much.

A study from Copenhagen ${ }^{2}$ reported a much lower prevalence of doctor's visit (3\%, our study $25 \%)$ and a higher prevalence for urge incontinence. Apparently, this study only looked at diseases for which instrumentation of the lower urinary tract was necessary (prostatectomy and urethral strictures). The authors explicitly sellected men who did not consult a doctor and they were unclear about the proportion of men who did present. In contrast, we looked at the total spectrum of diseases in an older age group.

For the prevalence of dysuria we found the same (and high) percentage as a population study in Edinburgh ${ }^{13}$ and a slightly higher percentage of 13 for the Leeds study.

Garraway 15 reported on visits for urinary symptoms. In this study, only 1 out of every 10 or 20 men with symptom consulted a doctor. In addition, a major impact of symptoms on activities of daily living and on level of bothersomeness was reported. Another study from Denmark ${ }^{16}$ was the first study to point out a large iceberg phenomenon for the presentation of chronic micturition problems. However, this data set was small, with 19 men defined as having "prostatism" of which 5 had sought medical attention.

The operation prevalence found in our study compares well with the Danish percentage of $10^{17}$ for the less elderly group (60-69 year). A study in Barcelona ${ }^{18}$ was the first to shed some light on the prevalence of prostate disorders, which was found to be $15.7 \%$. More details were not available.

Although prostate operation is among the most frequently undertaken operations in older men, 19 micturition problems are much more prevalent than a practicing doctor realizes. If a doctor is not active in questioning the patient on its presence, underdiagnosing could occur.

However, with growing mass media attention for micturition problems and urological diseases (eg. prostate awareness day in USA, treatment advertisements directed at the general public in Europe) it is likely that visit rates will increase, including the number of visits per patient because of the growing number of therapies available from which the patient might benefit. However, to advocate that all subjects with tor example a high symptom score, dribbling, dysuria and incontinence should be seen by a doctor is questionable. And more: to regard our findings as supportive for mass screening is fallacious. For incontinence in females, Lagro-Janssen ${ }^{20}$ showed that most women did not regard their symptoms as a medical problem large enough to consult a doctor (although treatment can be very successful). 
Fowler ${ }^{\mathrm{f}}$ showed the key importance of the patient attitudes in decision on prostate operation. As demonstrated in a decision analysis for TURP, 2,21 the patient's own expectations of positive and negative effects play a key role in the procedures that lead to a prostate operation. The patient's impression of what a doctor could do for him may even influence the decision whether or not to consult a doctor. In our study we were able indeed to find a substantial group of patients who had symptoms but had not consulted a urologist or general practitioner.

Several symptoms did show a relation with health care consumption for BPH in the past. The total score did not show a relation.

Advising treatment for BPH broadly can have two reasons. First, the doctor may expect a benefit in prognosis for the individual patient that outweighs possible adverse effects. Second, the patient himself wants improvement of his quality of life (eg. less nocturia, stronger urinary stream). When this last reason plays a major role (as is true for $70 \%$ of operations in the US $^{3}$ ), then more attention should be directed at on clarification and counseling of the (presumed) patient. In this context our results suggest that active case finding may be a fruitful effort.

In addition, faced with a large iceberg phenomenon for urinary symptoms and the present vagueness on why men do or do not consult a doctor, more studies about patient decisions to consult and the relation between symptoms and the course of BPH and related diseases are needed.

\section{References}

1. Fowler F.J., Wennberg J.E., Timothy R.P., Barry M.J., Mulley A.G. and Hanley D.: Symptom Status and Quality of Life Following Prostatectomy. JAMA, 259: 3018, 1988.

2. Krumins P.E., Fihn S.D. and Kent D.L.: Symptom severity and patients' values in the decision to perform a transurethral resection of the prostate. Med. Decis. Making, 8: 1, 1988.

3. Mebust W.K.: Surgical management of benign prostatic hyperplasia. Urol, 32: $12,1989$.

4. Garraway W.M. Collins G.N. and Lee R.J.: High prevallence of benign prostatic hyperthrophy in the community. Lancet, 338:469, 1991.

5. Knotmerus J.A., Wolfs G.G.M.C. and Muyrers P.E.M.. Benigne prostathyperplasie: een probleem voor patient en huisarts. Huisarts en Wetenschap, 32: 420, 1989.

6. Knotmerus J.A.: The effects of disease verification and referral on the relationship between symptoms and diseases. Med. Decis. Making $7: 139,1987$.

7. Boyarsky S., Jones G., Paulson D.F. and Prout G.R. Jr.: A new look at bladder neck obstruction by the Food and Drug Aministration regulators: guide lines for investigation of benigu prostatic hyperthrophy. Trans. Am. Assoc. Genitourin. Surg., 68: 29, 1976.

8. Mantel $N$., Haenszel W.: Statistical aspects of the analysis of data from retrospective studies of disease. J. Natl. Cancer Inst, 22: 719-748.

9. Kleinbaum D.G., Kupper L.L., Muller K.E.: Applied regression analysis and other multiwari able methods. Boston: PWS-Kent, second edition, 1988. 
10. Mckelvie G.B. Collins G.N. Hehiz M. and Rogers A.C.N.: A Study of Benign Prostatic Hyperplasia; a Challenge to British Urology. Br. J. Urol., 71: 348, 1993.

11. Chute C.G.. Panser L.A., Cirman C.J. Oesterling J.E., Guess H.A., Jacobsen S.J. and Lieber M.M.: The prevalence of prostatimm a population-based survey of urinary symptoms. J. Urol., 150: $85,1993$.

12. Sommer P., Wielsen K.K., Bater T., Kristensen E.S., Hermann G.G., Steven K. and Nordling J.: Voiding Patterns in Men Evaluated by a Questionnaire Survey. Br. J. Urol, 65: 155 1990.

13. Milne J.S., Williamson J. Maule M.M. and Wallace E.T.: Urinary symptoms in older people. Mod. Ger. 198, 1972.

14. Britton J.P., Dowell A.C. and Whelan P.: Prewalence of Urinary Symptoms in Men Aged over 60. Brit J. Urol., 66: 175, 1990.

15. Garraway W.M., Russell E.B.A.W., Lee R.J., Collins G.N., Mekelvie G.B., Hehir M., Rogers A.C.N. and Simpson R.II.: Impact of Previously Unrecognized Benign Prostatic Hyperplasia on the Leves of Middle-aged and Elderly Men. Brit. J. Gen. Pract, 43: 318, 1993 .

16. Jensen K.M.-E., Jørgensen J.B., Mogensen P. and Bille-Brahe N.E.: Some clinical aspects of uroflowmetry in elderly males. A population survey. Scand. J. Urol. Nephrol., 20: 93, 1986.

17. Beiersen Holgersen R. and Brum J.: Voiding pattern of men 60 to 70 years old: population study in an urban population. J. Urol., 143:531, 1990.

18. Fernandez E., Porta M., Alonso J. and Antó J.M.: Epidemiology of prostatic disorders in the city of Barcelona. Int. J. Epidemiol., 21: $959,1992$.

19. National Center for Heatth Statistics: 1987 National Hospital Discharge Survey Data Tape Documentation, P1389-121545, Bethesda, Maryland.

20. Lagro-Janssen A.L.M., Smits A.J.A., van Weel C.: Women with urinary incontinence: self-perceived worries and general practitioners' knowledge of problem. Brit. J. Gen. Pract., 40: $331,1990$.

21. Barry M.J. Mulley A.G., Fowler F.J. and Wennberg J.W.: Watchfull waiting vs immediate transurethral resection for symptomatic prostatism: the importance of patients" preferences. J.A.M.A., 259: 3010, 1988, 


\section{Determinants of doctor consultation for micturition problems in an elderly male population}

George GMC Wolfs 1

J. André Knottnerus ${ }^{1}$

Frans $G$ van der Horst ${ }^{1}$

Adriaan $\mathrm{P}$ Visser ${ }^{3}$

Ruud A Janknegt ${ }^{2}$

From the Department of General Practice', Department of Urology ${ }^{2}$, Department of Health Education ${ }^{3}$. University of Limburg, Maastricht, now working at: Helen Dowling institute for Biopsychosocial Medicine, Rotterdam, the Netherlands 


\section{Abstract}

Objective: To study which factors influence doctor consultation when a subject has micturition problems.

Methods: Postal questiomaire in an open population of older men $(n=1695)$, followed by investigations in 10 general practices, including uroflowmetry.

Results: $25 \%$ of the men had micturition problems, of which $10-30 \%$ presented their symptoms to a doctor. Almost $60 \%$ experienced an influence of their micturition habit on activities of daily living. More than $85 \%$ of the men were not able to compare their micturition pattern with others. In multiple logistic regression, presentation to a doctor was independently associated with obstructive symptoms, dysuria, men defining their situation as a complaint, depressive mood, more frequent sexual desire and smoking. Many other factors which might play a role in diagnosis and timing of treatment were not found to influence consultation.

Conclusion: Most men deal with micturition problems without consulting, although symptoms have a substantial impact on daily life. Consultation was associated with symptoms, psychological factors and smoking.

Key Words: Activities-of-Daily-Living, Prostatic-Hypertrophy, Patient-Acceptance-of-Health-Care, Urodynamics-, Urination-Disorders-complications, Prevalence, Micturition-Problems.

\section{Introduction}

In the male community, the prevallence of micturition problems has been reported to be about $25 \% .^{1,2}$ The majority (70-90\%) is not presented to a doctor, ${ }^{2,3}$ but nevertheless prostate operation is the second most frequent procedure performed among older men." The introduction of effective medication for benign prostatic hyperplasia and the growing number of relatively noninvasive treatments suggest that benign prostatic hyperplasia and related micturition problems can be treated more easily than before. "These developments, together with attention of the mass media, may lead to a growing number of patients presenting symptoms possibly related to benign prostatic hyperplasia. Only after presenting the micturition problem to a doctor can the decision to further diagnose and/or to treat the presumed disorder can be made. In this context, it is important to realize that between hospitals prostatectomy rates differ strikingly, ${ }^{5}$ indicating different decision thresholds for surgeons ${ }^{5}$ and patients. 6 Given that only a minority of patients is known to a doctor. it is important to gain more insight into the factors that influence presentation to a doctor.

In this paper we describe the results of a retrospective study in an open elderly male population, not operated on their prostate, with respect to the occurrence of micturition 
problems in the community and the determinants of presentation with urimary symptoms to a doctor.

\section{Materials and methods}

All men aged 55 years or older who were registered at 10 general practices (1.4 general practitioners) in Maastricht, a city of 115,000 persons in the Nether 1 ands, were considered for inclusion in the natural history study on a cohort ( $n=2734) .99(3.6 \%)$ persons were excluded by their general practitioner because they were bedridden, had a terminal illness, were chronically institutionalized or had severe memory problems.

A questionnaire modified from Boyarsky was used to rate micturition symptoms (first phase) occurring in the past week. The questionnaires were sent out between May 1990 and May 1992.2 A total symptom score was calculated from the answers to 7 questions about urinary hesitancy, terminal dribbling, impairment of size and force of the urinary stream, sensation of residual urine, straining or pushing to start urinary flow, frequency during daytime (more than 7) and nocturia. For irritative symptoms 3 questions were summarized: dysuria, frequency during daytime and intermittency.

In addition, the patient was asked to report every visit to a doctor for micturition problems and/or urogenital problems and/or kidney problems which had occurred in the past 5 years. Consultation possibly related to BPH was defined to be present when a doctor's visit was reported for any obstructive and/or irritative complaint or a diagnosis of BPH or urinary tract infection, without other diagnoses fully explaining the presence of complaints in the previous 5 years. If unclear information was presented, the medical record of the patient was studied. From a random sellection of 253 nonresponders the medical record was studied anonymously to obtain the percentage of consultation for micturition complaints in this group.

Respondents to the questionnaire were invited for further investigations (second phase) in their own general practitioner's office, excluding the men who had already been operated on the lower uninary tract, had insufficient writing skill, or could not stand up in privacy to void. At the general practitioner's office, the men were asked to void into a Dantec rotating disc flowmeter connected to Duc software which oati rate flow abnormality independent of voided volume. Their general practitioner performed a physical examination for bladder and prostate problems, with urinary and blood tests. Additional data were collected on variables with possible influence on medical consultation", (multidisciplinary expert opinion, see appendix II) such as micturition behaviour, opinion on prostate problems (5 questions, Cronbach's $\alpha=0.71$ ), interference with activities of daily living ${ }^{3}$ (9 questions, Cronbach's $\alpha=0.82$ ), perception of own micturition ( 5 questions), worry about own micturition ( 5 questions, Cronbach's $\alpha=0.79$ ), reaction of others to their micturition (7 questions). Also data on other factors which might have influenced consultation were collected ${ }^{9}$ (see appendix III): demographic and health related factors (general health, subjective 
health ${ }^{10}$ (13 questions, Cronbach's $\alpha .81$ ), feelings of depression ( 7 questions, Cronbach's $\alpha .8 .87$ ), health related risk factors (body mass index (BMI) smoking, alcohol consumption), tendency to visit a doctor ( 9 questions, Cronbach"s $\alpha=0.65$ ), actual doctor consultation and sexual behaviour ( 7 questions) were recorded. In case a man used medication with possible influence on micturition behaviour, this was noted. Cronbach" $\mathrm{s} \alpha$ is a measure with a range from 0.0 to 1.0 representing the internal consistency of a questionnaire. All items on a scale designed to measure the same construct should measure different aspects of the same trait and should therefore correlate with each other. An $\alpha$ from 0.60 to 0.69 is moderate, from 0.70 to 0.79 reasonable, from 0.80 good to excellent.

Bivariate analysis (contrast: present/absent) was carried out using Spearman's rank correlation coefficient ( $r$ ), the t-test for independent means and the Chi squared test for independent proportions. Multiple Jogistic regression analysis ${ }^{11,12}$ was used, with consultation for benign prostatic hyperplasia and related problems as a dependent variable, and potential determinants as independent variables, taking the included variables into consideration simultaneously. Selection of variables and model construction were made on the basis of judgement of clinical relevance, variable construction techniques, bivariate statistics and model building strategies in multivariable analysis. Results are shown for the reduced model $(p<0.20)$ found with forward and backward stepwise modelling and are expressed in odds ratios with $95 \%$ confidence intervals.

\section{Results}

For the postal questionnaire, a response rate of $64.3 \%(n=1695)$ was obtained after two written reminders. Of the responders, $20.4 \%(n=345)$ were excluded from the second phase.

As a result, 1350 subjects were invited for this second part of the study (visiting the general practitioner). For this phase the response rate was $61.4 \%(n=829 ; 792$ complete records). After checking the patient records anonymously, a history of consultation for benign prostatic hyperplasia and related problems was about as frequent in nonresponders to the postal questionnaire $(17.4 \%)$ as compared to the responders $(15.6 \%$ Chi squared test: $p=0.47$ ). This compares well with the percentage of $15.7 \%$ for the group that was examined in the general practice. The results presented hereafter involve patients examined at the general practice.

\section{Micturition problems and consequences}

The general picture is that micturition problems limit most men daily in leisure and household activities (table $1,58.3 \%$ ). Table 2 indicates that only $3.6 \%$ experience this 
table 1. Prevalencet of interference with activities of daily hing by moturition habits during the past month

Daily Living Affected

Micturition Habit Limits:

Some of the Time

Most or All of the Time

Fluid intake before bedtime

$30.6^{\text {t? }}$

$9.9^{i t i}$

Fluid intake before travel

$24.5^{\text {w2 }}$

$5.6^{\text {H. }}$

Going to places without toilet

$26.0^{\text {*nt }}$

$8.6^{\mathrm{k} 2}$

Driving for two hours

$24.8^{\text {* }}$.4

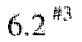

Playing outdoor sports / walking

Getting enough sleep at night

$26.6^{\mathrm{Ht}}$

$4.2^{\text {H6 }}$

$25.5^{\text {花 }}$

$4.4^{\# .5}$

Going shopping

$25.8^{\text {nit }}$

$3.6^{117}$

Going to cinema / theatre / church

$17.7^{\text {fto }}$

$3.0^{1145}$

At least one of these

42.3

16.0

†percentage; "rank numbers

interference as giving much hindrance. The answers to the question in which men were asked to compare their micturition habit with other men in the same age group suggest that most men $(87.9 \%)$ deal with their micturition in privacy and have almost no information to interpret their micturition habit.

Men were especially worried when they experienced more hindrance $(r=0.64)$; worry was not related with symptoms. Chronic micturition problems are regarded as a nuisance (table 3) and a large group would favour an operation for alleviating symptoms $(59.2 \%)$. These opinions were not associated with symptom scores, the men's own perception of complaints and consultation for benign prostatic hyperplasia and related problems. We also found men with few symptoms or signs who saw themselves as having a "large problem". No less impressive are the men combining many symptoms and low flow but who view themselves as "normal for their age". The men perceiving a micturition complaint reported in $26 \%(10.2 \% / 39.6 \%)$ a reaction of somebody else (table 4), in most cases their partner. The majority of these reactions were not positively appreciated by the men. If somebody did react, the advice given most often was to consult a doctor.

\section{Doctor consultation for micturition}

Of the symptoms we studied, most are significantly positively associated with consultation for benign prostatic hyperplasia and related problems (table 5). A 
table 2 a. Perception of own micturition thabits

How much are you hindered by your micturition complaints?

$\begin{array}{lr}\text { Very Much } & 0.1 \\ \text { Much } & 3.5 \\ \text { A Little } & 30.4 \\ \text { No Hindrance } & 44.1 \\ \text { Not Applicable }^{1} & 21.9\end{array}$

How does your micturition habit compare with that of men of the same age?

I do better

About the same

I do worse

I don't know

87.9

How severe do you consider your micturition complaints?

$\begin{array}{lr}\text { Very severe } & 0.4 \\ \text { Severe } & 3.6 \\ \text { Hardly Severe } & 13.4 \\ \text { Not Severe } & 31.7 \\ \text { Not Applicable }^{\text {N }} & 50.9\end{array}$

t percentages; "no notice of any micturition complaint connected with a notice of hindrance or severity judgement.

table 2b. Perception of own micturition habit, continued

\begin{tabular}{llcc}
\hline & \multicolumn{2}{l}{ Have you been worried during the last month about } \\
\cline { 2 - 4 } Micturition & Habits Acute & Retention & Prostate Cancer \\
\hline Very worried & 0.1 & 1.9 & 0.6 \\
Worried & 2.7 & 3.1 & 1.8 \\
A Little Worried & 17.9 & 17.2 & 15.2 \\
Not Wortied & 79.3 & 77.8 & 82.4 \\
\hline
\end{tabular}

i. percentages 
table 3. Opinion on prostate problems

\begin{tabular}{llll}
\hline Opinion & Agree & Don Agnee & Don' Know \\
\hline $\begin{array}{l}\text { Prostatism is a nuisance for elderly men } \\
\text { When a man complains about his prostate, it is better }\end{array}$ & 66.5 & 0.6 & 32.9 \\
$\begin{array}{l}\text { to remove the prostate surgically } \\
\text { When a man complains about his prostate, an }\end{array}$ & 53.8 & 4.9 & 41.3 \\
$\begin{array}{l}\text { Operation is unavoidable } \\
\text { A prostate operation affects sexual activity }\end{array}$ & 11.3 & 3.0 & 61.3 \\
$\begin{array}{l}\text { If the doctor were to let me decide whether or not I } \\
\text { need a prostate operation to alleviate my }\end{array}$ & & & 81.4 \\
complaint, I would choose an operation & 59.2 & 5.1 & 35.7
\end{tabular}

tpercentage; $4.3 \%$ missing in this question.

table 4a. Perceived reaction of others to men with micturition compliants

Did other people ever react to your micturition complaints?

$\begin{array}{ll}\text { Yes } & 10.2 \\ \text { No } & 13.4 \\ \text { They don't know } & 16.0 \\ \text { Total with complaint } & 39.6\end{array}$

table $4 \mathrm{~b}$. Specification of reaction of others to 108 men complaining about micturition habit ${ }^{\ddagger}$

If others reacted to your micturition complaints, how did you appreciate that?

$\begin{array}{lr}\text { Didn't Liked it } & 60 \\ \text { Neutral } & 21 \\ \text { Liked it } & 15 \\ \text { Missing } & 4 \\ \text { Partner } & 74 \\ \text { Children/Family } & 13 \\ \text { Relative/Friend } & 9 \\ \text { Fellow patient } & 4 \\ \text { Somebody Unknown } & 6 \\ \text { Consult Doctor } & 69 \\ \text { Medication } & 36 \\ \text { Operation } & 9\end{array}$

$\uparrow$ percentages 
U-shaped relation was found between consultation and depressed feelings, while no relation was demonstrated in linear statistical testing. The strongest positive factor related with doctor"s visit was the men"s recognition of the symptoms as a complaint. Other factors like hindrance, worry and severity were not associated with consultation rates, either linear or other. The few men who perceived their micturition as worse for their age tended to consult a doctor more frequently $(p=0.26)$. The advice to consult a doctor (most often given by their partner) was not significantly associated with a higher consultation rate.

The analysis of other factors that might affect general health care consultation did show some remarkable results. Smokers consult their doctor more often than non-smokers for benign prostatic hyperplasia and related problems. Furthermore, men with a higher educational level tend to consult more often. Abnormal performance on uroflowmetry was not related with visiting a doctor.

In table 6, the factors are shown which independently contributed to consultation for benign prostatic hyperplasia and related problems using multiple logistic regression. Apart from dysuria (not reaching significance below $p=0.05$ ), the obstructive symptom score had a positive influence. Within this score, nocturia and sensation of residual urine showed the most important contribution. The men's awareness of having a complaint was not as important as the obstructive symptom score. Again, feelings of depression showed a U-shaped relation with benign prostatic hyperplasia and associated problems, which was not explained by use of medication with a possible effect on micturition. Furthermore, men with more sexual desire tended to go to a doctor earlier. Several subpopulations were examined using the logistic model. For the younger age category of 55-64 years, symptoms show higher odds ratios (dysuria 2.63. sensation of residual urine 1.93, nocturia 2.25 ), and especially the most depressed category (4.07). For the age category above 64 years, the influence of indlividual symptoms was almost absent, but the obstructive symptom score contributed to consultation rate. Repeating the logistic regression analysis for consultation shorter than 2 years before the postal questionnaire and 1 year earlier revealed higher odds ratios for frequency of sexual desire (3.92) and awareness of a complaint (5.87); other factors did not substantially change. 
table 5. Factors related to doctor consultation for benign prostatio hyperplasia and related problems

Factor

\section{SYMPTOMS}

Dysuria $<3$ months

Hesitation

Dribbling

Size and Force Weak

Residuall feeling

Pushing to stant

Frequency daytime $>7$

Nocturia

$>1$

$>2$

$>3$

Incontinence

Intermittency

Haematuria $<12$ months

Obstipation

Obstructive symptom score

Irritative symptom score

Depressive score

- Worst $5.8 \%$

- Best 33.3\% odds ratio

2.78

2.05

1.50

1.98

3.00

2.07

1.83

2.67

3.45

1.83

2.52

1.01

2.94

1.40

2.03

1.86
$95 \%$ confidence interval, p-value

\section{PERCEIVED HEALTH}

Complaint of micturition

Compare micnurition behaviour with age group

- Better

- Same

- Worse

Symptoms Give Hindrance

Symptoms Are Severe

Symptoms Worry Me

Fear of Prostate Cancer 
wble 5. continued

Factor

- Noted a Reaction

odds ratio

$95 \%$ confidence interval

- Know It and No Rexction

$1.32 \quad 0.73-2.40$

- Others do not Know

1.14

$0.66-1.97$

Reaction of Partner

1.66

$1.04-2.66 \div 00324$

Advice to Consult a Doctor

1.49

$0.84-2.65$

1.07

$0.56-2.05$

\section{SEX-RELATED FACTORS}

Ejaculation in Last Month

$\begin{array}{ll}\mathbb{1} .02 & 0.73-1.42 \\ \mathbb{1 . 5 8} & 0.70-3.56 \\ \mathbb{1 . 4 7} & 0.97-2.22 \\ 0.89 & 0.56-1.42 \\ 0.81 & 0.56-1.19\end{array}$

Pain with Ejaculation

Able to Have an Erection

Able to Have an Erection when Desired

$0.56-1.19$

Satisfied About Sex

$1.62 \quad 1.02-2.55+0.0377$

a Weok

\section{PATIENT CHARACTERISTICS AND RISK FACTORS}

Age:

- 55-64 years

1.02

$0.70-1.48$

$-65-74$ years

1.09

-75 And Older

0.70

$0.75-1.59$

Insurance (Sick Fund)

0.82

Current Smoker

1.58

$0.34-1.45$

Alcoholic Consumption (units):

- Less than once w week

- Less than once a day

- Once a day and more than once

1.00

$1.09-2.31 \div 0.0167$

Body Mass Index:

$-<24.40$

$-24.40-26.75$

$-326.75$

1.06

1.16

$0.82-2.12$

Serum Creatinine $>116 \mu$ mol/

0.81

1.41

$0.68-1.46$

All Doctor Consultations in Previous Month

0.62

$0.68-1.49$

Hospital Stay in Previous Year

0.60

$0.71-1.56$

Living Alone

1.64

$0.78-1.73$

$0.53-1.23$

Educational Level:

0.76

$0.74-2.69$

- Lowest (Primary)

$0.36-1.06$

- Middle(Secondary and High School)

1.57

$0.30-1.19$

$0.98-2.73$

- Highest (Advanced and University) 
table 5 . continued

\begin{tabular}{lll}
\hline Factor & odds ratio & $95 \%$ confidence intervall \\
\hline FREE FLOW PARAMETERS & & \\
- Qmax < 8.2 ml/s & 1.36 & $0.87-2.12$ \\
- Qmax abnormal (software) & 1.09 & $0.73-1.62$ \\
- T100<20.1 s & 1.44 & $0.85-2.45$ \\
- T100 abnormal (software) & 0.84 & $0.58-1.23$ \\
- T90<13.5 s & 0.84 & $0.51-1.37$ \\
- T90 abnormal (software) & 1.08 & $0.74-1.58$ \\
\hline
\end{tabular}

$t \mathrm{p}$-value is are only given when $\mathrm{p}<0.05$.

table 6. Multiple logistic regression analysis' of consultation possibly related to benign prostatic hyperplasia

\begin{tabular}{lll}
\hline Factor & odds Ratio & $95 \%$ Confidence Interval \\
\hline Dysuria (last 3 months) & 1.62 & $0.92-2.85$ \\
Obstructive Symptom Score (4 categories ${ }^{2.3}$ ) & 1.43 & $1.10-1.86$ \\
Depressive Feelings (worst $6 \%$ ) & 1.82 & $0.81-4.07$ \\
Depressive Feelings (best 33.3\%) & 1.80 & $1.15-2.80$ \\
Complaint (yes/no) & 2.32 & $1.36-3.95$ \\
Sexual Desire (> I a week) & 1.81 & $1.08-3.01$ \\
Smokes Now & 1.61 & $1.05-2.48$ \\
Educational Level (middle) & 1.56 & $0.96-2.16$ \\
Educational Level (high) & 1.68 & $0.92-2.43$ \\
\hline
\end{tabular}

\footnotetext{
'logistic regression, results are shown for $p<0.20, n=668$ for the reduced model.

" linearly related categories; lowest scores $7-8=$ prevalence $34.9 \%$; then score $9-11=37.6 \% ; 12.15$ $=19.5 \%$ and $>16=8.7 \%$.

${ }^{3}$ replacement in the logistic regression of the obstructive symptom score by all seven symptoms showed the following 2 symptoms with $\mathrm{p}<0.20$ to have a positive correlation: nocturia $>1$ (odds ratio $1.73,95 \%$ confidence interval $1.05-2.85$ ) and residual feeling (odds ratio $1.85,95 \%$ confidence interval $1.07-3.20$ ).
} 


\section{Discussion}

Starting in 1988 , several at thors $6.13,14$ showed the importance of patient perception for the decision to undergo a prostate operation. Our analysis corresponds to these observations, while we provide information at a population level, excluding men who already underwent lower uninary tract surgery. In order to evaluate work-up and selection bias, 15,16 we made comparisons between the basic population level and the responders to the first and to the second part of our studies. There were no relevant differences between these groups.

Testing of multiple determinants in our study implied a risk of false positive conclusions, since there is a 1 in 20 probability that in the absence of a real association a $p$-value $<0.05$ is found. Therefore, in fact, the number of positive associations may be even lower than observed. On the other hand, using an adapted significance level (lower than 0.05 ) carries the risk of increasing the number of false-negative conclusions, since the sensitivity of the study will decrease. ${ }^{17}$ Another reason not to decrease the significance level is that all diagnostic items we tested were selected as potentially useful diagnostic indicator, based on the literature and clinical experience. So, the testing was hypothesis-based and there was no "data-dredging" or "data-trawling". We agree with Michels and Rosner, ${ }^{18}$ that the key to the sensible handling of data is careful interpretation of observed associations rather than artificial erection of

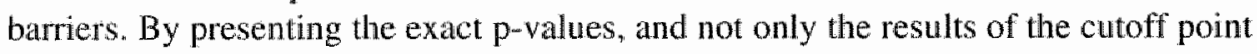
$p<0.05$, readers can evaluate the significance of our findings themselves.

The results of three other studies $1,3,19-23$ allow us to compare symptom prevalence, influence on activities of daily living, worry and hindrance and consultation for micturition problems with similar populations. Symptom prevalence seems comparable in percentage and ranking. Hindrance during activities is experienced $2-3$ times more frequently in our study as compared with the Scottish sample, while ranking this phenomenon between other factors shows a close similarity between Minnesota, Scotiand and Masstricht. It is important to note that all three studies specifically excluded men who where already operated on their urinary tract, becaluse of the diversities in the surgery group in terns of success and failure, together with the complicated time relation for analysis.

Jacobsen ${ }^{20}$ and Roberts ${ }^{21}$ report that worry and embarrassment for urinary symptons have a significantly positive effect on consulation rate. In bivariate analysis they found that these factors were also correlated with the obstructive symptom score. In addition, they also found that more depressive men went more often to see their doctor for micturition complaints. As a possible explanation for our finding that both 'optimistic' and "pessimistic' men tend to visit their doctor more often for benign prostatic hyperplasia, we suggest that there may be different groups of elderly men reacting on micturition complaints by visiting a doctor. One group of emancipated, well educated, healthy men have a more open attitude to discuss micturition symptoms with their doctor. In another group, symptoms evolved with substantial impact on their 
daily lives and mood, urging them to see a doctor. Such elderly men can have a pessimistic opinion that treatment cannot be helpful any more.

Jacobsen ${ }^{20}$ report a lower prevalence of health-care-seeking behaviour for urinary symptoms, but they studied a younger group than ours. In their study a higher bother score - or a higher symptom score 22 - was associated with doctor consultation. Unlike Jacobsen, we did not use a bother score per symptom but enquired after bother factors in a more general way and could not attribute a predictive value for doctor consultation to these factors. Both studies agree on the findings that consultation does not seem to relate to age or flow rate. Hunter and Simpson ${ }^{23.24}$ also identified symptom severity as explanatory for seeking health care, especially with their analysis of more recent consultations. Further research which also takes into account intercultural differences can clarify the various findings concerning bother, depression and health care use for benign prostatic hyperplasia and related problems, perhaps in a prospective study.

Recently, Kaplan et al. have shown results of patients' treatment choices when referred to an urological clinic. ${ }^{25}$ When information was presented in a neutral way, only $\rrbracket 0 \%$ selected TURP as first choice, mainly when symptoms were severe and flow rate was low. Baseline characteristics show that the population in this study is older, has more symptoms and poorer flow rates. In our study the majority of men were unaware of their actual flow although symptom severity made men see a doctor. The study of Kaplan also underlines the importance of the patient's decision process. To our knowledge, information is too indirect to warn a patient of a bad prognosis on the basis of poor flow rates or severe symptoms. The data reported by Cunningham-Burley ${ }^{26}$ agree with our findings that pain, haematuria, nocturia and severe symptoms cause patients to see a doctor, not the worry experienced or interference with daily life.

In the general population, interference of micturition symptoms with activities of daily living is highly prevalent. Most men adapt to their symptoms without discussing or comparing them with others. We identified several symptoms and signs which influence doctor consultation for benign prostatic hyperplasia and related problems. Our study did not reveal compelling factors for consultation. This may be partly explained by the low prevalence of some symptoms (eg. haematuria, dysuria). Higher educated men with more frequent sexual desire and who see their symptomatic micturition as a complaint have a higher consultation tendency for benign prostatic hyperplasia and related problems. The younger age group attached more weight to symptoms for consultation than the elderly. One of the most surprising findings is the fact that men aged 55-64 years with a very high or a low depression score consulted more often for benign prostatic hyperplasia and related problems. In multivariable analysis, many other factors did not show any additional contribution to presentation of benign prostatic hyperplasia. In this study it was not our intention to derive and validate a prediction model for doctor consultation. This was avoided because of the retrospective character of our study. The relatively long time period considering doctor consultation i.e. the last 5 years, and the exclusion of men who were operated also prevented a more detailed examination of our factors. Also, selecting a time frame 
shorter than 5 years for doctor consultation in multivariable analys is aiming at selecting explanatory factors would have been less efficient because of the low frequency of recent consultations versus the high number of possible factors.

The results of our study are an argument to openly discuss micturition habits with any older man. Diagnosis and treatment should be suggested, rather than forced upon the men, recognizing that the patient should be at the centre of the decision-making process $^{27}$. Between men the differences in weight attached to the same symptom severity also support the argument to let the man decide himself.

Finally, the results confirm that the determinants of the natural history of benign prostatic hyperplasia and inelated problems should be studied at the population level ${ }^{6,15}$ to provide differentiation between clinically relevant and irrelevant bladder outflow obstruction.

\section{References}

1. Garraway WM, Collins GN, Lee RJ: High prevallence of benign prostatic hypertrophy in the community. Lancet 1991;338:469-471.

2. Wolfs GGMC, Knottnerus JA, Janknegt RA: Prevalence and detection of micturition problems anong 2734 eldierly men. J Urol 1994:152:1467-1470.

3. Garraway WM, Russell EBAW, Lee RJ, Collins GN, McKelvie GB, Hehir M, Rogers ACN, and Simpson RJ: Impact of Previously Unrecognized Benign Prostatic Hyperplasia on the Daily activities of Middle-aged and Elderly Men. Brit \Gen Pract 1993;43;318-321.

4. Mebust WK, Holtgrewe HL, Cockett ATK, Peters, PC and writing committee: Transurethral prostatectomy: immediate and postoperative complications: A cooperative study of $₫ 3$ participating institutions evaluating 3,885 patients. J Urol 1989;141:243-247.

5. Wennberg JW, Mulley AG Jr, Hanley D, Timothy RP, Fowler FJ, Roos NP, Barry MJ, McPherson K, Greenberg ER: An assessment of prostatectomy for benign urinary tract obstruction. Geographical variations and the exaluations of medical care outcomes. JAMA 1988;259:3027-3030.

6. Barry MJ, Mulley AG Jr. Fowler FJ, Wenuberg JW: Watchful waiting vs immediate transurethral resection for symptomatic prostatism. The importance of patients" preference. JAMA 1988:259:3010-3017.

7. Boyarsky S, Jones G, Puulson DF, Prout GR Ir: A new look at bladder neck obstruction by the Food and Drug Administration regulators: guidelines for investigation of benign prostatic hypertrophy. Trans Am Assoc Genitourin Surg 1976;68:29-33.

8. Rollema HJ: Uroflowmetry: in Krane RJ, Siroky MB (ed): Clinical Neuro-Urology. Boston, Little, Brown and Co, 1991, second ed, pp 201-244.

9. Chrisman NJ: The Health Seeking Process: an Approach to the Natural History of Illness. Culture, Medicine and Psychiatry 1977;1:351-377.

10. Reek v J. Diederiks J, Philipsen H. Zutphen v W, Seelen T: Subjective complaints and blood pressure. J Psychosom Res 1982;26(2):155 165. 
11. Kleinbaum DG, Kupper LL, Muller KE: Applied regression analysis and other multivariable methods. Boston, PWS-Kent, second edition, 1988.

12. Hosmer DW, Lemeshow S: Applied Logistic Regression. New York, Wiley \& Sons, 1989.

13. Fowler FJ, Wemberg JE, Timothy RP. Barry MJ, Mulley AG, Hanley D: Symptom Status and Quality of Life Following Prostatectomy. JAMA 1988;259:3018-3022.

14. Krumins PE, Fihn SD, Kent DL: Sympton severity and patients' values in the decision to perform a transurethral resection of the prostate. Med Decis Making 1988;8:1-8.

15. Feinstein AR: Clinical Epidemiology: the Architecture of Clinical Research. Philadelphia, Saunders Company, 1985, pp 597-631.

16. Knotmerus JA: The effects of disease verification and referreal on the relationship between symptoms and diseases. Med Decis Making 1987;7:139-148.

17. Rothman KJ: No adjustments are needed for multiple comparisons. Epidemiology 1990;1:4346.

18. Michels KB, Rosner BA: Data trawling: to fish or not to fish. Lancet 1996;348:1152-1153.

19. Guess HA, Chute CG, Garraway WM. Girman CI, Panser LA, Lee RI: Similar levels of urological symptoms have similar impact on Scottish and American Men -although Scots report less symptoms. J Urol 1993;150:1701-1705.

20. Jacobsen SJ, Girman CJ, Guess HA, Panser LA, Chute CG, Oesterling JE, Lieber MM: Naturall History of Prostanism: Factors associated with discordance between frequency and bother of Urinary Symptoms. Urology 1993;42(6):663-671.

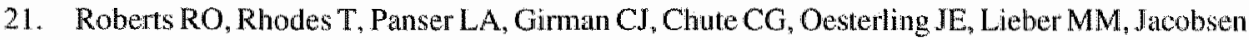
SJ: Natural history of Prostatism: worry and embarrassment from urinary symptoms and health care-seeking behavior. Urology 1994;43(6):62 I-628.

22. Jacobsen SJ, Chute CG, Girman CJ, Oesterling JE, Guess HA, Lieber MM, Panser LA: Do prostate size and urinary flow rates predict heal th care-seeking behaviour for urinary symptoms in men? Urology 1995;45(1):64-69.

23. Hunter DJW, McKee CM, Black NA, Sanderson CFB. Health care sought and received by men with urinary symptoms, and their wiews on prostatectomy. Br J Gen Pract 1995:45:27-30.

24. Simpson RJ, Lee RJ, Garraway WM, King D, McIntosh I. Consultation patterns in a community survey of men with benign prostatic hyperplasia. Br J Gen Pract 1994; 44:499-502.

25. Kaplan SA, Goluboff ET, Olsson CA, Deverka PA, Chmiel JJ. Eflect of Demografic Factors, Urinary Peak Flow rates, and Boyarski Symptom Scores on Patient Treatment Choice in Benign Prostatic Hyperplasia. Urology 1995;45(3):398-405.

26. Cunningham-Burley S, Allbutt H, Garraway WM, Lee AJ, Russell EBAW. Perception of urinary sy mptoms and healthcare-seeking behaviour amongst men aged $40-79$ years. Brit J Gen Pract 1996; 46, 349.352.

27. McConnell JD, Barry MJ, Bruskewitz RC, Bueschen AJ, Denton SE, Holtgrewe HL, Lange JL, McClennan BL. Mebust WK, Reilly NJ, Roberts RG, Sacks SA, Wasson JH.. Benign Prostatic Hyperplasia: Diagnosis and Treatment. Clinical Practice Guideline. Number 8. AHCPR Publication No. 94-0582. Rockville, MD: Agency for Health Care Policy and Research, Public Health Service, US Department of Health and Human Services; 1994. 


\section{Occurrence and determinants of urinary flow abnormalities of elderly men in an open population}

George G.M.C. Wolfs ${ }^{1}$

J. André Knottnerus ${ }^{1}$

Cees van de Beek ${ }^{2}$

Ruud A. JanKnegt ${ }^{2}$

From the Department of General Practice. Department of Urology ${ }^{2}$, University of Maastricht, Maastricht, the Netherlands 


\section{Abstract}

Purpose: To describe the distribution of urinary flow results in a male population and to study clinical determinants of low flow.

Material and Methods: All men older than 55 year were considered for a postal questionnaire $(n=2734)$. If no unnary tract operation had been undertaken, the men were asked for investigations in general practice regarding urinary flow and possible clinical deteminants of abnormal flow $(\mathrm{n}=829)$.

Results: Getting a reliable flow result is difficult to achieve for a substantial number of men (33\%). Low flow results varied from $21 \%$ among men of $55-59$ years of age to $70 \%$ among those of 80 or older. When low flow was corrected for voided volume with an age independent algolitm then this difference almost faded away.

Presentation to a doctor was not associated with a low flow result. If low flow was studied for it"s associations, then only the experience of a small stream, indices of urinary tract infection, and higher daily alcohol intake were related.

Conclusions: Low urinary flow can be found very often outside the scope of medical doctors and only few clinical determinants are correlated with its diagnosis. Whether it is risk full not visiting a doctor for low flow remains unclear and should be established in prospective studies.

Key Words: urinary flow, population survey, male, determinants, general practice.

\section{Introduction}

In urological practice urinary flow measurements are often used to discover outflow obstruction, Benign Prostatic Hyperplasia (BPH) or urethra strictures. ${ }^{l}$ Furthermore, uroflowmetry is widely applied to assess the severity of pathological condition and to quantify treatment outcome. Fundamental to interpretation of observed flow results is knowledge of the distribution of flow patterns in the open male population. In this context it is striking that in literature data on free flow results for the open population are sparsely reported ${ }^{2-9}$ and poorly documented, especially for elder men. To a large extent this may be brought about by the fact that many men do not present their symptoms to a doctor. In addition, diagnostic flow measurements are limited to the group of self-selecting elderly men who do visit a doctor with complaints and who subsequently are referred to an urological clinic. This gives way to an important source of bias on urological publications evaluating the diagnosis and management of BPH." This population and referral bias leads to a lack of knowledge with respect to normal distribution of flow results and consequently their relation with symptoms and signs. 12 Uroflowmetry cutoff point used nowadays like $<10 \mathrm{ml} / \mathrm{s}$ with a voided volume of at least $150 \mathrm{ml}$ may therefore be wrong or at least have to be validated correctly. 
This paper describes a survey to determine the distribution of flow restilts in an open elderly male population, not operated on their prostate. In addition, low flow results were related to various clinical determinants.

\section{Materials and methods}

All men aged 55 years or older, registered at 10 general practices (14 general practitioners (GPs)) in Maastricht, a Dutch city of 115,000 persons, were considered for inclusion in the study ( $\mathrm{n}=2734)$. Of these $99(3.6 \%)$ persons were excluded since they were bedridden, had a terminal illness, were chronically institutionalized or had severe memory problems.

A questionnaire modified from Boyarsky/3 was sent out to rate micturition symptoms. An obstruction symptom score was calculated from the answers to seven questions. ${ }^{10}$ For irritative symptoms three questions were summed: dysuria, frequency during daytime and intermittency. In addition, patients was asked to report every visit to a doctor for micturition problems in the previous five years. From a 1 in 4 random selection $(n=253$ ) of nonresponders the medical record was studied anonymously to obtain the frequency of doctor's consultation for micturition complaints (all urological problems, and BPH-related problems) in this group.

When response of an individual was obtained $(n=1692,64.3 \%)$, he was invited to be examined at his GP's office. This invitation was not sent to persons who previously underwent lower urinary tract surgery $(n=155,9.2 \%)$, were known with prostate cancer $(\mathrm{n}=7,0.4 \%)$, could not stand up in privacy to micturate, or were known to have severe reading problems (total exclusion: $n=400,23.6 \%$ ).

At the GP's office subjects were asked to void with at least average urge in an rotating disk flowmeter (Dantec urodyn 1000) ${ }^{14}$ connected to DUC-free flow software ${ }^{15}$ Furthermore it was asked not to move the urinary stream, not to use abdominal pressing and not to void at the bottom of the flowmeter. After the patient had answered questions for that specific void on straining, representativity, voiding at ease, rating of urge, and after the voided volume was entered, the software calculated a result. These results were expressed as 'normal', 'inconclusive', 'abnormal' or 'not classifiable' (less than average urge to void, or volume below $50 \mathrm{ml}$ or above $450 \mathrm{ml}$ ). Also all flow curves were visually inspected to identify possible disturbances ${ }^{16}$ of more than $50 \%$ on one of the volume-dependent, percentiled parameters (dI/dt40, $\mathrm{Qm}_{\operatorname{my}}, \mathrm{Q}_{\mathrm{max}}$ and $\left.\mathrm{T}_{\mathrm{dcss}}\right)$. Curves with these irregularities were marked as 'artefact' in adjunct to the software result and the parameter was corrected if possible. When the voiding was rated as 'inconclusive', "not classifiable" or 'artefact' the person was asked to return within short notice, and after individual instructions had been given to improve the quality of their spontaneous void, the flow measurement was repeated. Two times an inconclusive void was noted as end result 'inconclusive'. A maximum of three voids per person 
table 1. Basic popolation and response data for total population, postal questionnaire and GPexamination (column percentages, except for age (years)).

\begin{tabular}{|c|c|c|c|}
\hline participants for analysis & $\begin{array}{l}\text { population } \\
n=2734\end{array}$ & $\begin{array}{l}\text { response postal } \\
\text { questionnaure } \\
n=1692\end{array}$ & $\begin{array}{l}\text { response } \\
\text { GP-examination } \\
n=829\end{array}$ \\
\hline response & & 64.3 & 61.3 \\
\hline excluded for next phatse & 3.6 & 23.6 & \\
\hline atge & $66.8 \mathrm{SD} 7.1$ & $66.1 \mathrm{SD} 7.0$ & $65.1 \mathrm{SD} 6.3$ \\
\hline $\begin{array}{l}\text { Symptomscone posstive } \\
\text { doctor visit: }\end{array}$ & & 13.7 & 16.7 \\
\hline -all urological problems & $29.2 w^{2}$ & 25.2 & 24.5 \\
\hline -BPH-rellated & $17.4 *^{2}$ & 15.6 & 15.7 \\
\hline Qminix $<15 \mathrm{~m} / \mathrm{s}$ & & & 62.7 \\
\hline$Q_{\text {malx }}<10 \mathrm{ml} / \mathrm{s}$ & & & 35.8 \\
\hline \multicolumn{4}{|l|}{ flowresult DUC } \\
\hline -normal & & & 13.1 \\
\hline -inconclusive & & & 19.1 \\
\hline -abnormal & & & 34.6 \\
\hline -not classificable & & & $33.2^{3}$ \\
\hline whtefict on curwe & & & 20.0 \\
\hline
\end{tabular}

* I last five years, medical record, postal questionnaire, any doctor; 2 percentage of sample of nonresponders; $8318 \mathrm{x}$ no free fllow curve collected, $14 \mathrm{x}$ two times or more volumes $<50 \mathrm{ml}$ or $>$ $450 \mathrm{ml}, 209 \mathrm{x}$ one inconclusive-curve, $34 \mathrm{x}$ one flow curve with too little urge and the other curve had a volume out of range.

table 2. Distribution of uroflow results ( $n=743$ one decisive flow per patient, volumes of $50 \mathrm{ml}$ or above, row percentiles).

\begin{tabular}{|c|c|c|c|c|c|c|c|}
\hline & lowest & PIO & $\mathrm{P} 20$ & P50 & P80 & PQO & highest \\
\hline $\mathrm{Q}_{\text {mas }}(\mathrm{ml} / \mathrm{s})$ & 2.0 & 7.0 & 8.6 & 13.6 & 20.7 & 25.2 & 47.1 \\
\hline$Q_{\mathrm{min}}(\mathrm{m} / \mathrm{s})$ & 0.58 & 3.4 & 47 & 8.3 & 13.5 & 16.7 & 36.2 \\
\hline T90 (s) & 4.6 & 11.0 & 13.8 & 22.0 & 35.7 & 45.6 & 144.9 \\
\hline $\mathrm{T} 100(\mathrm{~s})$ & 6.0 & 17.0 & 20.8 & 31.4 & 48.9 & 62.5 & 176.7 \\
\hline Tdesc (s) & 0.1 & 6.1 & 7.9 & 14.3 & 26.8 & 35.3 & 142.5 \\
\hline $\mathrm{dl} / \mathrm{dt} 40(\mathrm{~mm} / \mathrm{s})$ & 0.14 & 3.9 & 4.9 & 8.1 & 13.4 & 16.0 & 35.4 \\
\hline volume (ml) & $* 50$ & 90 & 115 & 190 & 300 & 350 & 450 \\
\hline
\end{tabular}

by definition 
was accepted. The final result of the free flow investigations was noted as the softwane result for the void.

Furthermore, the general practitioners performed a physical examination for bladder and prostate disorders, in addition to taking urinary and blood tests (blood glucose and serum creatinin). Additional patient data were collected with another questionnaire with respect to factors with possible influence on medical consultation for micturition problems, ${ }^{16}$ such as marital status, comorbidity, tendency to wisit heath care and the subject's own health assessment. Also, questions were put forward to detect possible risk factors for low flow results like alcohol consumption and smoking.

For the analysis of the relations between presence of symptoms and low flow results, we used as cut-off values, the 20 th and 40 th percentile of the lowest $Q_{\text {max. Statistical }}$ testing of these relations was based on Spearman's correlation coefficient. Multiple logistic regression analysis with artefacts, low flow results and doctor consultation as dependent variables in separate analyses, was used to evaluate the effects of symptoms, clinical data and other patient characteristics, taking the influence of these factors into consideration simultaneously.

\section{Results}

Table $\Perp$ shows the response to the investigations using the open population as a reference. The small differences in age were caused by excluding men who underwent TURP (cumulative prevalence of $32 \%$ for men aged 80 or above) and men who were severely ill. Symptom scores were somewhat higher in the group entering GP-examinations. No relevant difference in the frequencies of BPH-related doctor's consultations were noted. Among those who underwent uroflowmetry in our study, we found no difference in the subgroup reporting doctor's consultations for micturition problems.

Normality of urinary flow was not frequenty established. Many men produced "not classifiable" voids, or combined a classifiable void with still an "artefact curve".

A spontaneous flow with at least $150 \mathrm{ml}$ voided, feeling at ease, without artefact and without straining, was difficult to reach for many men (tables 1 and 2). By a substantial number of men, voiding under study conditions was not considered representative for their daily habit (table 3 ).

The measured flow parameters showed very wide variations of results with skewed distributions (table 2). Of the decisive voids, $35.4 \%$ did not reach $150 \mathrm{ml}$.

Figure I shows that an abnormal flow defined as $Q_{\max }$ smaller than $10 \mathrm{~m} / \mathrm{s}$ was present in $21 \%$ of the group $55-59$ years, but in $70 \%$ of the men aged 80 and older. However, if the correction for voided volume was used (the mean volume was $239 \mathrm{ml}$ for $55-59$ years, $116 \mathrm{ml}$ for 80 and older) flow achievements were equal, meaning that the difference in voided volume explains the lowering of absolute parameters values as seen at higher age. 
tavle 3. Micturition bethavior as recorded during all produced curves. (percentages, $n=1290$ ).

distubinces on spontaneous flow curve

$\begin{array}{lr}\text { antefact } & 24.7 \\ \text { admitted to be not reluxed } & 3.0\end{array}$

urge to start urinating

-less than sverage

-average

69.0

more than average $\quad 16.6$

- not conclusive $\quad 0.5$

Multiple logistic regression andysis revealed that voided volumes lower than 150 $\mathrm{ml}$ (highest odds ratio 4.2 for volumes under $100 \mathrm{ml}$ ), age higher than 75 (odds ratio 1.8) and a low flow rate were determinants for the occurrence of artefacts. In addition, also high flow ratestended to be positively associated with artefact risk, which suggests an U-shaped relationship between flow rate and the probability of artefacts.

Symptoms appeared to play a modest role in differential diagnosis of low flow rates (table 4). Often there was no linear relation between symptom severity and low flow rate. Only the observation of a small urinary stream by the patient is significantly correlated with low flow. Incontinence is associated with higher peak flow, not with low flow. Using the volume corrected approach to define abnomal flow did not substantially change the results. For the association between abnormal sof ware result and symptom score $>15$, an odds ratio of $2.2(95 \% \mathrm{Cl}: 1.6-3.1)$ was found.

Mean flow rate improved with $2.2 \mathrm{ml} / \mathrm{s}$ with the rise in total alcohol consumption to 5 units a day. also when the $Q_{\text {max }}$ was volume-corrected (figure 2). There seemed to be a $S$-fomed relation with a plateau at more than 3 units of alcohol a day. In addition, a larger alcohol consumption tended to be associated with higher voided volumes, which was not explained by micturition frequency.

Remarkably, we did not find a correlation between low flow rate and parameters on hindrance. For low flow rate, also no correlation was found with marital status, smoking, presence of diabetes, body mass index, abnormalities found with physical examination (including prostate size), blood glucose, serum creatinine, tendency to visit health care, and the patient's own overall judgment on his health.

For indices for urinary tract infection (urine sedimentary count on leucocytes, history of (recurrent) infection) a small but statistically significant bivariate relation with low flow rate was found. 


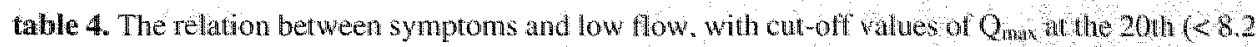
$\mathrm{ml} / \mathrm{s}$ ) and 40 th percentile $(<11.4 \mathrm{~m} / \mathrm{s})$, respectively (left collumin). Results for the subgroup that reported a positive result for any of the evaluated symptoms (all scoring categones on a question are shown in columns wo to six; numbers and between brackets: percentages of total with low flow on that category).

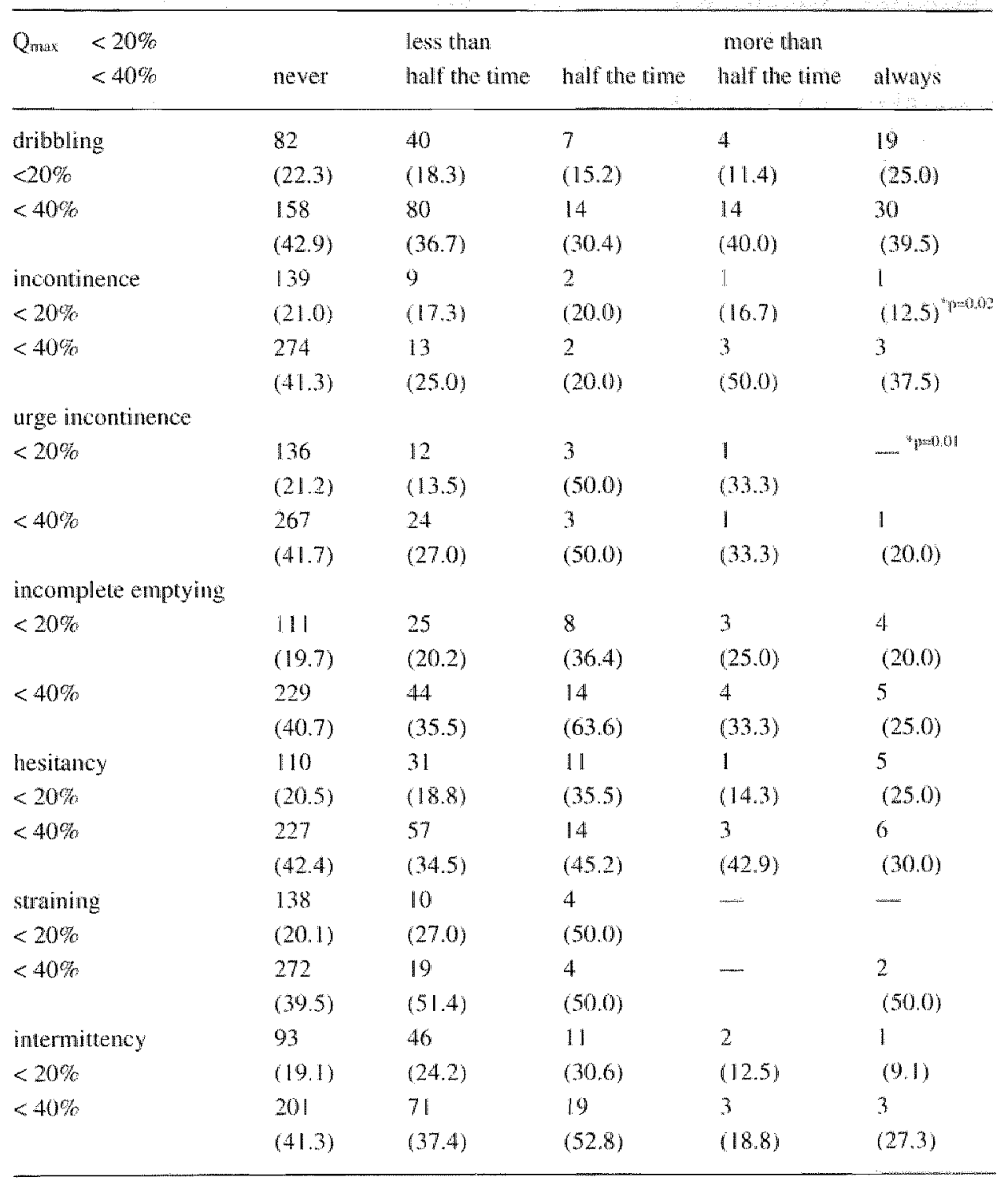


table 4. continued

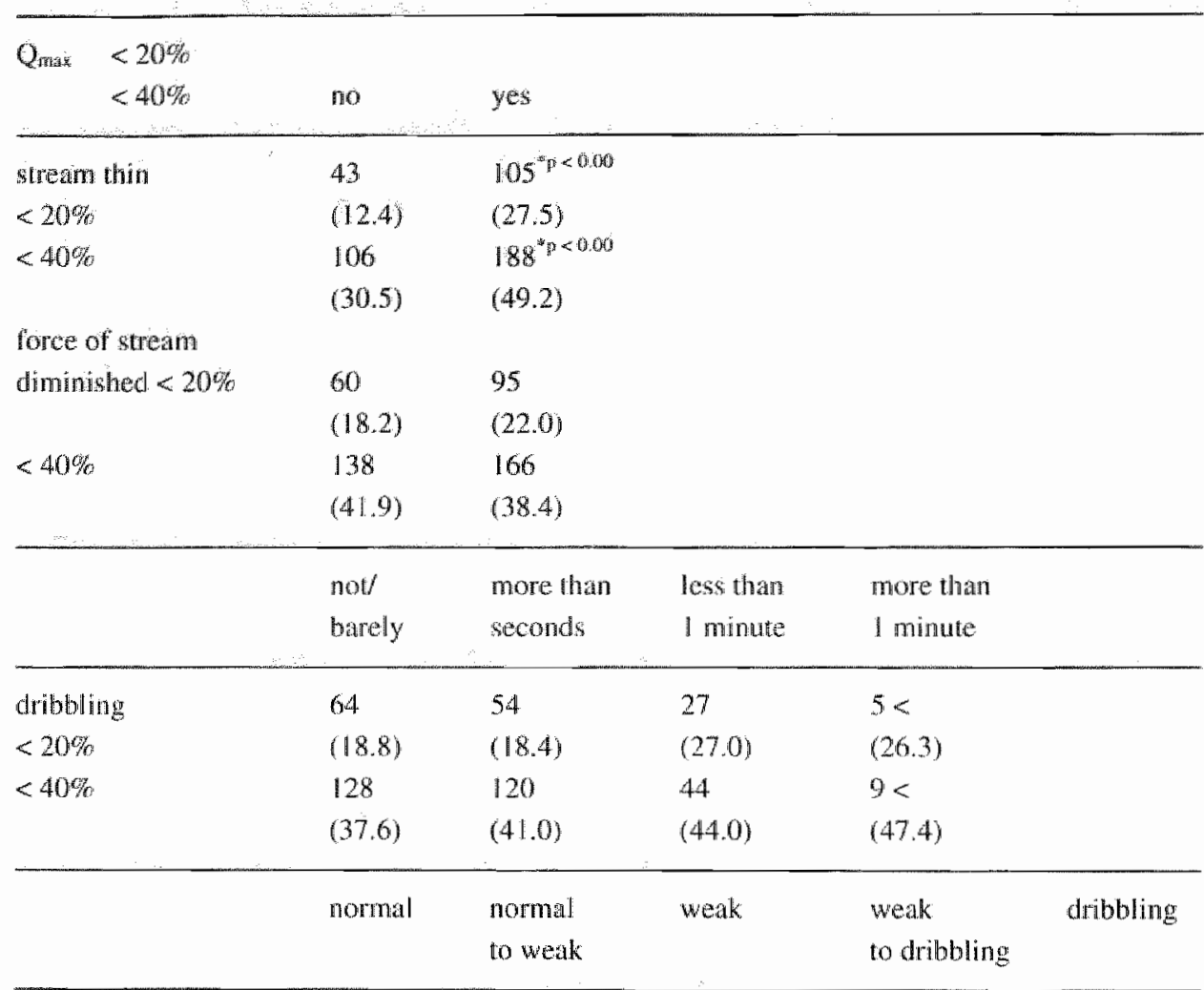

force of stretum now

\begin{tabular}{llllll}
$<20 \%$ & 74 & 66 & 18 & & \\
$<40 \%$ & $(18.8)$ & $(22.7)$ & $(24.3)$ & & \\
& 169 & 111 & 31 & 3 & \\
\hline & $(43.0)$ & $(38.1)$ & $(41.9)$ & $(21.4)$ & \\
\hline & much less & less & about equal & more & don't \\
& & & & know
\end{tabular}

micturition quantity

$\begin{array}{llllll}<20 \% & 5 & 63 & 58 & 8 & 21 \\ <40 \% & (16.1) & (25.8) & (17.8) & (15.4) & (16.0) \\ & 13 & 96 & 137 & 20 & 48 \\ & (41.9) & (39.3) & (42.2) & (38.5) & (36.6)\end{array}$


table 4. continued

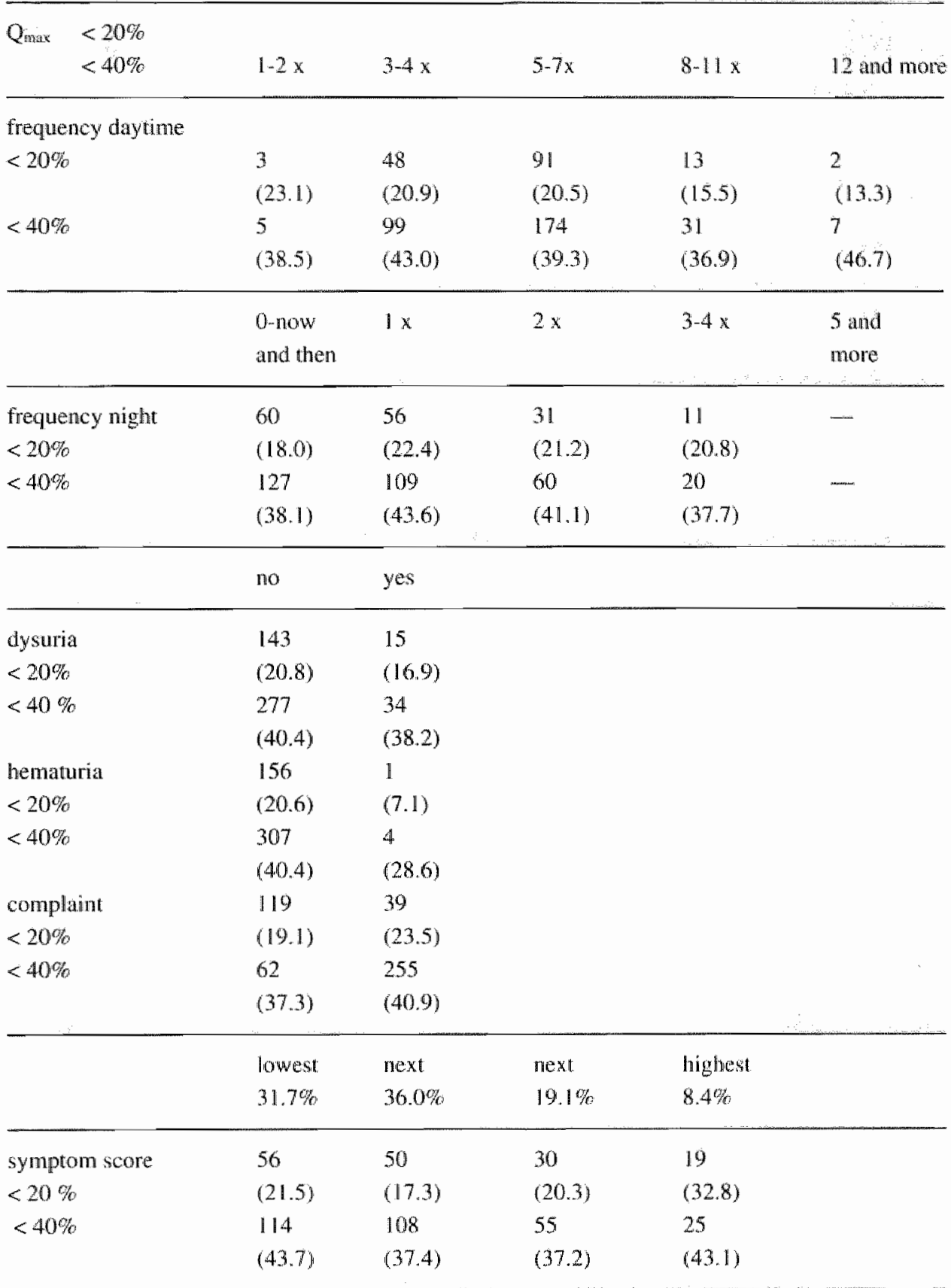

"p-value according to Spearman"s correlation coefficient 


\section{Free flow result}

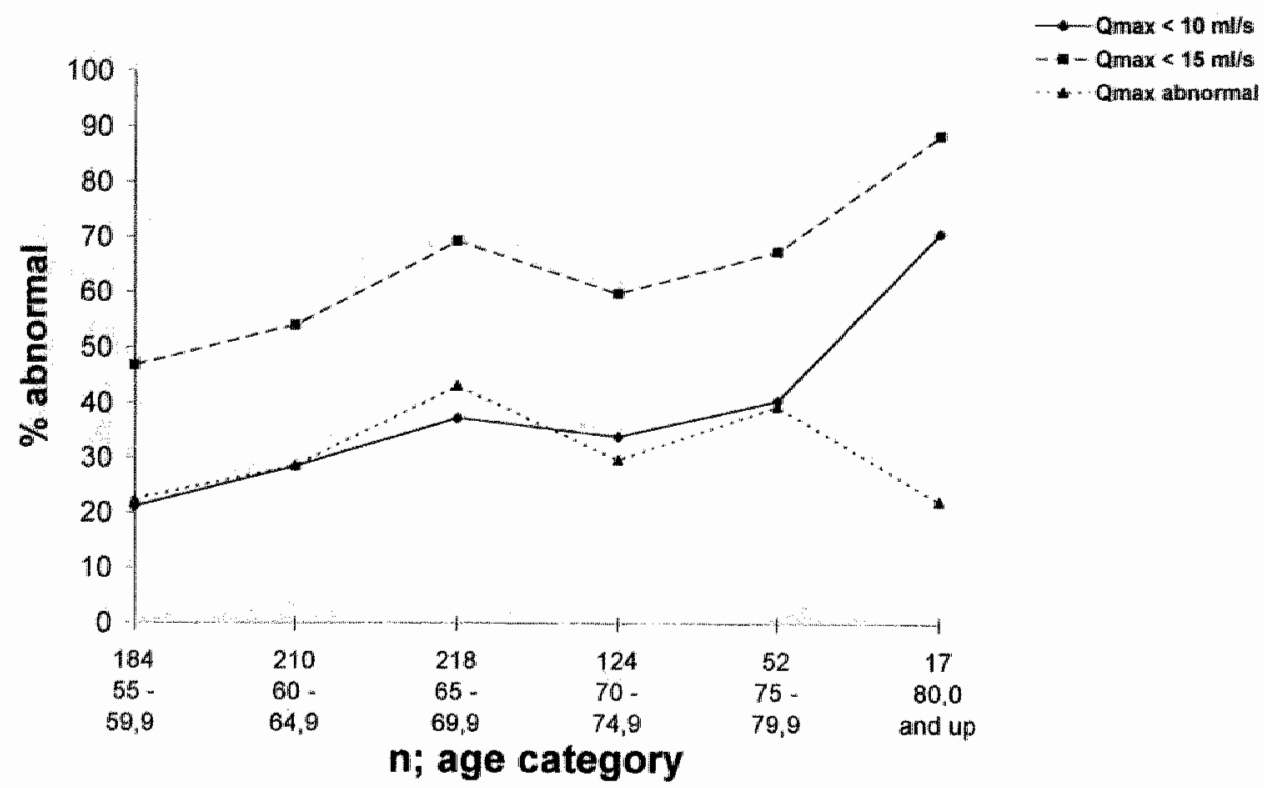

figure 1. $Q_{\text {max }}<10 \mathrm{~m} / \mathrm{s},<15 \mathrm{~m} / \mathrm{s}$ volumecoir.

\section{alcohol intake and peakflow}

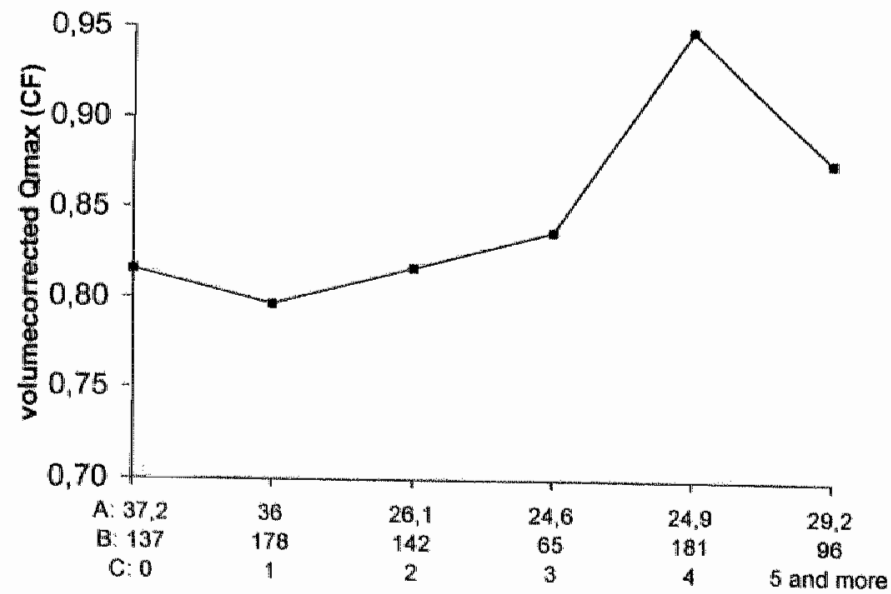
A: $\%$ with $Q \max <10 \mathrm{~m} / 1 \mathrm{~s}$
B: \# participants
C: units daily alcohol

figure 2. $\mathrm{Q}_{\operatorname{man}} \mathrm{x}$ alcohol 
figure 3. doctor consultation $\mathrm{x}$ symptom score (A); $x Q_{\text {max }}$ raw; $x Q_{\max }$ volumecorr. (B): $x$ micturition volume (C)
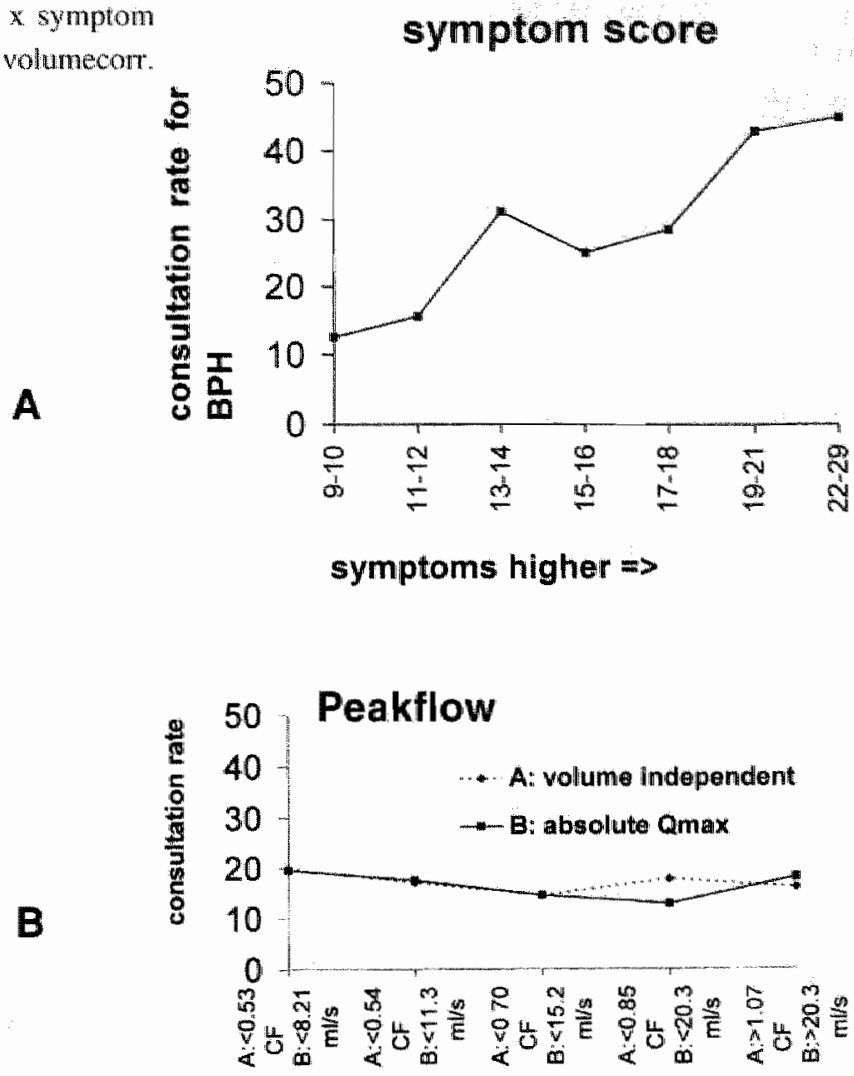

\section{micturitionvolume}

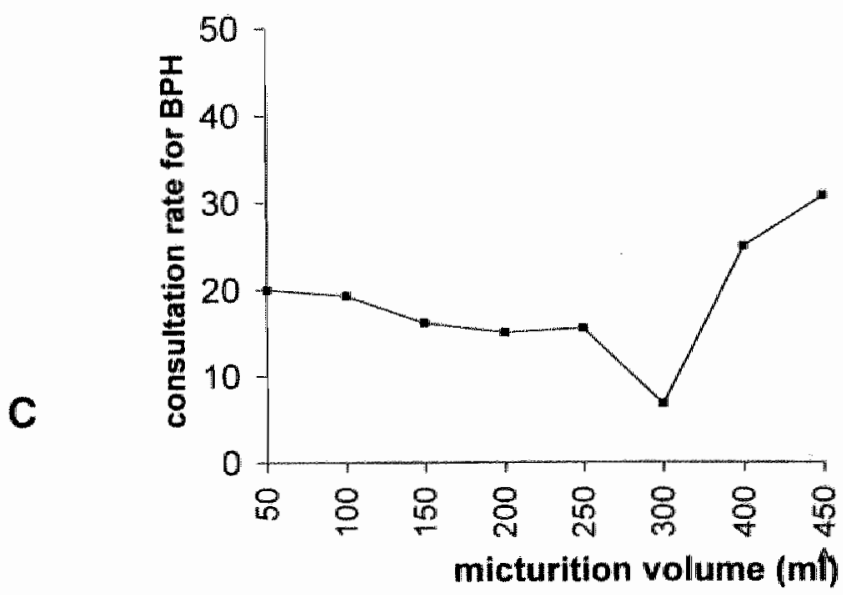


Figure 3 presents information on determinants of reporting doctor consultation for BPH in the previous 5 years, indicating the extent to which the problem has been known to doctor. The symptom score was positively associated with doctor consultation (A), implying that the men's awareness of symptoms is important. Peakflow seemed to be unrelated with consultation $(\mathrm{B})$, both in absolute measurement and after correcting for micturition wolume. As for micturition volume, both small and large volumes appeared to correlate with a higher consultation rate (C).

Multiple logistic regression with low flow rate and doctor consultation as dependent variables, respectively, did confirm the identification of the abovenentioned clinical determinants without detecting any other.

\section{Discussion}

In our open study population of elderly men, without lower urinary tract surgery, abnormality of flow was diagnosed in more than a third of the investigated subjects. Abnotmality of flow is the most freqent diagnosis among very old men, largely explained by a decrease in voided volume. Normality of flow could often not be reached. A wide variation of flow parameter results was observed in the studied population. The occurrence of flow curve artefacts appeared to be correlated with both very small and large voided volumes and with old age. While most micturition symptoms were not clearly related with flow rates, the experience of a small stream was associated with low flow and incontinence correlated with higher peak flow. Alcohol consumption seems to be a determinant of higher flow rates and a larger volume. Of the many evaluated clinical variables $s_{*}$ only indices of urinary tract infection. were (modestly) related with low flow. A higher symptom score appeared to influence doctor consultation but flow rate did not seem to do so. However, consultation was associated with small and large voided volumes. Why large voided volumes gave the highest consultation is unclear to us.

While stowing a somewhat higher symptom score, the responders to the examination at the $G P_{s}$ offices were quite representative for the relevant source population as 10 BPH-riated consultation behavior. Therefore, finding no relation between flow achievement and BPH-related health care consumption cannot be explained by the selection process in the context of the study. In a Scottish study, using a different selection procedure and a different defintion of BPH (size of prostate) this absence of a relation with medical consumption was also noted. 17

Although providing substantial information on the population parameters of free flow, our study lacks complete insight since a large group of men did not show up to void another time with a possibly more valid measurement. A reason for this may be that we had to state to the men at the entrance of the study that low flow results could lead to more diagnostic investigations, possibly in the academic hospital. This may have conflicted with spontaneous voiding and returning for another void. In addition, 
the task to void according to specified criteria like "more than $150 \mathrm{ml}$ ", "in relaxed state without pushing', while knowing that the adequacy of the performance will be evaluated, appears to be too difficult for a number of men. The latter group drops out of most urologic study populations, but might represent a relevant subcategory with relevant complication risks related to voiding dysfunction. However, since our data do not indicate important selection as to voiding habits or doctor consultation, we do not expect different uroflow results among the group of nonrespondents to the office examination.

Normality of uroflow seems to be a more complicated issue than just placing a cutoff point to a seemingly quantitative, objective and reproducible measurement. In the first place, in the analysis and interpretation of flow patterns and symptom score, the many men outside regular medical attention strongly contribute to the denominator for assessing the normal distribution of free flow results and symtoms. ${ }^{12}$ In addition, the concept of 'normal uroflow' needs more attention as to what doctors should ask to the patient or what criteria we should use: (1) a representative flow reflecting the men"s daily voiding habit), (2) the best possible flow in terms of improving the score ("power flow'), (3) voiding above arbitrary international criteria (> $150 \mathrm{ml}$, looking at $\mathrm{Q}_{\max }$ without looking too much to the shape of the curve) or (4) using any of the nomograms, which takes into account voided volume correction, a kind of age-cortection $^{2.8}$ or a percentile-rated, volume-controlled approach like the one we used. ${ }^{15}$ of course, overlap exists between these approaches but research up to now has not been conclusive as to what is the best to use. A problem is that the comparability of (the classification of) flow results from various studies is hindered Furthermore, defining a normal uroflow implies defining the distinction between artefacts and the bladder action to be measured, since micturition force can be influenced by other factors than the musculus detrusor"s activity. Asking the patient whether he only uses his emptying reflex is helpful but not very reliable, and when unsmooth flow curves are produced, it is sometimes difficult to say whether purely the bladder itself or (also) other factors (like 'artefacts' or a pelvic floor muscle relaxation) caused the deviation. However, accounting for artefacts, as we tried, is not usually dealt with or even reported by researchers. Therefore, this issue needs to be resolved in future in a standardised way eg. the ICS-standardisation committee.

In our study quite a number of men have an average voided volume less than $150 \mathrm{ml}$. Therefore, our entrance criterion of $50 \mathrm{ml}$ at least has the advantage to cover a wide spectrum. Other studies also did show the difficulty of elder men to void over 150 ml. 7.18 .19 Usually these men are left out of other publications.

As far as reported by others, our study produced results comparable to the peakflows found by Jorgensen. ${ }^{6}$ Results reported from the Ollmsted County cohort study are somewhat higher, most likely based on asking a forced flow." This group also reported a small improvement in peak flow rate in $70+$ males as our figure 1 shows. To us it is unclear whether this can be explained by selecting out the operated group. Prevalences found for $Q_{\text {max }}<10 \mathrm{ml} / \mathrm{s}$ are similar in all three studies. 
As a possible risk factor for ourflow obstruction-related clinical complications (ike urinary tract infection), low flow has at best a small contribution. This is reflected in the trival relation between low flow and doctor consultation: most men do not see a doctor in retation to this sign. Possibly this can be explained by the fact that $85 \%$ of the men is not even aware of their micturition performance. 6,20

In ths context it is interesting that, while $Q$ max decreases with higher age, this is also true for voided volume. Given the impact of correcting for volume, it is not unlikely that the contractile power does not decrease with age. This information complies with our finding that 139 men of this study on pressure-flow investigation did not show an age decrease in bladder contractility either."

The observation of many men living in the community with low flow conditions not presented to a doctor $(80 \%$, figure $3 \mathrm{~B})$ yields also important epidemiological insights in the interpretation of studies on prognosis of treated and untreated patients (e.g. those on the preoperative waiting list for TURP), since undocumented selection processes may distort the results of such studies. 11,12

In our population based study abnormal flow was not related to most symptoms, clinical variables or hindrance scores. This suggests the hypothesis that high symptom scores and low flow rates reflect different clinical entities with at best indirect relations. Follow up of men with these entities could learn us more about differences in prognosis of such entities. Also our data warn to mix up low flow results with BPH.

For the finding that flow achievements are positively influenced by, already moderate, alcohol consumption, we have no clear explanation. Apart from producing higher voided volumes, it is possible that alcohol contributes to a more relaxed voiding habit. Further study is indicated to confirm and clarify this observation. Between peak flow rates and cigarette smoking our study was not able to report an association, as Roberts et al did. ${ }^{22}$

We conclude that in an open elderly male population an abnormal uroflowmetry result, according to various criteria, is more frequently observed than a definitely normal result. Correction for voided volume and artefacts supports the interpretation of the results, and adequately dealing with these issues needs intemational consensus. While in this cross-sectional population study the correlation between symptoms, urinary flow results, and doctor consultation are not strong and often absent, individual clinical judgment has to consider which variables are most important for medical decision making. To support this process, prospective population-based evaluations of the impact of symptoms, clinical data and especially low flow results on prognosis are urgently needed. 


\section{References}

1. Dawson C, Whitfield $\mathrm{H}$ : Bladder outflow obstruction. ABC of Urology. BMJ 312:767-770; 1996.

2. Drach, G. W., Layton, T. N., and Binard, W. J.: Male peak urinary flow rate: relationships to volume voided and age. J. Urol., 122: $210,1979$.

3. Siroky, M. B., Olsson, C. A. and Krane, R. J.: The flow rate nomogram: I. Development. J. Urol, 122: 665, 1979.

4. Siroky, M. B., Olsson. C. A. and Krane, R. J.: The flow rate nomogram: li. Clinical correlation. J. Urol., 123: 208, 1980 .

5. Drach, G. W., Layton. T. N., and Bottacini M. R.: A method of adjustment of male pealk urinary flow rate for vaying age and volume voided. J. Urol., 128: 960, 1982.

6. Jørgensen, J. B., Jensen K. M.-E., Bille-Brahe N. E. and Mogensen, P.: Uroflowmetry in Asymptomatic Elderly Males. Brit. J. Urol., 58: $390,1986$.

7. Jensen K. M.-E., Jørgensen, J. B., Mogensen, P. and Bille-Brahe N. E. Some clinical aspects of uroflowmetry in elderly males. Scand. J. Urol. Nephrol., 20: 93, 1986.

8. Haylen, B. T., Ashby, D., Sutherst, I. R., Frazer, M. I. and West, C. R.: Maximum and average urine flow rates in normal male and female populations-the Liverpool nomograms. Brit. J. Urol., 64: 30, 1989.

9. Girman, C. J., Panser, L. A., Chute, C. G., Oesterling J. E., Barrett, D. M., Chen, C. C., Arrighi H. M., Guess, H. A. and Lieber, M. M.: Natural history of prostatism: urinary flow rates in a community-based studly. J. Urol., 150: 887, 1993.

10. Wolfs, G. G. M. C., Knotmerus and J. A., Janknegt, R. A.: Prevalence and detection of micturition problems among 2734 elderly men. J. Urol., 152: 1467. 1994.

11. Feinstein A.R. Clinical Epidemiology; The Architecture of Clinical Research. Philadephia PA, WB Saunders Company. 1985

12. Knotmerus J.A.: The effects of disease verification and referral on the relation between symptoms and diseases. Med. Decis. Making 7:139, 1987

13. Boyarski, S., Jones, G., Paulson, D. F., and Prout, G. R. Jr.: A new look alt bladder neck obstruction by the Food and Drug Aministration regulators: guide lines for investigation of benign prostatic hyperthrophy. Trans. Am. Assoc. Genitourin. Surg., 68: 29, 1976.

14. Rowan, D. McKenzie, A. L... McNee. S. G., et al.: A technical and clinical evaluation of the Disa uroflowmeter. Br, J, Urol, 49: 285, 1976. 15.

15. Rollema, H. J., Uroflowmetry. In: Krane, R. J., Siroky, M. B., editors. Clinical Neuro-urology. Boston: Little, Brown and Company, pp. 201-244, 1991.

16. Wolfs, G. G. M. C., Knotnerus, J. A., van der Horst F. G., Visser, A. P., Janknegt R. A.: Determinants of doctor consultation for micturition problems in an elderly male population. In press, Eur. Urol.

17. Tsang, K. K. and Garraway, W. M.: Prostatism and the burden of Benign Prostatic Hyperplasia on Elderly Men. Age Ageing, 23: 360, 1994.

18. Prescott, R. J. and Gartaway. W. M.: Regression to the mean occurs in measuring peak urinary flow. Brit. J. Urol., 76: 611, 1995. 
19. Bosch, JL, Hop WC. Kirkels WJ. Schroder FH. Natural history of benign prostatic hyperplasia: appropriate case defition and estimation of its prevalence in the community. Urology $1995 ; 46($ supp 3 A) $: 34-40$.

20. Jacobsen, S. J., Chute, C. G., Girman, C. J, Oesterling, J. E, Guess, H. A., Lieber, M. M. and Panser, L. A.: Do prostate size and urinary flow rates predict health care-seeking behaviour for urinary symptoms in men? Urology, 45(1): 64, 1995.

21. Wolfs, G. G. M. C., Knotnerus, J. A., van de Beek, C., Boender H., van der Waart, T., Janknegt, $\mathbb{R}$. A.: Detection of bladder outflow obstruction among elderly men in the community with symptomatology and lowmetry. Submitted.

22. Roberts, R., Jacobsen, S. J., Rhodes, T., Guess, H. A., Girman, C. J., Panser, L. A., Chute C. G., Oesterling J. E. Lieber M. M.: Cigarette smoking and prostatism: a biphasic association? Urology, 43: 797, 1994 


\section{Detection of bladder outflow obstruction among elderly men in the community with symptomatology and flowmetry}

George GMC Wolfs ${ }^{1}$

$J$ André Knottnerus ${ }^{1}$

Cees van de Beek ${ }^{2}$

Hugo Boender 1,2

Thea van der Waart ${ }^{1}$

Ruud A Janknegt ${ }^{2}$

From the Departments of General Practice' and Urology ${ }^{2}$, University of Marstricht, Maastricht, the Netherlands

Among elderly men with micturition symptoms, no relation holds with either bladder outflow obstruction or bladder weakness, although both standard diagnoses frequently occur in the community.

*submitted for publication 


\section{Abstract}

Background: Micturition symptoms are very frequent among elderly men. For evaluating the clinical significance of these symptoms, there is a need for data on the relation between presence of signs and symptoms with bladder outflow obstruction (BOO) and bladder weakness (BW).

Methods: A questionnaire was sent via family practitioners to an open population of 2635 men, at least 55 years old. The responders who met the inclusion criteria were invited for an examination at the general practice ( 829 were examined). Of these, men with micturition abnormalities (positive symptom score and/or abnormal urinary flow) were evaluated using urodynamic investigations to detect $B O O$ and $B W(n=191)$.

Results: In the selected group, mean prostate size was $25.5 \mathrm{ml}$; postvoid residual urinary volumes $>100 \mathrm{ml}$ detected in $50 \%, \mathrm{BOO}$ in $40 \%$ of the cases. No relation between presence of symptoms and $\mathrm{BOO}$ was observed. BOO was negatively related with urinary peakflow and positively with postvoid residual volume. $\mathrm{BW}$ was found in $71 \%$ of the men, and was not related with any clinical findings.

Conclusions: In the community of elderly men, bladder outflow obstruction and especially bladder weakness frequently occur. However, a relevant relation between these urodynamic standard diagnoses and symptomatology was hardly found.

Key Words: Symptoms and signs, Community survey, Urodynamics, Bladder outflow obstruction, Bladder Weakness, Diagnosis.

\section{Introduction}

Symptom prevalence of micturition problems in the elderly male population is high. ${ }^{1.2}$ A minority of the symptomatic men consult a doctor ${ }^{3.4}$ Of those who do consult, one-fifth undergo surgery for their prostate. ${ }^{2}$ Still, prostate surgery represents the second most frequent surgicall procedure among older men. ${ }^{5}$ Factors such as increasing life expectancy, the broadening range of therapeutic options and the growing attention paid by the media, will lead to more patients asking for medical care.

In recent years, clinical guidelines have been published to support the diagnostic and therapeutic management of men presenting with symptoms presumably related to benign prostatic hyperplasia (BPH) ${ }^{6.7}$ Of all possible diagnostic aids only a symptom score was recommended for diagnosing $\mathrm{BPH}$ in each patient. It is to be expected that the use of these guidelines will reduce the substantial inter-doctor variability when dealing with similar patients. ${ }^{8.9}$

Yet in these guidelines the clinical concept "BPH" has not been unequivocally defined. To overcome this problem. Hald introduced the term "clinical BPH" 10 comprising three overlapping conditions: (1) prostatic enlargement, (2) presence of 
symptoms commonly referred to as prostatism, and (3) presence of bladder outflow obstruction ( $\mathrm{BOO}$ ).

To clarify this concept, it is necessary to study the relation between these three conditions. Until now, this relation has been studied in hospital-based subpopulations, selected by generally undocumented processes. Such selection may have strongly influenced the observed results and limited their generalization, eg. to the men in the community. ${ }^{11,12}$ These limitations cannot easily be resolved, since especially invasive urodynamic evaluation is not an acceptable procedure to be applied to (a sample of) the general male population. As an alternative approach, to allow a clear interpretation of the possible consequences of selection processes, the referral procedure and criteria should be systematically designed, standardized and clearly documented, starting from an unselected male population. In the study presented here we relate signs, symptoms, history, prostatic size, postvoid residual urine (PVR) and free flow as found in the community, to urodynamic diagnoses for $\mathrm{BOO}$ and bladder weakness (BW) in a well-defined indicated population.

\section{Materials and Methods}

\section{base population}

All men aged 55 years or older ( $n=2734$ ), registered at 10 general practices (with 14 general practitioners) in Maastricht and representing the local general population, were considered for inclusion in the study (figure 1). In this context it is important to note that all Dutch inhabitants are registered in a local general practice. As a consequence, the patient list represents a general population denominator. In addition, Dutch patients need to consult their general practitioner before consulting other doctors. Therefore, the medical record at the general practice integrates all information from all medical specialties and other health care workers.

\section{exclusion from base population}

Excluded were $99(3.6 \%)$ persons because of a terminal illness or other reasons (eg. chronically institutionalized persons, severe memory problems).

\section{questionnaire}

The 2635 men received a postal questionnaire between May 1990 and May 1992, modified from Boyarsky et $\mathrm{al}^{2.13}$ (appendix 1) in order to rate micturition symptoms for the previous week. Dysuria and hematuria were inventoried for the previous 3 months. The total symptom score was calculated from the response to 7 questions about urinary hesitancy, terminal dribbling, impairment of the size and force of the urinary stream, incomplete emptying, straining or pushing to start urinary flow, frequency during daytime, and nocturia. The men were also asked to indicate the duration of 
micturition complaints - if any. Finally, the questionnaire dealt with doctor's visits possibly related to micturition.

From a random selection of 250 nonresponders to the postal questionnaire, the medical record was studied anonymously to obtain intormation on consultation for micturition complaints.

\section{invitation for GP study}

When an individual responded $(n=1692,64.3 \%)$, he was invited for examination at his general practice.

\section{exclusion from GP study}

The invitation was not sent to persons who had previously undergone lower urinary tract surgery $(n=155,9.2 \%)$, were known to have prostate cancer $(n=7,0.4 \%)$, could not stand up in privacy to micturate or were known to have severe reading problems (total exclusion: $n=400,23.6 \%)$.

\section{data collected}

At the general practice, history taking, physical examination and laboratory investigations were used to exclude persons with a full explanatory diagnosis not related to abnormalities of $\mathrm{BOO}$ or $\mathrm{BW}$. Subjects were asked to void with at least average urge (as compared to their usual voiding habit) in an rotating disk flowmeter (Dantec urodyn 1000$)^{15}$ connected to DUC free flow software. ${ }^{15}$

\section{analysis}

After the patient had answered questions on straining, representativeness of voiding habit, voiding at ease and rating of urge, the software classified the flow result prestation as 'normal', "inconclusive' or "abnormal". All voids of less than average urge to void or volume autside the range of $50-450 \mathrm{ml}$ were recorded as "not classifiable". Every curve was visually inspected on the printout to identify possible disturbances 15 exceeding $50 \%$ of one of the volume-dependent, percentiled parameters (dl/dt40, $\mathrm{Q}_{\mathrm{m} 90} \mathrm{Qmax}$ and $\mathrm{T}_{\text {desc }} 15$ ). Curves with any of these irregularities were marked as 'artelact' against the software result and the parameter was corrected if possible. When the voiding was rated 'inconclusive', "not classifiable' or 'artefact", the person was asked to return and individual instructions were given to improve the quality of their spontaneous void. The last result of the free flow investigations was accepted as the software result for the void. If an inconclusive void was noted twice, then the end result was recorded as "inconclusive". A maximum of three voids was collected.

\section{exclusion from hospital study}

Exclusion criteria were: a full explanatory diagnosis for micturition problems (like neurogenic bladder disturbances) and an unavoidable additional risk when undergoing 
one or more of the investigations (severe COPD, unstable hemodynanic condition, medication affecting hemostasis which could not be safely stopped for 2 weeks). Temporary exclusion was given to patients with active uninary tract infection, clinical suspicion of prostate cancer, hematuria, and elevated serum glucose. After successful treatment the patient could be reintroduced in this study.

\section{invitation for hospital study}

After completing the examination at the general practice, subjects with a symptom score $>15$ (= the highest $15 \%$ found in a pilot study catried out previously in a general practice population in the same area, not participating in this study) and/or an abnormat software result of the free flow investigation were considered for urological examination at the University Hospital.

\section{data collected}

Examinations at the urological clinic included digital rectat examination (DRE), transrectal ultrasound of the prostate (Multiplane endorectal probe $7.5 \mathrm{Mh}$, scanner 250 from Pie Medical), pressure-flow investigation, and postvoid residual urine. Each pressure-flow investigation consisted of at least 3 successive filling and voiding cycles. Bladder filling was performed at a medium filling rate $(40 \mathrm{ml}$ per minute) via one channel of a 9F suprapubic double lumen catheter; intravesicular pressure was measured via the other channel. Rectal pressure was subtracted to obtain detrusor pressure. Filling was carried out with the patient sitting, and voiding was done into a uroflowmeter with the patient standing.

\section{analysis}

Detrusor pressure and flow signals were stored and analyzed with CLIM computer software. ${ }^{16}$ BOO was quantified using the URA parameter - with a cutoff point for abnormality $>29.0 \mathrm{~cm}$ water ${ }^{16}$ - and bladder contractility was chancterized by the variable $W_{\max }$ using a cutoff point for abnormality $<9.9 \mathrm{~W} / \mathrm{m}^{2}{ }^{2}{ }^{17}$ These cutoff points were constructed in a separate study on 29 consecutive preoperative TURP patients to optimally discriminate with one value the shape of pressure-flow plots. 16.17 The PVR was determined after the first void through a suprapubic catheter, which was also used for the consecutive pressure-flow investigation.

For analysis, all signs and symptoms were dichotomized in present/absent and, where appropriate, severe/mild. The software results 'normal' and 'inconclusive' were combined into a single 'not abnormal' category. For reasons of comparability, the definition of abnormality for pressure-flow investigations was recalculated to two levels of abnormality: first (severe) quintile (see table 2 ) and second quintile ( $W_{\text {max: }}$ : less than $7.8 \mathrm{~W} / \mathrm{m}^{2}$; URA: higher than $32.1 \mathrm{~cm}$ water). 


\section{statistics}

Diagnostic items with at least 5 abnormalities in the urological clinic group were evaluated. Predictive values for positive and negative results and crude odds ratios (ORs) (with 95\% confidence interval) were calculated. The T-test was used to compare means and the chi square test to compare proportions, both for independent samples. Multiple logistic regression analysis was used to calculate ORs (and their $95 \%$ confidence interval) for the relation between the (dichotomous) dependent variable (W $W_{\text {max }}$, URA) and the studied symptoms, signs, medical history and results of other diagnostic studies (independent variables), taking the included variables into consideration simultaneously (full model). Forward and backward stepwise procedures were used to identify the best reduced set of independent variables.

\section{Results}

With three selection-response steps the reported group consists of $5 \%$ of the population (figure 1). This group consists of relatively healthier younger men with more symptoms and poorer flow than the total population. Of this group $15.7 \%$ were known to have BPH-related problems, so most men were entering urological studies for the first time (table 1).

In the nonresponse group to the postal questionnaire, $4 \%$ more urological problems were noted in their history, the proportion of cases with clinically known BPH remains constant throughout the selection process (table 1 and figure 1).

According to our decision rule for flow, $13 \%$ of the men investigated at the general practice $(\mathrm{n}=829)$ voided normally and $35 \%$ abnormally; in $33 \%$ there was insufficient information. The mean number of flow curves was 1.55 per patient (mean volume 207 $\mathrm{ml}, \mathrm{SD} 144 \mathrm{ml}, \mathrm{Q}_{\max }$ mean: $13.9 \mathrm{ml} / \mathrm{s}$, median $12.5 \mathrm{ml} / \mathrm{s}$ ). Thirty-six percent of the total group had a $Q_{\max }$ smaller than $10 \mathrm{ml} / \mathrm{s}$. Of the group with an abnormal software flow result, $52 \%$ showed a $Q_{\operatorname{mas}}<10 \mathrm{ml} / \mathrm{s}$ and $82 \%<15 \mathrm{ml} / \mathrm{s}$. For the association between abnormal software results and symptom scores $>15$, an odds ratio of 2.2 (Cl $95 \% 1.6$ - 3.1) was found in the GP population.

The selection for the urological investigation ( $n=249,30 \%$ prevalence) was mainly based on an abnormal software result (78\%), while almost half of the selected group $(46.1 \%$ ) had a positive symptom score. Normal free flow as defined by the software was rare in this subpopulation, as it was in the group of 829 men.

Men declining the invitation for the urological studies had a lower symptom score less frequently than the responders ( $27 \%$ vs $46 \%$ ). Reasons for men not participating were: the investigation was viewed as too invasive, lack of interest, shame, or fear of unexpected disease.

Flow abnormality was the most prevalent sign in the hospital-selected group (table II). Twenty-nine percent of the men could not achieve free flow voidings larger than $150 \mathrm{ml}$. During the pressure-flow investigations voided volumes could be more than 
tablile 1. Process of selection of study population (percentages).

\begin{tabular}{lllll}
\hline Phase & Base & Postal Questionnaire & GP Study & Urological Chinc \\
No. Pts. & Population & Response & Response & Study Response \\
& $n=2734$ & $n=1692$ & $n=829$ & $n=191$
\end{tabular}

\section{Paricipanis}

\section{Excluded from}

next phase

23.6

12.3

Response

64.3

64.2

72.3

Age (years)

66.8

66.1

65.1

65.5

$\mathrm{SD}$

7.1

7.0

6.3

6.2

Symptom score

Positive score

16.7

46.1

Doctor's visit

All urological

problems

$29.2^{\circ}$

25.2

24.5

21.3

BPH-related

$17.4^{\circ}$

15.6

15.9

15.7

Flow result

$\mathrm{Q}_{\mathrm{rag}}<15 \mathrm{ml} / \mathrm{s}$

77.6

$Q_{\text {max }}<10 \mathrm{ml} / \mathrm{s}$

35.8

51.6

Sofware:

- Normal

13.1

3.1

- Inconclusive

19.1

16.8

- Abnormal

34.6

78.0

- Not classifiable

$33.2+$

With artefact

20.0

23.6

* percentage of sample of nomresponders and men who whed to stop; " $18 x$ no fied flow curve collected, $14 \mathrm{x}$ two or more volumes smaller than $49 \mathrm{~m}$ or larger than $450 \mathrm{ml}, 209 \mathrm{k}$ one inconclusive curve, $34 x$ one flow curve with too little urge and/or volume out of range.

doubled as compared to free flow, indicating the importance of urgency to void; in the laboratory setting of the urological clinic, only 2 men (1.4\%) could not reach voiding volumes larger than $150 \mathrm{ml}$.

The pressure-flow abnormality most often found is bladder weakness $(7 \| \%)\left(W_{\text {max. }}\right.$ W/min: ${ }^{2}$ min: $2.5 a x: 18.4$ ). BOO was present in $40 \%$ of the cases (URA, $\mathrm{cm} \mathrm{H}_{2}$ ), max: 74, min: 4). Eighty-four percent of the men had either $B W, B O O$ of both. $B W$ 
base population:

\section{4}

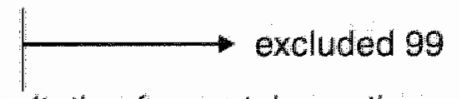

invitation for postal questionnaire: 2635

response:

1692

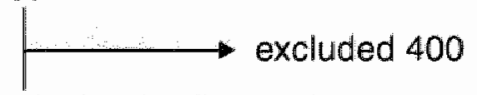

invitation for GP-study:

1292<smiles>C=C</smiles>

response:

829

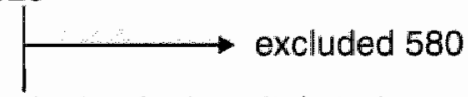

invitation for hospital study:

249

response:

191

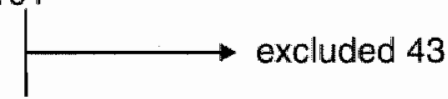

pressure-fllow investigation: 148

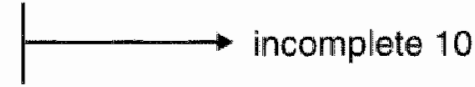

full result:

138

figure 1 . group description (numbers) and BOO tended not to occur in the same man, as the odds ratio of 0.15 shows (Cl 95\%:0.07-0.35, for symptomatic men 0.08 ). Only two men had normal and URA values as defined with preoperative criteria. $\mathrm{BOO}$, based on the URA parameter increased with age ( $55-64$ years: $33 \%(n=63)$, $65-74$ years: $42 \%(n=62) ; 75$ and older: $57 \%(n=14))$. Detrusor instability occurred in $6 \%$ of the men.

of the 191 men investigated by ultrasound and on the basis of the clinical profile and DRE, who were expected to be free of prostate cancer by the GP, 18 were suspected by the urologist to have prostate cancer. After a clinical and unstandardized work-up, one of them indeed turned out to have prostate cancer.

The relation between signs and symptoms on the one hand and belonging to the lower 40 or 20 percentiles of BOO (table III) on the other is generally weak to absent. None of the individual symptoms traditionally linked to BPH showed a statistically significant relation. Urge incontinence has a significantly negative odds ratio at the 40 th percentile level (OR 0.12 . $\mathrm{Cl} 95 \% 0.02-0.98$ ), indicating pathology other than $\mathrm{BOO}$. A high symptom score did predict BOO only at the 20th percentile level of URA (OR 2.9, CI 95\% 1.2-6.6). With regard to the clinical profile, the diagnosis of BPH as indicated by the GP is positively associated with $\mathrm{BOO}$, reaching significance for the 20 th percentile (OR 2.80, Cl 95\% 1.2-6.4). Past consultation for $\mathrm{BPH}$ is not significantly indicative of present $\mathrm{BOO}$, as measu- 
table 2. Results of the urological evaluation of the 1911 men included on the bass of an abnomal symptom score or abnomal flow result.

\begin{tabular}{|c|c|c|c|c|}
\hline Investigation (No. Pts) & Mean & Median & $20 \%-80 \%$ & w Alinomal \\
\hline \multicolumn{5}{|l|}{ Free flow ( $n=249$, total group $\left.{ }^{*}\right)$} \\
\hline $\mathrm{Q}_{\operatorname{MAx}}(\mathrm{ml} / \mathrm{s})$ & 11.5 & 10.1 & $7.1-15.2$ & 65.4 \\
\hline Micturition volume $(\mathrm{ml})$ & 220 & 210 & $129-308$ & \\
\hline \multicolumn{5}{|l|}{ Transrectal whasound $(\mathrm{n}=191 \%)$} \\
\hline Prostate size $(\mathrm{ml})$ & 25.5 & 23 & $15.8-34.0$ & \\
\hline \multicolumn{5}{|l|}{ Pressureffow $\left(n=148^{2}\right)$} \\
\hline Bladder capacily (ml) & 462 & 450 & $339-600$ & \\
\hline Postroid residual urine $(\mathrm{ml})$ & 134 & 100 & $47-213$ & \\
\hline$W_{\operatorname{MAx}}\left(W / m^{2}\right)$ & 9.0 & 8.6 & $6.3-11.6$ & 70.9 \\
\hline URA $\left(\mathrm{cm} \mathrm{H}_{2} \mathrm{O}\right)$ & 31.4 & 27.0 & $20.0-44.0$ & 39.6 \\
\hline
\end{tabular}

* Values are different because of entry differences (referrals, response, contraindications) to diagnostic elements

red in this study. The patient's perception of his micturition profile as a complaint seems to have no diagnostic value for $\mathrm{BOO}$. When the patient has had urinary tract infection, the risk of having $\mathrm{BOO}$ is increased, although significance was not reached due to small numbers. BOO shows a rather strong relation with postvoid residual volume, especially in the case of larger residuals. Contrary to common knowledge, serum creatinine seems to be lower when the patient is obstructed. To conclude the bivariate analysis, both $\mathrm{Q}_{\max }$ and the software result are positively associated with the presence of $\mathrm{BOO}$.

Applying logistic regression modelling to $\mathrm{BOO}$ as the dependent variable (table IV), three factors remained in the reduced model. In this model, the (adjusted) OR of a large residual urine volume was not less than 6.9 , while, both for fixed cutoff points and for an ordinal rating according to quintiles, $Q_{\text {mix }}$ was clearly negatively associated with $\mathrm{BOO}$. The presence of an artefact on the flow curve appeared to be related with a lower probability of $\mathrm{BOO}$.

With larger voiding volumes, the predictive power ruling out BOO increased (as was also shown by internal analysis of pressure-17ow data). Repeating the logistic model for the nonsymptomatic group and the abnormal flow group separately did not lead to different findings. When the flow parameters had values within the lowest $20 \%$ of their range, the indication for a significant artefact effect on the classifying parameters was even stronger. Logistic modelling for BOO with only anamnestic and clinical information as the dependent variables revealed that only urge incontinence had a significant (negative) contribution, thereby confirming the bivariale results. 
table 3. The refation between bladder outlow obstruction (BOO) and diagnostic characteristics (URA, lowest quintiles, bivariate results) $n=139$.

\begin{tabular}{|c|c|c|c|c|c|c|c|}
\hline Symptom or Sign & $\begin{array}{l}\text { All } \\
\text { abnor: } \\
\text { malities }\end{array}$ & $\begin{array}{l}\text { With } \\
\mathrm{BOO}\end{array}$ & $\begin{array}{l}\mathrm{PV}+ \\
\%\end{array}$ & $\begin{array}{l}\text { PV- } \\
\%\end{array}$ & $\begin{array}{l}\mathrm{OR} \\
(40 \%)\end{array}$ & $\begin{array}{l}95 \% \\
\text { Confidence } \\
\text { Interval }\end{array}$ & $\begin{array}{l}\text { OR } \\
(20 \%)\end{array}$ \\
\hline
\end{tabular}

\section{SYMPTOM}

\begin{tabular}{|c|c|c|c|c|c|c|c|}
\hline & & & & & & & \\
\hline Dysuria (last 3 months) & 14 & 5 & 36 & 61 & 0.86 & $0.27-2.7$ & $1: 6$ \\
\hline Datyt me freq $>8$ (last wk) & 18 & 4 & 22 & 58 & $0.39 \%$ & $0.12-1.3$ & $0.42 *$ \\
\hline Nycturia > 1 (Jast week) & 37 & 14 & 38. & 60 & 0.93 & $0.43-2.0$ & 1.5 \\
\hline Voided volume decreased & 48 & 19 & 40 & 60 & 0.96 & $0.47-2.0$ & 0.75 \\
\hline Size and power limited & 63 & 24 & 38 & 60 & 0.90 & $0.45-1.8$ & 0.87 \\
\hline Size and power decreased & 72 & 31 & 43 & 64 & 1.4 & $0.67-2.7$ & 1.02 \\
\hline Hesitation & 36 & 12 & 33 & 59 & 0.73 & $0.33-1.6$ & 0.83 \\
\hline Incontinence & 12 & 2 & 17 & 58 & $0.28^{2}$ & $0.06-1.3$ & 0.69 \\
\hline Dribbling & 65 & 22 & 34 & 56 & 0.65 & $0.32-1.3$ & 1.3 \\
\hline Pushing to start & 13 & 5 & 39 & 61 & 0.97 & $0.30-3.1$ & 1.7 \\
\hline Residual feeling & 29 & 12 & 41 & 62 & 1.2 & $0.50-2.7$ & 1.9 \\
\hline Intermittency & 51 & 18 & 35 & 59 & 0.77 & $0.37-1.6$ & 0.98 \\
\hline Urge incontinence & 12 & 1 & 8 & 58 & $0.12 * \dagger$ & $0.02-0.98$ & $0.30 *$ \\
\hline Sympltom score: > 15 & 60 & 24 & 40 & 61 & 1.03 & $0.52-2.1$ & $2.9 * 4$ \\
\hline \multicolumn{8}{|l|}{ CLINICAL PROFILE } \\
\hline Complaint & 31 & 10 & 32 & 58 & 0.67 & $0.29-1.6$ & 0.64 \\
\hline Visit BPH/relat. problems & 22 & 9 & 41 & 61 & 1.1 & $0.42-2.7$ & 0.52 \\
\hline Visit for $\mathrm{BPH}$ & 10 & 4 & 40 & 62 & 1.1 & $0.29-4.0$ & $2.8^{*}$ \\
\hline BPH as present diagnosis & 47 & 23 & 49 & 65 & 1.7 & $0.85-3.6$ & $2.8^{* 4}+$ \\
\hline Clinical Detrusor Instability & 14 & 7 & 50 & 62 & 1.6 & $0.52-4.8$ & 0.98 \\
\hline Urinary Tract Infections & 7 & 5 & 71 & 62 & $4.1^{*}$ & $0.77-21.9$ & $\mathrm{x}$ \\
\hline Prostatitis/Cystitis & 5 & 4 & 80 & 63 & $6.7 *$ & $0.73-61.6$ & 2.6 \\
\hline \multicolumn{8}{|l|}{ PHYSICAL EXAMINATION } \\
\hline Prostate size, > II (DRE) & 21 & 11 & 52 & 63 & 1.9 & $0.74-4.8$ & 1.2 \\
\hline \multicolumn{8}{|l|}{ SPECIFIC TESTING } \\
\hline \multicolumn{8}{|l|}{ Prostale size (TRUS) } \\
\hline$>34 \mathrm{ml}$ & 24 & 12 & 50 & 63 & 1.7 & $0.67-4.1$ & 1.7 \\
\hline Postvoid residual $>50 \mathrm{ml}$ & 106 & 47 & 44 & 76 & $2.55^{* !+1}$ & $1.03-6.0$ & $0.2 I^{*}$ \\
\hline Postwoid residual > $214 \mathrm{mml}$ & 29 & 20 & 69 & 68 & $4.8^{*}+$ & $2.0-11.5$ & $2.4^{*}$ \\
\hline Serum creatinine $>110 \mu \mathrm{mol}$ & $\| 3$ & 5 & 39 & 61 & 0.97 & $0.30-3.2$ & $0.29 *$ \\
\hline \multicolumn{8}{|l|}{ FREE FLOW } \\
\hline$Q_{\text {nais }}$ Soltware classification & 91 & 39 & 43 & 70 & 1.7 & $0.81-3.6$ & $2.1{ }^{*}$ \\
\hline Qmaix Lowest $40 \%$ & 51 & 28 & 55 & 70 & $2.9 \div$ & $1.4-5.9$ & $2.6 *+$ \\
\hline Q new Lowest $20 \%$ & 21 & 14 & 67 & 66 & $3.9^{*}+$ & $1.4-10.3$ & $3.6^{* 4}$ \\
\hline Artefiact & 38 & 11 & 29 & 57 & 0.54 & $0.24-1.2$ & 1.00 \\
\hline \multicolumn{8}{|l|}{ Free flow: End result } \\
\hline (softwarte) & 112 & 48 & 43 & 80 & 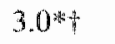 & $1.1-8.6$ & $7.6 *+$ \\
\hline
\end{tabular}

$\mathrm{OR}=$ odds ratio; * odds ratio $<0.5$ or $>2.0 ; \mathrm{t} p<0.05 ; \mathrm{x}=$ cell with zero observations 
table 4. Results of multiple logistic regression analysis with bladder outhow obstruction as the dependent variable (reduced model including statistically significant independent wariables only) $(n=138)$.

\begin{tabular}{|c|c|c|c|c|c|}
\hline & Beta & S.E. & $\mathrm{p}$ & $\mathbb{R}$ & Odds ratio \\
\hline Residual $>214 \mathrm{ml}$ & 1.93 & 0.56 & 0.001 & 0.240 & 6.90 \\
\hline$Q_{\operatorname{mix}} *$ & -0.55 & 0.16 & 0.001 & -0.223 & 0.58 \\
\hline Artefact on flow curve & -1.38 & 0.52 & 0.008 & -0.169 & 0.25 \\
\hline Constant & 1.08 & 0.55 & 0.048 & & \\
\hline
\end{tabular}

* $\mathrm{Q}_{\text {nasx }}$ in quintiles for range $(\mathrm{m} / \mathrm{s}): 2.5-7.0,7.1-9.2,9.3-11.4,11.5-15.3,15.4-31.8$ ), other variables are dichotomous

None of the clinical and specific testing variables appeared to be statistically significant predictor of the diagnosis of bladder weakness. Whille for the most severe $20 \%$ of $W_{\text {max }}$ a high symptom score showed the lowest OR $(0.45, \mathrm{CI} 95 \% 0.18-1.1)$ and an abnormal flow result the highest OR (3.6, CI 95\% $0.80-16.4)$, neither of these being significant. Multivariable analysis confirmed this picture. With the rule-in criterion set at $\mathrm{p}<0.05$ or $\mathrm{p}<0.10$, respectively, no discriminating item was found.

\section{Discussion}

In a population-based survey, using a standardized refertal procedure appropriate for primary care (based on symptoms or flow abnormality), information was collected to diagnose micturition problems. Flow abnormalilies appeared to be highly prevalent in an elderly male community. In men with a positive symptom score or an abnormal flow, $\mathrm{BOO}$ and $\mathrm{BW}$ were very frequently observed. $\mathrm{BOO}$ was not related to sy mptoms, but clearly associated with postwoid residual volume and a low flow rate.

Five studies presented free flow results from open elderly male populations. $1,18-22$ Results similar to ours were reported by Jensen, ${ }^{18}$ who found $18 \%$ normal flow, compared to the present study ${ }^{*} \$ 13 \%$. We observed lower $Q_{\text {max }}$ results than Girman ${ }^{10}$ (mean $16 \mathrm{ml} / \mathrm{s}$ ), probably due to their higher entrance criterion for valid flow volume. A Scottish study reported similar $Q$ max results for a comparable group, while Jacobsen $^{20}$ found much higher" $Q_{n a x}$ values. It is difficult to evaluate the various findings further, since details on possible differences in populations and procedures are not available.

For prostate size our data are comparable with the autopsy data of Berry, ${ }^{23}$ but we find smaller prostates than Bosch who selected his sample from a prostate cancer diagnostic study. ${ }^{24}$ The average prostate size in our study is also (about $33 \%$ ) smaller 
than that reported by Garraway. While symptom severity seems comparable, different measuring techniques could account for this difference.

Comparing the results in our population, selected on symptom score and flow result, with those from patient series in the urological clinic, the latter show slightly lower values for mean peakflow (approximately $10 \mathrm{ml} / \mathrm{s}$ ). Furthermore, mean voided volumes between 181 and $260 \mathrm{~m} \|$ were reported. ${ }^{25-35}$ Difficulty to reach a voided volume of $150 \mathrm{ml}$ was also found in these studies.

The rate of $\mathrm{BOO}$ we found is about half the rate found in studies in preoperative patients: range $38-87 \%$ with a median of approximately $75 \%, 33,34,3644$ However, in the light of a consultation rate of $15.7 \%$ (table 1 ), the actual prevalence of $\mathrm{BOO}$ in the population may be more than three times higher than expected based on observations at the urologic clinic. Such an iceberg-phenomenon could be even more the case for $\mathrm{BW}$, with reported preoperative prevalences of $18-47 \%$ (median approximately $25 \%) .37-39,41,42$

For detrusor instability, prevalences of 10-69\% (median $50 \%)^{30,42,45}$ have been reported. The differences may be caused by differences in technique of performing pressure-flow studies. Our urologic clinic results show a low prevalence of detrusor instability, for which the suprapubic approach with small catheters might deserve most of the credit. On the other hand, this technique may also have yielded higher PVR results than in hospital-based studies. $28,30,33,34,43,44$

The symptoms traditionally considered to contribute to "prostatism" or "obstructive micturition" individually failed to predict BOO. The positive symptom score, however, can be useful to make a first impression whether BOO is more or less likely (OR=2.9 for the relation between a score $>15$ and an URA value in the lowest quintile). Our study looked beyond bivariate analysis which can suggest that relations are not present, when they would be present if more information were known of a person. Multivariable analysis is one of the most appealing tools simulating statistically complex information decisions to predict the simplest diagnostic answer: presence or absence of disease. While in multiple logistic modelling the symptom score could not be included as valuable, the logistic regression analysis suggests that BOO as defined with URA can partly be predicted when looking at easily available diagnostic data such as low $\mathrm{Q}_{\max }$ large postvoid residual urine volume and absence of urge-incontinence. In addition, a (not statistically significant) indication was found for a positive relation between $\mathrm{BOO}$ and a history of urimary tract infections. Therefore, the BOO concept as used in this sudy appears to be conelated with clinical complications assigned (by tradition) to BPH and generally influencing the decision for surgical treatment.

In our study, most men were found to have BW. However, we did not observe a relation between BW and any of the evaluated diagnostic items. At the lowest $20 \%$ of BW there are possibly some useful climical indicators (incontinence, daytime frequen$\mathrm{cy}$, free flow end result, serum creatinine). Theoretically, it is possible that, in a larger study population, cutoff point variation beyond the range used in our study would show 
a diagnostic value of some variables. However, bearing in mind the disappointing results found in the urological clinic, ${ }^{16,17}$ this does not seem realistic:

Although our cross-sectional study does not allow conclusions in terms of cause-effect relations, our finding of a strong negative association between bladder obstruction and bladder weakness supports the hypothesis that BOO leads to an increase in contractility of the M.Detrusor.

Our study reports on a group selected from a general population according to a standardized protocol. The main reasons for limiting the urological clinic studies to men with abnormal findings found in the population were that invasive studies cannot ethically be offered to an asymptomatic population and, no less relevant, that the diagnostic outcome in the clinically manifest population is of primary interest. As a result, our findings are valid in the first place for such 'indicated' populations. Since referral for signs or symptoms may lead to less clinical contrasts and weaker relationships between symptoms and diseases, ${ }^{11.12}$ it is possible that, in an unselected (not referred) GP population, symptoms and the symptom score are somewhat more predictive for BOO. This can, however, only be directly investigated if a sample of asymptomatic men were to be subjected to pressure-flow studies. For the above-mentioned reasons this is not likely to occur.

At the GP examination, a substantial group had a "not classifiable result" of the free flow investigation. These men did not enter urological clinic investigation. Future studies should evaluate whether such results are related to an abnormal flow pattern and adverse clinical outcome. From these men with noncompliant woiding and those not accepting the invitation for urological evaluation, we gained the impression that there are a considerable number who find it difficult to reach several spontaneous voids, who have a lack of interest in the evaluation of their micturition, or who are afraid to be identified as abnormal. This again taught us to pay adequate attention to patient counselling in the context of diagnostic evaluation of micturition problems.

In our population selected for urological evaluation, thought to be free of cancer by the GP on the basis of the clinical profile and a carefully performed rectal examination, the clinical workup by the urologist revealed only one case of prostate cancer $(0.5 \%)$. In light of the uncertain benefit of treatment in early stages, ${ }^{46,47}$ this result seems clinically acceptable.

\section{Conclusions}

Urinary flow abnormalities are highly prevalent in an open elderly male population. In men with a positive symptom score or abnormal flow, $\mathrm{BOO}$ and $\mathrm{BW}$ are very frequently observed. $\mathrm{BOO}$ is clearly associated with a higher postvoid residlual urine volume and abnormal flow parameters. Adding information on symptoms did not improve the prediction of a pressure-flow diagnosis. 
The thimate goal for diagnosis is to predict prognosis. ${ }^{48}$ At present, however, there is lack of evidence on the value of diagnostic data to predict the clinical course of "prostate obstruction" "prostatism" or "BPH". Therefore, it has been advocated that treatment decisions should preferably be made by the patient himself in weighing potential benefits and disadvantages of influencing the uncertain clinical course by treatment, taking risks of adverse effects and failure into consideration. The prognostic value of diagnostic data is to be valuated in community-based follow-up studies, with non-invasive investigations providing the primary entry criteria. In addition, for clinically relevant subgroups, prospective followap studies could help clarify the prognostic significance of $\mathrm{BOO}$ and $\mathrm{BW}$ parameters in relation to clinical outcome.

\section{References}

1. Garraway WM, Collins GN, Lee RJ: High prevalence of benign prostatic hypertrophy in the community. Lancet 1991;338:469-471.

2. Wolfs GGMC, Knotherus JA, Janknegt RA: Prevalence and detection of micturition problems among 2,734 elderly men. J Jrol 1994:152:1467-1470.

3. Tsang KK, Garraway WM: Prostatism and the burden of benign prostatic hy perplasia on elderly men. Age Ageing 1994:23(5):360-364.

4. Wolfs GGMC, Knottnerus JA, wan der Horst FG, Visser AP, Janknegt RA: Determinants of doctor consultation for micturition problems in an elderly male population. (In press: Eur Urol)

5. Holtgrewe HL, Mebust WK, Dowd JB, Cockett ATK, Peters PC, Proctor C: Transurethral prostatectomy: practice aspects of the dominant operation in American urology. J Urol 1989;141:248-253.

6. Cockett ATK, Khoury S, Aso Y, Chatelain C, Denis L, Griffiths K, Murphy G (ed): "Proceedings of the 2nd International Consultation on Benign Prostatic Hyperplasia (BPH)," 1993 June 27-30; Paris, France. Jersey, Channel Islands: Scientific Comunications Int. Ltd. 1993.

7. MoConnell JD, Barry MJ. Bruskewitz RC. et al: "Benign Prostatic Hyperplasia: Diagnosis and Treatment, Clinical Practice Guideline," Number 8. AHCPR Publication No 94-0582. Rockwillie, MD: Agency for Health Care Policy and Research, Public Health Service, U.S. Department of Health and Human Services. Febnary 1994.

8. Wennberg JE, Mulley AG Jr. Hanley D. Timothy RP, Fowler FJ Jr, Roos NP, et al: An Assessment of prostatectomy for benign urinary tract obstruction. Geographical variations and the evaluation of medical care ourcomes. JAMA 1988:259:3027-3030.

9. Stoevelaar HJ, Beek van de C, Casparie AF, Nijs HCT, McDonnell J, Janknegt RA: Vanatie in diagnostiek en behandeling wan benigne prostaathyperplasie (BPH) in de urologische praktijk [Variation in diagnosis and treatment of BPH in the urological clinic]. Ned Tijdschr Geneeskd 1996;140 15):837-842. (Dutch).

10. Hald T: Urodynamics in benign prostatic hyperplasia: a survey. Prostate (Suppl) 1989:2:69-77. 
11. Knottnerus JA: The effects of disease verification and referral on the relationship between symptoms and diseases. Med Decis Making 1987;7:139-148.

12. Knottnerus JA, Leffers $P$ : The influence of refermal patterns on the characteristics of diagnostio tests. J Clin Epid 45 1992;(10):1143-1154.

13. Boyarsky' S, Jones G, Paulson DF, Prout G R Jr: A new look at bladder neck obstruction by the Food and Drug Administration regulators: guidelines for imvestigation of benign prostatic hypertrophy. Trans Am Assoc Genitourin 1976; Surg 68:29-32.

14. Rowan D. McKenzie AL, McNee SG, et al: A technical and clinical evaluation of the Disa uroflowmeter. Br J Urol 1976;49:285-289.

15. Rollema HJ, Uroflowmetry. In Krane RJ, Siroky MB (ed). "Clinical Neuro-urology," Boston: Litte, Brown and Company, 1991, pp 201-244.

16. Rollema HJ, van Mastrigt R: Improved indication and followup in transurethral resection of the prostate using the computer program CLIM: a prospective study. JUrol 1992; $148: 111-116$.

17. van Mastrigt $\mathbb{R}$. Rollema HJ: The prognostic value of bladder contractility in transurethral resection of the prostate. J Urol 1992; 148:1856-1860.

18. Jensen KM-E, Jorgensen JB, Mogensen P, Bille-Brahe NE: Some clinical aspects of uroflowmetry in elderly males: a population study. Scand J Urol Nephrol 1986:20:93-99.

19. Girman CI, Panser LA, Chute CG, Oesterling JE, Barret DM, Chen CC. Arrighi HM, Guess HA, Lieber MM: Natural history of prostatism: urinary flow rates in an community-based study. J Urol 1993; 150:887-892.

20. Jacobsen SJ, Chute CG, Girman CJ, Oesterling JE, Guess HA, Lieber MM et al: Do prostate size and urinary flow rates predict health care-seeking behawiour for urinary symptoms in men? Urology 1995;45:64-69.

21. Diokno AC, Brown MB, Goldstein NG, Herzog AR: Urinary flow rates and voiding pressures in elderly men liwing in a community. J Urol 1994; 15!:1550-1553.

22. Diokno AC, Brown MB, Brock BM, Herzog AR, Normolle DP: Clinical and Cystometric characteristics of continent and incontinent noninstutionalized elderly. J Urol 1988;140:567. 571.

23. Berry SJ, Coffey DS, Walsh PC, Ewing LLw: The development of human benign hyperplasia with age. J Urol 1984;132:474-479.

24. Bosch RJLH, Kranse R, van Mastrigt R, Schroder FH: Reasons for the weak correlation between prostate volume and urethral resistance parameters in patients with prostatism. J Urol 1995:153:689-693.

25. Shoukry I, Susset JG, Elhilali MM, Dutartre D: Role of uroflowmetry in the assessment of lower urinary tract obstruction in adult males. Brit J Urol 1975;47(Pt 2):559-566.

26. Gleason DM, Bottaccine MR., Drach GW, Layton TN: Urinary flow welocity as an index of male voiding function. J Urol 1982;128:1363-1367.

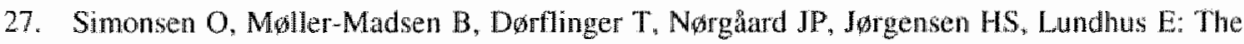
significance of age on symptoms and urodynamic and cystoscopic findings in benign prostatic hypertrophy. Uroll Res 1987:15:355-358. 
28. Bany MJ, Cocket ATK. Holtgrewe HL; McConnel JD, Sihelnik SA, Winfield HN: Relationship of symptoms of prostatism to commonly used physiological and anatomical measures of the severity of benign prostatic hyperplasia. J Urol 1993;150-351-358.

29. Frimodt-Møller PC, Jensen KM-E, Iversen P. Madsen PO. Bruskewitz RC: Analysis of presenting symptoms in prostatism. J Urol 1984:132:272-276.

30. Jensen KM-E, Bruskewitz RC. Iwersen P, Madsen PO: Predictive walue of voiding pressures in benign prostatic hyperplasia. Neurourol Urodyn 1983;2:117-125.

31. Jengen KM-EE, Bruskewitz RC, Iversen P, Madsen PO: Significance of prostatic weight in prostatism. Urol Ine 1983,38:173-178.

32. Jensen KM-E, Bruskewitz RC, Iversen P. Madsen PO: Spontaneous uroflowmetry in prostatism. Urology $1984,24: 403-409$.

33. Jensen KM E, Jøgrgensen JB, Mogensen P: Urodynamics in prostatism: I. Prognostic value of Uroflowmetry. Scand J Urol Nephrol 1988;22:109-117.

34. Scháfer $W$, de la Rosette JIMCH, Hofner $K$, Kinn A-C, Walter $\$$, Abrams $P$ and the ICS-BPH study group. The ICS-BPH study: pressure-flow studies, quality control and initial analysis. Neurourol Urodyn 1994;13(4):491-496.

35. Kaplan SA, Goluboff ET, Olsson CA, Deverka PA, Chmiel JJ: Effect of demographic factors, urinary peak flow rates, and Boyarski symptom scores on patient treatment choice in benign prostatic hyperplasia. Urology 1995;45(3):398-405.

36. Kuo HC, Tsai, TC: The predictive value of urine flow rate and voiding pressure in the operative outcome of benign prostatic hypertropy. Taiwan I Hsueh Hui Tsa Chih 1988:87:323-330.

37. Schafer $W$, Noppeney R, Rubben $H$, Lutzeyer $W$ : The value of free flow rate and presure/flow-studies in the routine investigation of BPH patients. Neurourol Urodyn $1988 ; 7: 219-221$.

38. Schäfer W, Rübben H. Noppeney R, Deutz F-I: Obstructed and unobstructed prostatic obstruction. A plea for urodynamic objectivation of bladder outflow obstruction in benign prostatic hyperplasia. World J Urol 1989;6:198-203.

39. Seaman EK, Jacobs BZ, Blaivas JG, Kaplan SA: Persistence or recurrence of symptoms after mansurethral resection of the prostate; a urodynamic assessment. J Urol 1994;152:935-937.

40. Schou J, Poulsen AL, Nordling J: The anatomy of a prostate waiting list: a prospective study of 132 consecutive patients. Brit J Urol 1994:74:57-60.

41. Yalla SV, Sullivan MP, Lecamwasam HS, DuBeau CE, Vickers MA, Cravalho EG: Correlation of American Urological Association symptom index with obstructive and nonobstructive prostatism. J Urol 1995; 153:674-6880.

42. Chancellor MB, Blaivas JG, Kaplan SA, Axelrod S: Bladder outlet obstruction versus impaired detrusor contractility: the role of urollow. J Urol 1991:145:810-812.

43. Andersen JT, Nordling J: Prostatism II. The correlation between cystourethroscopic, cystometric and urodynamic findings. Scand J Urol Neplrol 1980;14:23-27.

44. Andersen JT: Prostatism III. Detrusor hyperreftexia and residual urine. Clinical and Urodynamic Aspects and the influence of surgery on the prostate. Scand I Urol Nephrol 1982; $16: 25-30$. 
45. Ameda $K$, Koyanagi $T$. Nantani $M$, Taniguchi $K$, Matsmo $T$. The relevance of preoperative cystometrography in patients with benign prostatic hyperplasia condating the findings with clinical features and outcome after prostatectomy.J Uroll 1994:152(2 Pat 11).43-447.

46. Lu-Yao GL, Greenberg ER: Changes in prostate cancer incidence and treatment in USA. Lancet 343:251-254, 1994. Comment in: Lancet 1994;343:1436-1437.

47. Adami H-O, Baron JA, Rothman KJ: Ethics of a prostate cancer trial, Lancet 1994:343:958-960. Comment in: Lancet 1994:343:1436-1437.

48. Feinstein AR: "Clinical Epidemiology; The Architecture of Clinical Research." Philadephia: Saunders, 1985. 
General discussion 


\section{Introduction}

In daily clinical life it is common knowledge that the term "BPH" is used to describe many other conditions than the tissue diagnosis. This chapter describes observations of the difficulties attached to this subject in a general and more phenomenological way.

Throughout literature, BPH is often used to describe several different entities in a group of older men also when the tissue diagnosis is not made. One could uncover the aspecific use of the term BPH and replace it for at more clear description like "micturition problems", "low urinary flow prestation", "flow less than $10 \mathrm{ml} / \mathrm{s}$ ", "obstructive symptoms", "prostatism", "proven obstruction with pressureflow", "high pressure chronic retention"4, "lower urinary tract obstruction"s," "anybody at the left side of the Abrams/Griffiths nomogram" or "pathological condition as a result of chronic dysfunctioning of storage and emptying of urine", "anybody on the waiting list for TURP7.8, or "prostate size larger than $20 \mathrm{ml}$ and flow less than $15 \mathrm{ml} / \mathrm{s}^{\text {"9 }}$. In a recent thesis, R. Bosch reports even on more than 10 definitions. ${ }^{10}$ This has a lot of rational advantages, but it is difficult to assess the impact of diagnosing one of these in itself more accurately described conditions. Still research is incomplete for resolving the weaknesses behind the basic concepts of these "alternative diagnoses for BPH",

Accepting a more pragmatic definition for anyone involved in this field of studying BPH (to mention some groups: patients, urologists, general practitioners) is imperative to daily clinical life. In doing so, one has to be aware of the effects of the present terminological misunderstanding. Besides, the easy use of the term BPH covers a lot of diagnostic problems, which are difficult to recognize. A lot can be done to clear up validity issues behind the more preferable use of terminology, but, for example up to the pages of the Lancet " powerful in stead of rational remarks can be found on which symptom score is "the best".

Guidance as to how to proceed with accepting (or rejecting, or rephrasing) diagnostic items can be found in clinical epidemiology handbooks like "Clinical epidemiology". ${ }^{2}$ One of the fundamental issues of definition is the problem of stability of a diagnostic test. If the result of a test is different when the test is applied for a second time in the same person (with a stable diseased situation), then basic problems arise. In urology, literature about this test-retest situations was not published until the recent nineties. It would be useful to adopt a consistently solid clinical epidemiological aproach in evaluating dingnostic procedures in urology.

The AHCPR publications ${ }^{13}$ on diagnosis and treatment of "BPH" put up an excellent documentation of clinical epidemiological analys is of the field, but this group was reluctant to criticise its own choice of symptom score, the position of its use in all day practice and still uses the "tissue" term BPH to cover several subjects. The advice to always undertake history taking and a "physical examination" is left rather unspecified except for the issues of differential diagnosis of prostate cancer. In fact, the only diagnostic instrument the AHCPR advises for the diagnosis of BPH is using a symptom score. Barry discussed the impact of questions like "Can one continue with 
watchful waiting policy till symptoms suggestive for hydronephrosis appear?", or "Can one really wait till acute painful retention, or hematuria, or urinary tract infection, do cause a problem?" 14 These questions cannot be definitively answered by the research presented here. In this context, we put the results of our study into perspective.

\section{Main findings}

Micturition symptoms are very prevalent in the elderly male population. Less than $10 \%$ is completely symptom free. Even at the severest level of symptoms most men did not discuss their (hindrance of) micturition with their general practitioner or urologist. The probability to develop new symptoms does not seem to increase with age. Cumulatively the prevalence of prostate operation rises to $32 \%$ at age 80 and higher, making it the most frequent operation among older men (Chapter 3).

Of all older men, $60 \%$ experienced a negative influence on activities of daily living because of their micturition problems. More than $85 \%$ of all men did not have the opportunity to compare their micturition pattern with others. The minority who did consult a doctor had a higher level of symptoms, were responsive to some psychological factors and smoked more. Hindrance of micturition symptoms in itself did not extra motivate to visit a doctor. The role of the signalising partner was not present in terms of raising the percentage of doctor's visit (Chapter 4).

In the urologically investigated group prostate size was relatively small $(25.5 \mathrm{ml})$. Postvoid residual urine $>100 \mathrm{ml}$ was found in $50 \%$ of the men but could have been overestimated with our measuring technique. Bladder outflow obstruction was present in $40 \%$ of this group and was negatively related to peak flow prestation and positively with postvoid residual urine. Bladder weakness was found in $71 \%$ of the men and was not related with any clinical finding. Bladder weakness (BW) and bladder outflow obstruction (BOO) seemed two different conditions in this group, negatively related to another. However, many other signs, symptoms, results of physical examination, flowmetry and simple lab testing did not contribute to discriminate between presence or absence of BOO. This is even more the case for BW. Variables showing a statistically significant association with the diagnostic outcome in bivariate analysis, often do not show a significant contribution in multivariable analysis (Chapter 6).

Getting a reliable flow result is difficult to achieve for a substantial number of men. Artefact definition helps to improve diagnostic precision. Low flow results are very prevalent in the population of older males. A "healthy" or "normal" flow was documented only in a minority of men (Chapter 5).

In chapter 2 the methodologic issues together with the practical issues of how to deal with the patient are described. A pragmatic approach is advocated where the doctor helps the man to choose between the various diagnostic and treatment regimens, being aware of the hidden uncertainties often attached to micturiton and genital problems. ${ }^{13}$ On the basis of prognostic information, only a small minority of men can be urged to 
undergo treatment. In an outpatient clinic many patients hope their doctor will decide for them about treatment.

\section{Methodologic issues}

\section{Advantages of our design}

- The study was based on a population based register. This made our study epidemiologically sound, with a well defined population denominator, thus providing denominators in $2 \times 2$ analysis. Most population based studies have published on the prevalence of symptoms only, without reporting on other data relevant to urologic decision making. There are at least 50 studies reported in Uiterature, describing the value of diagnostic information in a consecutive group of patients attending an urologic outpatient clinic. At the outpatient clinic the diagnostic information is decisive in management. These studies could technically be better equipped to provide information. However, selection processes of who will go -and who is not going to the outpatient clinic are still so unclear that the denominators of these studies are largely unreliable. Our study reported directly on the gap between the population prevalence and the outpatient clinic prevalence, showing that most men with severe voiding symptoms are not seen by a doctor.

- The registration of what the men reported us about morbidity could be checked in his patient record. This facilitates a nearly complete registration of medical consultation so that relevant comorbidity, incidents and repetitive data collection could be based on the advantages of the Dutch general practice listing and data registration system.

- Many factors which possibly could play a role were registered. This gave opportunity to multifactorial analysis with different cutoff-points and different definitions of the dependent variable.

- Selection of cases for gold standard examination was possible with a clear definition of cutoff- points, including a broad clinical spectrum.

- Considering abnormality of uroflow, we could use a broad range of analysis techniques, including the most often used. Again, the selection and reporting of our studly could provide information of unselected cases also in relation to abnormality in flow prestation.

- The study obtained a relatively high percentage of participation, when looking at participation percentages at other studies. Also high numbers of complete registration could be attained.

- The whole spectrum of abnormal symptoms and abnormal flow was studied, not preselected by any "confounding by indication".

- The Maastricht study population integrated many aspects of the BPH-problem in a combined study, where prognostic analysis can be eventually used as the most 
prominent parameter. Indeed, (determinants of) improvement or deterionation of the men's condition is pivotal to decision-making.

These above mentioned advantages are quite unique in literature. The first population based study on other aspects than symptom registration published only on free flow data, ${ }^{15}$ later followed by a longitudional follow up of a relatively small group. Diokno et al. ${ }^{16.17}$ based their studies on $4 \%$ volunteers of a population, not presenting any information on possible biases. Garraway in Edinburgh ${ }^{9}$ was the first to publish on integrative information in the field of chronic micturition problens among older men. Girman $^{18}$ reported from another study integrating urological information in 1993 , based on the Minnesota data. Bosch ${ }^{10}$ published on BPH in a study aimed at detection and management of prostate cancer. Because it is not clear to the public whether diagnosing prostate cancer will improve the prognosis of a patient, attendance to this study may have been quite low. Therefore, selection bias can have had influence on the results published.

What makes the Maastricht study unique is that we were able to undertake pressure flow on a clearly defined population based group. This gave us much opportunity to register important information on the concepts possibly explaining diagnosis and progression of socalled BPH.

\section{Limitations of our design}

- Since we chose the symptom score to be used already in 1990 . we could not make use of the nowadays most popular symptom scores which are advocated (ICS-score, AUA, WHOPPS). A comparison between different symptom scores and their internal stabilities has been made and will be published. It appears that the Boyarski symptom score has an acceptable agreement with more recently developed scores.

- Under the heading of micturition problems several entities can be placed. Relatively "hard" reasons for encounter like acute painful urinary retention (although having different pathophysiological routes!) are quite easy to define because one needs a catheter to resolve the advanced cases. However, although "difficult micturition" often cannot be defined with full clarity, our research made clear that even people with "hard indications" (hematuria, dysuria) did not visill a doctor.

- The diagnostic study was not based on presented cases of micturition problems. Conceptually, in those cases most diagnostic decisions are made. Waiting and motivating the (rare) patient with "spontaneously presented micturition problems" to participate in the study and starting data gathering at that moment could have made the answers to our diagnostic workup analysis more directly related to daily reality in the consultation of patients. However, such an approach would miss the cases not presented to a doctor, thereby ignoring the substantial "iceberg phenomenon" and would have required "waiting" for a long time in a greal number of practices. Therefore we have chosen the population based approach, while informing and checking on doctor consultation additionally. 
- The "gold standard" pressure-flow examination in this study was quite unique and therefore difficult to compare with other studies. The Maastricht methods for pressure-flow analysis are relatively unknown in other clinics. Comparison of different pressure-flow methods and analysis is under way but not yet published. Some methodologic questions still remain (effect of measuring PVR with the freshly inserted suprapubic catheter in situ, after a spontaneous void, before pressure-flow filling and repetitive measuring), others are answered (difference between transurethral route and suprapubic route for urinary catheter in pressureflow measurement, in measuring instability, numbers of fillings necessary to get a stable result). The laboratory setting as a cause of extra abnormalities might be overcome by using the technique of ambulatory urodynamics as developed by eg. van Waalwijk van Doorn ${ }^{19}$. But still thinking and deciding on what is relevant in diagnosis on lower urinary tract symptomatology is important.

- Especially above the age of 75 it seems that our study is somewhat selected towards a more healthy population. At this age already $30 \%$ had a prostate operation. It also became increasingly likely that other exclusion reasons (eg. comorbidity) were present. And the attitude of the "healthy remainers" often could be noted as stoic, proud on what they reached.

- Gold standard investigation could not be undertaken to a group of asymptomatic subjects without diseased flow. For analysis this would have made our picture complete, but as explained earlier it would have asked too much from healthy volunteers.

- Diagnostic information collection could not be blinded for the registration personnel. This is likely to be only a theoretical problem because our study did not find many correlations, while presumed clinical assumptions on symptomatic correlations would have probably biased the results towards positive associations. And for the free flow result as collected in general practice the researchers in the urologic clinic were blinded.

\section{Consequences for the (GP)-clinician:}

One of the aspects brought up by our study is that the interrelation between many factors which in the past were associated with the "enlarged prostate" is at best weak, mostly even absent. This already was known from urological research at the level of candidates for surgery, but this could have been caused by a selection effect since referral is generally based on both symptoms and prostatic enlargement ${ }^{20}$ In primary care and in unselected populations, an association still could be the case, so a population based conclusion is important. The conclusions clinicians made as yet were various. Instead of cautiously making use of only little diagnostic instrumentation many doctors order many diagnostics. Standardisation of diagnosis and treatment is not at all usual. ${ }^{22}$ The same patient could be operated within a month "to get rid of his prostate" just 
because he went to a doctor who beforehand was already of the opinion that any older man who has conplaints should be helped through operation, while another urologist can be reluctant to do any invasive diagnostic instrumentation or treatment.

A workup for standard differential diagnosis for "chronic micturition problems" could not be found with great exactness in textbooks of urology, and was formulated for GPs not earlier than $1993 .^{23}$

On pathophysiology of BPH a lot of ideas still exist which stem from history and non-evaluated nor updated impressions. In short: one assumes that in older age BPH-related lower urinary tract obstruction occurs, which can give rise to "obstructive symptoms". In some cases where obstruction is worse enough or where adaptation mechanisms like hypertrophy of the bladder are insufficient, complications arise. One can view chronic hydronephrosis, loss of kidney tissue, bladder diverticula, urinary tract infection, acute retention and worsening symptoms as caused by the obstruction. Hard clinical epidemiologic data on these relations is sparse. In absence of well designed natural history studies encompassing the relation between the above mentioned items only indirect information can help to clear up these relations. Therefore the Maastricht study will in future publish about natural history data. At the baseline measurement of this study we already looked, in this thesis, at the subject in an indirect and retrospective manner. The dangers of "untreated prostate obstruction" did not show up from our data. Furthermore, preliminary results from the prospective follow-up indicate that even in the subgroup with symptoms or flow abnormalities no upper tract complications could be seen using ultrasound. ${ }^{24}$ In addition, men with many symptoms often did not note these as severe or as giving rise to much hindrance. Almost no men were able to relate their micturition habit to their own age group, let alone judge his habit correctly.

For doctors reading about our Maastricht study ${ }_{4}$ many aspects attached to diagnosis are left without final certainty. The diagnosis BOO can be made as often in asymptomatic men as in severely symptomatic men. And the diagnosis of BOO was not clearly associated with the possible "dangers" of obstruction. So it seems not helptul to put effort in trying to collect such information from individual patients unless one would consider 'screening' for BOO regardless of symptoms. The latter option would in our view by far not meet the screening criteria of Wilson and Jungner. ${ }^{25}$ This comment can be repeated with even more emphasis to the concept of $B W$.

The practical implication is that diagnosis and treatment should be undertaken with caution: presence or absence of sympoms or signs are only very little related to prostate size or other urinary tract disorder-concepts. There are entities which should steer treament such as thematuria, acute painful urinary retention ${ }^{26}$ and urinary tract infections and these should be dealt with accordingly. Clarification of the patients' questions, problems and own ideas, concentrated attention to the patient and awareness of questions behind the question (eg, fear of prostate cancer, problems with old age; problems in relation with the partner, sexual problems) seem very important to deal with the problems presented by the men themselves. 
Our data suggest, that if a doctor is interested in the field of micturition problems then many men can be identified, who-after overcoming some shame-can be indeed cared for in general practice. That is to say that the condition gives room for clarifying eventual underlying themes like acceptance of old age, influence of sex in their lives, hindrance by the condition (in comparison with previous experience), patient expectations, medical support that could be helpful, with their advantages and disadvantages. As such the subject gives room for various aspects of modern health care delivery and for deepening the quality and relation with the patient.

\section{Further research}

\section{Prevention research}

Since the development of hindrance from micturition symptoms appears to be largely a functional and anatomic problem, etiologic and preventive intervention studies might shed light on whether behavioral (eg. micturition behaviour over a long time) or psychological (eg attitude aspects) factors might have etiologic or preventic relevance.

\section{Diagnostic research}

In particular, it seems clinically relevant to develop and evaluate more precise protocols to distinguish early between those symptomatic men who can be conservatively treated or left untreated (with counseling needed) at the one hand, and the small group which is at risk to develop obstructive complications at the other hand. Such protocol development, of course, would need more information from prognostic studies.

\section{Prognostic research}

Two types of prognostic research are recommended:

(A) Population based studies on natural history and clinical course, in order to analyse the prognosis, and the determinants of prognosis and complications. Such studies can inform us, free from selection bias as a result of consultation or referral behaviour, about (the determinants of) expected severity and on clues for therapy. In addition, the determinants of presenting symptoms to a doctor should be studied more in depth.

(B) Prognostic studies based on cohorts of patients presenting the symptoms to a GP. Such research can provide clinically relevant follow-up information on the "iatrotropic" population, seeking help from the doctor. 
In the Maastricht study, a follow-up study of the first type is undertaken on the basis of our cross-sectional study, and will be reponted later.

\section{Therapeutic research}

Attitudes and subjective experiences may be of influence in dealing and coping with symptoms. Therefore, in addition to research on drugs influencing bladder function and prostatic morphology, and on the effectiveness of various surgical procedures in selected cases (considering also effect modification), research on the effectiveness of non-drug interventions to deal/cope with symptoms should be extended.

\section{References}

1. Wolfs GGMC, Knotnerus JA, Janknegt RA: Prevalence and detection of nicturition problems among 2734 elderly men. J Lirol 1994;152:1467-1470.

2. Cockett ATK, Aso Y, Chatelain C, Denis L, Griffiths K, Khoury S, Murphy O. (eds). The International Consultation on Benign Prostatic Hyperplasia (Proceedings). Paris, june 26-27, 1991

3. Rollema H.J, wan Mastrigt R. Objective analysis of Prostatism: A Clinical Application of the computer program CLIM. Neurourol Urodynamics 1991;10:71-76.

4. George NJR. Chapter 10, Basic considerations, chapter 11 and 12: Obstructive and functional abnormalities part I and II. pp. 198-289. In O'Reilly: Obstructive uropathy. Berlin: Springer Verlagg, 1985.

5. Abrams P. Managing lower urinary tract symptoms in older men. BMJ 1995 Apri1 29;310:11137.

6. Abrams PH, Griffiths DI. The assessment of prostatic obstruction from urodynamic measurements and from residual urine. Br J Urol 1979:51:129-34.

7. Schou J, Poulsen AL, Nordling J. The anatomy of a prostate wating list: a prospective study of 132 consecutive patients. Brit J Urol 1994: 74:57-60.

8. Barham CP. Pocock RD, James ED. Who Needs a Prostaticcomy? Review of a Waiting List. Brit J Urol 1993;72,314-3॥7.

9. Garraway WM, Collins GN, Lee R J: High prevalence of benign prostatic hypertrophy in the community. Lancet 1991:338:469-471.

10. Bosch JLHR. Epidemiological and pathophysiological aspects of benign prostatic hyperplasia. Thesis, Erasmus Universily Rotendam, 1995.

11. Andersen JT Treatment of benign prostatic hyperplasia. The Scandinavian BPH study group. Lancet 1996;347:1270.

12. Feinstein AR: Clinical Epidemiology: the Architecture of Clinical Research. Philsdelphia, W.B. Saunders Company, pp. 597-631, 1985. 
13. MeConnell DD, Barry MJ. Bruskewitz RC. Bueschen AJ, Denton SE, Holtgrewe HL, Lange JL. McClemnan BL, Mebust WK, Reilly NI, Roberts RG, Sacks SA, Wasson JH. Benign Prostatic Hyperplasia: Diagnosis and Treatment. Clinical Practice Guideline, Number 8. AHCPR Publication No. 94-0582. Rockville, MD: Agency for Health Care Policy and Research, Public Heath Service, U.S. Department of Health and Human Serwices; 1994 Febr.

14. Barry MJ. Determining the utility of surgery for benign prostatic hypertroplay. Boston (Mass.): Massachussets General Hospital, 1986.

15. Jensen KM-E, Jorgensen IB, Mogensen P, Bille-Brahe NE. Some clinical aspects of uroflowmelry in elderly males. A population survey. Scand J Urol Nephrol 1986:20:93.

16. Diokno AC, Brown MB, Brock BM, Herzog AR, Normolle DP. Clinical and Cystometric characteristics of continent and incontinent noninstutionalized elderly. J Urol 1988;140:567571.

17. Diokno $\mathrm{AC}$, Brown MB, Goldstein NG, Herzog AR: Urinary flow rates and voiding pressures in elderly men liwing in a community. J Urol 1994:151:1550-1553.

18. Girman CJ, Panser LA, Chute CG, Oesterling JE, Barrett DM, Chen CC, Arrighi HM, Guess HA, Lieber MM: Natural history of prostatism: urinary flow rates in an community-based study. J Urol 1993; 150:887-892.

19. van Waalwijk wan Doorn ES, Meier AH, mbergen AW, Janknegt RA. Ambulatory urodynamics: extramural testing of the lower and upper urinary tract by Holter monitoring of cystogram, uroflowmetry, and renal pelvic pressures. Urol Clin North Am 1996:23:345-71.

20. Berry SJ, Coffey DS, Wals/ PC , Ewing LL: The development of human benign hyperplasia with age. J Urol 1984;132:474-479.

21. Stoevelaar, HJ. Management of Benign Prostatic Hyperplasia: practice variation and appropriateness of care. Thesis, Erasmus University Rotterdam, 1996.

22. Klomp MLF, Gercama AJ, de Jonge-Wubben JGM, et al. Bemoeilijkte mictie bij oudere mannen. [NHG-standaard] Huisarts Wet 1994;37;357 65.

23. Knottmerus JA. The influence of disease verification and refertal on the relationship between symptoms and diseases. Med Decis Making 1987; 7 ; 139-148.

24. van der Waart Th, Boender H, van der Beek C, Wolfs GGMC, Janknegt RA, Knottnerus JA. Uitity of ultrasound of the upper urinary tract in eldery men with indication of obstructive symptons or abnormal flow. [submitted]

25. Wilson JM, Jungner YG. Principles and practice of mass screenig for disease. Bol Offucina Sanit Panam. 1968 oct(65(4):281-393.

26. Elzinga GJW, Gorgels WJMJ, Wolfs GGMC, Janknegt RA, Knotherus JA. Acute retentie bij mannen $>55$ jatr: ook voor de huisars een dringend probleem? [Engl ish abstract] Huisarts Wet 1997:40:102-104. 


\section{General summary}


In this study the prevalence of obstructive and other micturition problems, and uroflow patterns among elderly men in the community were studied, and its determinants were anallysed. In addition history data, physical examination and laboratory data were evaluated as to their diagnostic value. Finally, in a subset of men clinical diagnostic items were compared with urodynamic measurements for obstruction and bladder weakness.

\section{Chapter 2}

In chapter 2 the general methodologic issues together with the practical issues of how to deal with the patient is described. A pragmatic approach is advocated where the doctor helps the man to choose between diagnostic and treatment regimens, being aware of the hidden uncertainties most often attached to micturiton and genital problems.

In elderly men, micturition problems posibly related to Benign Prostatic Hyperplasia (BPH) is the rule rather than the exception. The disease involves quite a number of health problems and constitutes the most frequent indication for surgery in elderly men. Yet, there remains much to be elucidated about diagnostics, course and complications, and on the effects and side-effects of surgical and pharmacological treatment. Selection processes from primary to secondary care limit the generalisability of medical knowledge from the hospital to general practice. Due to the lack of sound efficacy studies, no unequivocal management advice can be given for the large group of patients in primary care for whom there is no absolute surgery indication and in whom the clinical picture is largely determined by complaints. In these cases, watchful waiting seems an appropriate option. In most cases one may monitor the natural course, while in diagnostic uncertainty or with motivated patients for invasive therapy referral to the urologist should be considered. A question to what extent progress of symptoms and/or abnormal uroflowmetry in general practice may be riskful to develop medical arguments for therapy, deserves further study.

\section{Chapter 3}

In previous studies, symptom prevalence of micturition problems in the population appeared to be high. Our study supports these data and adds retrospective data on doctor's visits. Less than $10 \%$ of all men is symptom free. The risk to develop new symptoms does not seem to increase with age. Of the men describing their micturition situation as a medical complaint, only $10-30 \%$ presented their symptoms to a doctor.

And still the prevalence for prostate operation rised to $32 \%$ at age 80 and higher, making it the most frequent operation among older men in the eighties. But in this decennium already $30 \%$ decrease in operations for the Netherlands despite growing numbers of elderly men.

In our study $25 \%$ of the elder male population reported a doctor's visit over the last 5 years for a micturition problem. 


\section{Chapter 4}

Almost $60 \%$ experienced influence on activities of daily living because of their micturition habit. But even at the severest level of symptoms most men did not discuss their (hindrance of) micturition with their general practitioner or urologist, although symptoms have substantial impact in daily life. All symptoms (hematuria, dysuria, incontinence and symptoms possibly related to BPH) showed substantial numbers of patients who were not sufficiently motivated -or not had the opportunity- to visit a doctor for diagnosis and advice. Multiple logistic regression analysis showed a number of symptoms that independently predict doctor's visit for BPH and related diseases (frequent urination at night, frequent urination during the day, incomplete emptying, dysuria and incontinence). Other factors also predicted doctor's visit: men's defining their situation as a complaint, depressive mood, more frequent sexual desire and smoking. Many other factors which might play a role in diagnosis and timing of treatment were not found to influence consultation: hindrance of micturition symptoms in itself did not extra motivate to visit a doctor. The role of the signalising partner was not present in terms of raising the percentage of doctor's visit

More than $85 \%$ of the men were not able to compare their micturition pattern with others, and most men did not note any reaction of others to their micturition.

\section{Chapter 5}

Getting a reliable urinary flow result is difficult to achieve for a substantial number of men (33\%). Artefact definition helps to improve diagnostic precision. A wide variety of flow patterns could be found. Low flow results varied from $21 \%$ among men of 55-59 years of age to $70 \%$ among those of 80 or older. When low flow was corrected for voided volume with an age independent algolritm, then this difference almost faded away. A "healthy" or "normal" flow was documented only in a minority of men. Presentation to a doctor was not associated with a low flow result. If low flow was studied for it's associations, then only the experience of a small stream, indices of urinary tract infection, and higher daily alcohol intake were related. Whether it is risk ful not visiting a doctor for low flow remains unclear and should be established in prospective studies. For the present use of defining normal and abnormal flow, be it with software or with Qmax borders at round number like $10 \mathrm{ml} / \mathrm{s}$ little scientific arguments can be found.

\section{Chapter 6}

Micturition symptoms are very frequent among elderly men. For evaluating the clinical significance of these symptoms, there is a need for data on the relation between presence of signs and symptoms with bladder outflow obstruction and bladder weakness; the last two conditions were regarded as the best intellectual appealing definitions for explanation of the origin to chronic micturition problems.

In the selected group, mean prostate size was found to be $25.5 \mathrm{ml}$; postvoid residual urinary volumes larger than $100 \mathrm{ml}$ were detected in $50 \%$ of the men, Bladder outflow 
obstruction in $40 \%$ of the cases. No relation between presence of symptoms and Bladder outflow obstruction was observed. Bladder outflow obstruction was negatively related with urinary peakflow and positively with postwoid residual volume. Bladder weakness was found in $71 \%$ of the men, and was not related with any clinical findings.

In the community of elderly men, bladder outflow obstruction and especially bladder weakness frequently occur. However, a relevant relation between these urodynamic standard diagnoses and symptomatology was hardly found.

\section{Chapter 7}

Methodological strengths and limitations of the study are discussed and evaluated. The most important findings are summarized, and related to their implications for the practitioner. Finally, recommendations for further research are presented for preventive, diagnostic, prognostic and therapy research. 


\title{
Algemene samenvatting
}

\author{
Obstructieve plasproblemen bij oudere mannen \\ vóórkomen en diagnostiek in de huisartspraktijk
}

In een bevolkingsstudie onder 2734 mannen van 55 jaar en ouder, ingeschreven in 10 huisartspraktijken gevestigd in Mastricht werd in de jaren 1990 tot en met 1993 de aanwezigheid van plasklachten met een enquête geregistreerd. Daarnaast is in een kleinere groep gemeten hoe hun plasgewoonte was. Aanvullend werden gegevens verzameld over hun medische voorgeschiedenis en hun gezondheid, en werd nader klinisch diagnostisch en laboratorium onderzoek verricht. Tevens werden allerhande mogelijk van betekenis zijnde meningen en eigen ideeën door middel van een vragenlijst verkend.

Uiteindelijk werd een groep mannen geselecteerd met langer durende plasklachten en/of plasstraalzwakte. Met aanvullend onderzoek werd bepaald in hoeverre hun blaas verzwakt was of de blaasuitgang vernauwd leek.

\section{Hoofdstuk 2}

In hoofdstuk 2 wordt een algemene inleiding gegeven over de klinische en methodologische onderwerpen op dit onderzoeksterrein. Tevens wordt beschreven hoe een arts met een man met klachten om kan gaan en waarop gelet dient te worden. Een pragmatische aanpak wordt aangeraden waarbij de man die het probleem presenteert geholpen wordt zelf te kiezen tussen de verschillende diagnostische en therapeutische mogelijkheden. Dit bij gebrek aan een duidelijk op feiten gebaseerde voorspelling van het beloop van de aandoening. De presentatie van plasklachten door een patiënt kan bovendien andere onzekerheden en angsten verbergen die te maken met ouder worden en sexualiteit.

Het is bij oudere mannen eerder regel dan uitzondering om plasmoeilijkheden te hebben. Menigeen denkt dat deze te maken hebben mel goedaardige prostaatvergroting, Deze aandoening wordt meestal gekoppeld atan andere aandoeningen zoals blaasontsteking, bloed in de urine, totaal onvermogen om te kunnen plassen, nierstuwing en prostaatkanker. Eind jaren tachtig leidde dit er toe dat een prostaatverwijdering de meest uitgevoerde operatie was bij oudere mannen. Toch zijn er nogal wat onduidelijkheden op te helderen over prostaatvergroting en de relatie met andere aandoeningen. Daarnaast was het onduidelijk hoe de diagnose prostaatvergroting precies gesteld diende te worden, hoe het verloop dan zou zijn, welke komplikaties er kunnen optreden en welke de invloed van operatie, medicatie of andere behandelingen zou zijn. Het feit dat zeker niet iedere man met plasklachten bij een huisarts komt en daarnaast ook niet iedere patiënt naar het ziekenhuis wordt verwezen maakt dat de kennis welke in 
zickenhuizen verworven is over prostaat-en blaasaandoeningen niet zonder meer op de patièten in de huisartspraktijk, laat staan de algemene bevolking van toepassing is.

Door het ontbreken wan goed opgezette effektiviteitsstudies kunnen thans geen algemene aanbevelingen voor de grote groep van mannen bekend in de hüsartspraktijk worden geformuleerd. Er is wel enige indirekte informatie beschikbaar over mannen met absolute noodzaak tot prostatuterwijdering of over mannen bij wie komplikaties optreden. In de meeste gevallen lijkt "Waakzaam afwachten" zonder therapie een goede eerste keus. Als er diagnostische twijfel is of indien de patiënt sterk gemotiveerd is voor ingrijpender therapie is verwijzing naar een uroloog voor de hand liggend. Het is mogelijk dat uit het natuurlijk beloop van plasklachten en/ of plaskrachtmeting in de huisartspraktijk argumenten te putten zijn voor therapie. Dit is echter tot op heden niet met zekerheid vatsgesteld.

\section{Hoofdstuk 3}

Voordat de Maastrichtse studie afgerond was bleek reeds dat de aanwezigheid van plassymptomen onder de algemene bevolking hoog was. Onze studie bevestigde dit en voegde er gegevens aan toe over de mate waarin oudere mannen hiermee naar een dokter gingen. Het bleek dat minder dan $10 \%$ van de algemene, oudere, mannelijke bevolking geheel symptoomvrij was. Dit leek overigens niet verder af te nemen met hogere leeftijd. Zelfs als de mannen hun plasgewoonte als medisch relevante klacht beoordeelden gingen ze soms maar in $10-30 \%$ van de gevallen naar een arts. Toch was er in de leeftijdsgroep boven 80 jaar reeds $32 \%$ an hun prostaat geopereerd. In het huidige decennium daalde echter de neiging om prostaatoperaties uit te voeren evenwel met $30 \%$, ondanks de toenemende vergrijzing en reeds voordat werkzame medicatie in Nederland toegepast kon worden. Ten tijde van onze studie rapporteerde $25 \%$ van de mannen een doktersbezoek voor plasproblemen of geslachtsorgaanproblemen dat in de afgelopen 5 jaar plaatsgevonden had.

\section{Hoofdstuk 4}

Bijna $60 \%$ van de mannen merkte dat hun plasgewoonte aanpassing van hun dagelijks leven teweeg bracht. Mar zelfs bij zeer ernstige klachten hadden veel mannen hun plasgewoonte niet besproken met hun huisarts of met een uroloog. Dit terwijl de klachten een behoorlijke invloed op hun dagelijks leven konden uitoefenen. Alle symptomen, inclusief alarmsymptomen als bloed in de urine, pijn bij het plassen, ongewenst urineverlies (naast de symptomen die mogelijk verbonden zijn met goedaardige prostaatvergroting) kwamen voor bij mannen die niet voldoende gemotiveerd waren om hun arts om diagnose en advies te vragen. Met rekenkundige analyses (multiple logistische regressie) kon echter wel een aantal symptomen gevonden worden die los van elkaan in stant lijken doktersbezoek voor prostaatvergroting en hiermee verbonden ziekten te verklaren: vaak 's nachts het bed uit moeten om te plassen, vaak overdag plassen, niet kunnen leegplassen, pijn bij het plassen en ongewenst urinever- 
lies. Ook andere factoren verklaarden mogelijk doktersbezoek: indien mannen hun plasgewoonte als "klacht" zien, indien ze er depressief van werden of indien ze relatief vaak sexuele verlangens hadden. Ook roken lijkt mannen met plasklachten enigszins vaker naar een arts te brengen. Naast deze factoren konden we vele andere factoren bedenken die mogelijk een rol zouden kunnen spelen in de neiging om een dokter te spreken. Toch toonden deze faktoren geen extra waarde: dit gold ook voor de hoeveelheid hinder die de plasgewoonte teweeg brengt. Inbreng van de partner die de plasgewoonte van haar man bespreekt (en vaak het advies gaf on de dokter te bezoeken) bleek niet van invloed op het daadwerkelijke doktersbezoek.

Tevens bleek meer dan $85 \%$ van de mannen niet in de gelegenheid om hun plasgewoonte ten opzichte van andere mannelijke leeftijdgenoten te vergelijken. Ook bleek dat de meeste mannen dachten dat niemand iets van hun plasgewoonte wist.

\section{Hoofdstuk 5}

Om op een ontspannen en ongestoorde manier een gewoon plasje te plegen in een apparaat op een toilet bij de huisarts bleek niet mogelijk bij $33 \%$ van de deelnemers. Overigens kon een grote variatie in plasgewoonte worden gemeten. Een geregistreerde plaskrachtmeting kon verbeterd worden door correctie van verstoorde registratie. Een zwakke plasstraal kon worden gevonden bij $21 \%$ van de mannen die tussen 55 en 60 jaar oud waren. Bij hogere leeftijd nam het percentage mannen met een zwakke plasstraal toe tot $70 \%$ (bij mannen van 80 jaar en ouder). Wanneer de zwakte van de plasstraal werd afgezet ten opzichte van de hoeveelheid uitgeplaste urine dan werd er vrijwel geen toename van afwijkingen meer gevonden bij hogere leeftijdsgroepen. Een "gezonde" of "normale" plaskracht werd slechts in een minderheid van de groep vastgesteld. Het gaan naar een dokter hing niet samen met een zwakke plasstraal. Bij uitgebreide studie naar de samenhang van een zwakke plasstraal met andere factoren werden weinig statistische samenhangen gevonden. Wel waren van invloed: het zelf weten dat er een zwakke plasstraal is, aanwijzingen voor blaasontsteking en hogere alcoholconsumptie. Of het nadelig is om niet met een zwakke plasstraal naar een dokter te gaan is een onderwerp voor toekomstig onderzoek. In onze studie zijn geen overtuigende argumenten gevonden. Wel laat deze studie zien dat er nog veel vragen zijn te stellen over de definitie 'normaal' en 'abnormaal' voor de plaskrachtmeting, of deze nu gesteld wordt met geavanceerde software of met eenvoudiger bepalingen.

\section{Hoofdstuk 6}

Plasklachten komen dus veel voor bij oudere mannen. Om het klinisch belang van deze klachten en symptomen te bepalen is het zinvol on te beschrijven hoe het verband is tussen de aanwezigheid van symptomen enerzijds en blaasobstructie en blaaszwakte anderzijds. De laatste twee kenmerken worden beschouwd als de meest aansprekende definities die zouden kunnen verklaren hoe chronische plasklachten ontstaan. In een geselecteerde groep (op basis van duidelijke symptomen of plaszwakte) was de gemiddelde prostaatgrootte $25.5 \mathrm{ml}$; een urineresidu meer dan $100 \mathrm{ml}$ werd bij $50 \%$ 
vain de mannen vastgesteld, en blaasobstructie bij $40 \%$ van hen. Er was geen verband aantoonbaar tussen de aanwezigheid van symptomen en blaasobstructie. De mate van blaasobstructie bleek wel omgekeerd evenredig met de maximale plaskracht en recht evenredig met blaasresidu. Blaaszwakte was bij $71 \%$ van de mannen aanwezig en bleek niet samen te hangen met klinische verschijnselen.

Dus: in een uit de bevolking geselecteerde groep mannen bleken blaasobstructie en in nog sterkere mate blaaszwakte vaak voor te komen. Echter; er leek weinig verband te ziij tussen deze urodynamische standaard-diagnosen en klinische verschijnselen.

\section{Hoofdstuk 7}

In dit hoofdstuk staan de meest belangrijke resultaten samengevat en besproken met betrekking tot de gevolgen voor de klinisch werkend arts. De methodologie van deze studie werd besproken, gesplitst in sterke punten en beperkingen. Als laatste zijn aanbevelingen voor toekomstig preventief, diagnostisch, prognostisch en therapie-onderzoek geformuleerd. 


\section{Dankwoord}

Dit proefschrift en het daaraan werbonden onderzoek, met zoveel delicate kenmerken, had nooit tot stand kunnen komen zonder de bereidwilligheid van de onderzochte mannen. Ik ben hen veel dank verschuldigd voor hun inzet en betrokkenheid.

Vooral ook aan André Knottnerus die mij al die jaren met veel geduld, vasthoudendheid, begrip en warmte heeft begeleid. Hij was voor mij een energiebron en voorbeeld. Hij zelf is de ontdekker en onderzoeker die deze witte plek op de wetenschappelijke landkaart durfde in te vullen.

Dank aan mijn collega-onderzoekers die met mij de "ware diagnose" probeerden te ontdekken: Jelle Stoffers, Michiel Cornel, Piet Portegijs, Richard Starmans, Jean Muris, Mark Brueren, Victor Kaiser, Geert-Jan Dinant en Paul Zwietering. Helaas gaandeweg en ook noodgedwongen minder team dan voorheen.

Ruud Janknegt, warm, menselijk en deskundig uroloog, ogenschijnlijk rustig in een woelende vakgroep.

Marga van der Aa als onverschrokken, efficiënt, rustig, nuchter en rechtstreeks, hard werkende alleskunner zonder welke het $\mathrm{BPH}$-onderzoek nooit tot oogst had kunnen komen.

Thea van der Waart, onderzoeker van de beloopsstudie waarvoor ik me haast teveel inzette.

Trudie Seegers, die zoals "altijd" snel en rechtstreeks hulp bood bij tegenvallers en twijfels.

De onderzoeksassistentes die tijdelijk ondersteunden: Silvia Bours en Monique Koekkelkoren.

Cees van de Beek, onderzoeksmaat, de eerste uroloog die realistisch inzicht gaf in de dagelijkse werkwijze wat tot dan toe een abstract en technisch onderwerp leek.

Cees van Winzum, MSD, voor zijn open, transparante en brede kijk. Speciaal dank voor zijn verrijkende blik en zijn erkenning van bijzondere onderzoeksproblemen.

Hans Vermeulen, MSD, voor zijn ruimhartige, geinteresseerde begeleiding, brede steun, geduld bij het oplossen van vrijwel onoplosbare problemen.

Paul en Paula Muyrers-Maussen, voor hun gastvrijheid in hun efficiënte huisartspraktijk. Paul nog als onderzoeksmaat van het eerste uur.

Raymond Leclercq, puur op enthousiasme en interesse zich voor het onderzoek inzettend. Via zijn huisartspraktijk kwam de pilotstudie tot stand.

Frans van der Horst en Adriaan Visser voor hun richtinggevende adviezen bij de verkenning van mogelijke faktoren bijdragend tot doktersbezoek. 
Hilde Wahlen, verpleegkundige, waarbij de eerste onderzoekspatiënten direct in vertrouwde handen leken. Spil achter de schermen van het datamanagement. Ook Sabine Geurts en Theo Vanspauwen vingen de mannen deskundig op voor een toch belastend onderzoek.

Peter Rosier en Hugo Boender voor de dataverzameling en het data-management bimnen de vakgroep urologie; Hugo in het bijzonder nog voor zijn steun bij het verzamelen van huisartsgeneeskundige gegevens.

Huisartsen die de zware en omvattende taak van gegevensverzameling op zich namen en uitvoerden. Met flexibiliteit en hoge inzet, weinig concrete of rechtstreeks beloning, vooral in het besef dat de huisartsgeneeskunde dit soort onderzoek hard nodig heeft. Ik ben ze veel dank verschuldigd: M.A.A.W. Heynen, P.E.M. Muyrers, V.A. Zwietering, A.H. Wintjens, S. Dijkstra, G.L.M. van Pelt, K. Verstraete, A.W.M. van Dongen, M.W.P.G. Bots, R.A.J. Hendriks, L.L.J.M. Keysers, W.H.R. Croughs, J.R.A.Y. wan Rooy, H.Th.H. Ramaekers, Dr J. Zuidweg, Dr Th.F.W.A. Krebber.

Doktersassistenten die de organisatie en quasi spontane "flow" van het onderzoek samen met de "praktijkoverstroming" die dit onderzoek met zich meebracht in banen moesten leiden. Huisartsen zijn de kwetsbare evenwichtskunstenaars van de Nederlandse gezondheidszorg, hun assistenten de feitelijke organisatoren en uitvoerders.

Willem Elzinga, Astrid Aansorgh, Mathilde Kuypers: destijds medisch studenten die tijdens hun werk en keuzestage ogenschijnlijk maar "één zin" aan een manuscript konden toevoegen.

Jan-Joost Rethans, niet inhoudelijk betrokken op het onderwerp, maar essentieël in mijn ontwikkeling als huisarts en onderzoeker.

Paul Höppener heeft ogenschijnlijk niets bijgedragen aan dit onderzoek maar zijn relativering en steun gaven mij meewind waarop een voor mij zo noodzakelijk. zelfvertrouwen kon groeien.

En dan nog de praktijkassistenten Mildred Spronck, Connie Pieters, Linda Boender-Beglinger en Monika Kop. Zij organiseerden ook onder crisisomstandigheden omwegen zonder al lerhande praktijkobstructies. 


\section{Curriculum vitae / levensloop}

George Wolfs is geboren 25 mei 1960 te Almelo als jongste zoon van een gemeenteambtenaar en een glazenierster. Van 1972 tot 1978 ging hij nalar het Pius X college in Almelo. De geneeskundestudie duurde van 1978 tot 1984 en werd găandeweg gekombineerd met verschillende taken ten gunste van onderwijsverbetering. Voor de International Federation of Medical Student Associations was hij tot 1986 voorzitter van de commisie "Medical Education".

In 1985 begon hij te werken bij de vakgroep Huisartsgeneeskunde onder leiding van Prof.dr. C.A. de Geus aan de inrichting van het registratienet huisartspraktijken. In de deeltijds huisartsopleiding kwam hij bij Paul Höppener te Heerlen te "leerwerken". Vanaf 1989 begon zijn aanstelling als onderzoeker en huisarts op het "BPH"project. Deze aanstelling liep I juli 1997 af. In Maastricht begon het werken alls huisarts in 1989 bij Paul Muyrers aan de Meerssenerweg. In februari 1991 begon hij te werken in de centrumpraktijk van Jean Dejong, welke hij in 1996 zelfstandig voorzette. JanJoost Rethans heeft de huisartsgeneeskunde ook in deze praktijk bedreven, nadat hij eerst als "opleider" bij Paul Höppener reeds samen werkte.

Op de dag van zijn promotie trouwt hij -eindelijk-met Rosalie Sprooten. 


\section{Appendix I}

questionnaire to rate micturition symptoms:

Modified Boyarski, translated from MK-906 protocoll of MSD 1989, prepared by Harry Guess.

Answer the questions, relating your average voiding situation during the last seven days.

1. How often do you void during DAYTIME? If you know the exact answer, please fill in a number; otherwise select one choice out of five.... [number of voids during DAYTIME]

- $\quad \mathbb{- 2}$ void(s) a day

- 3-4 voids a day

- 5-7 voids a day

- 8-11 voids a day

- 12 voids or more often

2. How often do you need to leave your bed at night to void?

- never/now and then

- 1 time a night

- 2 times a night

- 3-4 times a night

- 5 times a night or more often

3. How do you compare the amount of urine you void to what you used to void?

- large decrease

- some decrease

- not changed

- more

- I don't know

4. If you need to void does it take some time before voiding starts?

- never

- less than half of the times

- about half of the times

- more than half of the times

- always 
5. How often do you need to strain or press on your belly to let the voiding start?

- never

- less than half of the times

- about half of the times

- more than half of the times

- dways

6. How often do you involuntarily lose urine when you experience urgency to void?

- never

- less than half of the times

- about half of the times

- more than half of the times

- always

7. How often is your voiding stream interrupted?

- never

- less than half of the limes

- about half of the times

- more than half of the times

- always

8. How often do you experience dribbling after voiding?

- never

- less than half of the times

- about half of the times

- more than half of the times

- always

9. How often do you involuntarily lose urine?

- never

- less than half of the times

- about half of the times

- more than balf of the times

- always

10. How often do you experience that, after voiding, there still is urine in your bladder?

- never

- less than half of the times

- about hall of the times

- more than half of the times

- always 
11. Do you experience that the power and size of your urinary stream is decreased as compared to the past?

- yes

- no

12. How do you rate the power and size of your stream?

- normal

- varies between normal and weak

- weak

- varies between weak and dribbling

- dribbling

13. If (1) you have at least one voiding complaint or (2) you note that the urine is not $\mathrm{OK}$, how long do you think you have been experiencing this?

- 1 day

- 1-7 days, (namely .. days)

- 1 week - 1 months (namely .. weeks)

- 1 month - 12 months (namely .. months)

- more than a year (namely .. year)

- I do not have voiding complaints

The next questions relate to your voiding during the last 3 months.

14. Did you experience pain or a burning sensation with your woiding some lime during the last THREE MONTHS?

- yes

- no

15. Did you note that there may be blood in your urine during the last THREE MONTHS?

- yes

- no

16. Have you EVER been operated on your kidneys/uninary tract (kidneys, urinary tract, bladder, prostate, genitals)?

- yes, please give us a description:

- operated on:

- because of:

- which year?

- no 
17. Have you seen a doctor during the past FIVE YEARS because of complaints related to your voiding /or genitals/ or prostate; kidney; urinary tract, bladder

- yes, which doctor

- general practitioner

- urologist

- orher

- please name the doctor

- when did you see him? year..... month......

- abour what did you see him?

- no

\section{Symptom score}

Each symptom was scored according to a 5-point scale for frequency, with a score of 1 indicating the absence of a symptom and a score of 5 the presence of the symptom with each voiding ('never', 'less than half the time', 'half the time', 'more than half the lime', 'always"). For 3 questions different five-point scoring categories were defined: frequency during daytime (1-2 times, 3-4, 5-7, 8-11, 12 and up), nocturia $(<1$, $1,2,3-4,5$ and up) and impairment of the size and force of the urinary stream ('normal", 'normal-weak', 'weak', 'weak-dribbling', 'dribbling').

The total symptom score was calculated from the response to 7 questions about urinary hesitancy (question 4), terminal dribbling (question 8), impairment of the size and force of the urinary stream (question 12), incomplete emptying (question 10), straining or pushing to start urinary flow (question 5), frequency during daytime (question 1), and nocturia (question 2). The score ranged from 7 to 35 . 


\section{Appendix II}

Questionnaire used to measure possible factors with influence on doctor consultation:

\section{Demographic}

- living situation:

independent, on my own / with spouse / with spouse and child(ren)/with children / with parents / in institution, especially home for elderly

- marital status:

married or living together / never been married, never lived with a partner / divorced, nor living together any more / widow / other

- education:

elementary school / lower professional education / middle-level general education / high level general education / higher professional education / university

- profession:

- employment status:

paid job for more than 20 h per week/paid job, less than 20 h per week/unemployed $/$ ill for work, at least $80 \% /$ ill for work, percentage less than $80 \% /$ retired/ other

\section{voiding behaviour and related detailed anamnesis}

- can you void far away?

yes / no

- do you think your voiding stream is thinner than it used to be? yes / no

- how long lasts dribbling on average? more than one minute / less than one minute / more than a few seconds / I do not experience dribbling or I only dribble a few drops

- did you ever wake up from involuntary urinary loss? yes/no

- did you notice pain or a burning sensation during urination in the past 12 months? yes / no

- did you think you possibly lost blood in your urine in the past 12 months? yes / no

- are you ever been treated because of inability to void? yes / no

- have you ever had an infectious disease of your genitals or any venereal illness? yes/no 
- have you ever had an injury to your genitals or urinary system? yes/no

Interference with activities of daily living

- how much hindrance in daily Jife: wery much /much flithe /no / not applicable

- how often did you notice any hindrance in the last month by your voiding habits to the following daily activities? never hindrance / now and then / sometimes / often / always

- drinking something before traveling: never hindrance / now and then / sometimes / often / always

- drinking before sleeping: never hindrance / now and then / sometimes / often / always

- drive two hours before stopping: never hindrance / now and then / sometimes / often / always

- get sufficient sleep at night: never hindrance / now and then / sometimes/often/always

- go to places without toillet: never hindrance / now and then / sometimes / often/always

- go for a walk: never hindrance / now and then / sometimes / often / always

- go to church/theatre: never hindrance / now and then / sometimes/often/always

- go shopping: never hindrance / now and then / sometimes / often/always

\section{Direct perception of own voiding}

- compare voiding behaviour with other men of the same age better /sane /worse /don't know; can't compare

- how severe do you consider your voiding complaints? very severe /severe Aithe /no /not applicable

\section{Worry about own voiding}

- how much are you worried about your voiding? very worrited /worried Aithe /no /not applicable

- are you worried that some day you may not be able to void spontaneously? very worricd / worried lirle /no

- are you worried that you might have prostate cancer? very worried worried Nitlle /no 


\section{Reaction of others to their voiding}

- has there been any reaction ever on your voiding habits (by spouse, family, friends or others)?

yes, often/yes, sometimes/no: they do not react/no: they do not know my problem I not applicable, I have no micturition problem

- if somebody did react to your voiding, how did you evaluate this reaction(s)? very annoying / annoying/little annoying / not annoying/not at all annoying/not applicable

- which people reacted to your voiding?

spouse, partner / friend or relative / children or fanily / a doctor / somebody who has the same problem / somebody unknown.

- did people give you suggestions to deal more easily with your voiding habit? yes and it helped / yex, but it did not help / no, no suggestions to deal with habit not applicable

- did somebody advise you to see a doctor for your voiding habit? yes/no/not applicable

- did somebody advise you to have an operation for your voiding problem? yes / no / not applicable

- have you ever used any kind of medication to resolve prostatism? yes / no / not applicable

\section{Opinion on prostate problems}

- Prostatism is a muisance for elderly men agree/don't agree/don't know

- When a man complains about his prostate it is better to remove the prostate surgically

agree / don 't agree /don't know

- When a man complains about his prostate, an operation is unavoidable agree/don't agree /don't know

- A prostate operation affects sexual activity agree/don't agree/don't know

- If the doctor were to let me decide whether or not Il need a prostate operation to alleviate my complaint, I would choose an operation agree / don't agree / don't know

\section{Sexual behaviour factors}

- how satisfied are you with your sexual life (or the lack of sexual life)? very unsatisfied / unsatisfied/sometimes satisfied sometimes not / satisfied/very satisfied 
- how often have you experienced sexual interest during the last month? never/once $/ 2-3$ times a month/once a week /2-3 times a week/4-6 times a week levery day /nore than once every day

- how often have you experienced an erection if you felt sexually interested during the last month?

never / a few times / sometimes/ mostly / always

- how often have you experienced an erection when waking up during the last month? never/a few times/sometimes/mostly/always

- do you see your sexual abilities changed during the last 12 months? much decreased/decreased/decreased a little / about the same/slighty increased I increased / much increased

- have you experienced an ejaculation during the last month? yes / no

- was any ejaculation painful in the past 12 months? yes $/$ no

Health related factors (general health, subjective health, major medical conditions)

- change of weight during the past 12 months got heavier/ unchanged/lost weight/don't know

- increase of trouser size? yes / no / don't know

- have you experienced obstipation? always / often / sometimes / no or rarely / not applicable

- have you experienced more thirst during the last 3 months? yes / no / don't know

- can you lay flat in a bed? yes / no

- on how many pillows do you sleep at night?

[numberl

- do you experience swollen feet or ankles? yes / no

- do you experience a taut stomach? yes / no

- are you dizzy? yes / no

- do you leel without energy? yes / no

- do you experience back pain? yes / no 
- do you experience any pain in the chest? yes / no

- are you tired after awakening in the moming? yes $/$ no

- do you experience headache? yes / no

- do you experience shortness of breath? yes/no

- do you sometimes have a numb of tingling feeling in your arm(s) or leg(s)? yes / no

- do you often feel tired? yes / no

- is your stomach often upset? yes / no

- do you have any pain in your bones or muscles? yes / no

- is your tolerance to exercise decreased? yes / no

\section{Feelings of depression}

- Have you experienced nervousness during the last month? very nervous, so much that I could not deal with my daily activities / much nervousness / quite nervous/some nervousness, sufficient to slightly worry/slightly nervous / not nervous

- did you experience feelings of helplessness, disappointment, sadness in such a way that you though whether it was all worth living for?

very sad, I do not like it any more / much sadness / quite sad / sad. sufficient to worry about/a little sad/nor sad at all

- I have felt depressed during the last month always / mostly / most of the time / sometimes / now and then / never

- I have felt selfconfident during the last month always / mostly / most of the time / sometimes / now and then / never

- how much energy, initiative or interest to live have you felt during the last month? no energy or interest/very little energy / in general litte energy / energy changed a lot/mostly energetic/much energy or initiative

- I have felt tired, exhausted, worn out during the last month always / mostly / most of the time / sometimes / now and then / never

- I have woken up fresh and relaxed during the last month always / mostly/most of the time / sometimes/now and then / never. 


\section{Health related risk factors}

- body mas sindex

- do you smoke?

yes / no, but I did smoke / no and I never smoked:

if yes or any smoking history. number of years, number of sigarettes/pipes/cigars per day:

eventually: years from cessation of smoking

- do you drink alcohol?

yes: on average less than one unit per week: namely [number] per month/

yes: on average less than one unit per day: namely lnumberl per week

yes: on average about Inumber $/$ per day/no

\section{Tendency to visit a doctor}

- would you wisit your doctor if you felt weak for three days with a high temperature? yes / no / don't know

- would you wisit your doctor if you felt weak for three days and experienced a high temperature on the third day?

yes / no / don "t know

- would you visit your doctor if you had a severe cough, lasting one week and without improvement?

yes / no / don't know

- would you visit your doctor if you felt tired with loss of interest for one week and you didn"t know any explanation?

yes / no/don't know

- would you visit your doctor if you twisted your knee and you could not walk without hindrance during three days?

yes / no / don't know

- would you visit your doctor if you got a severe nose cold without fever for 3 days? yes / no/don it know

- would you visit your doctor if you got a sore throat for four days, which did not have a tendency to improve?

yes / no d don't know

- would you visit your doctor if you felt worried for weeks without knowing any catuse?

yes / no/don't know

- would you visit your doctor if you noticed blood in your stools while you felt excellent?

yes/ no / don't know 
Actual doctor consultation

- how often have you visited a doctor during the last month? [number]

- how many nights have you spent in hospital during the last 12 months? [number] 